\title{
EVALUATIONOF CHEMICAL SENSORS FOR IN SITU GROUND-WATER MONITORING AT THE HANFORD SITE
}

\author{
E. M. Murphy \\ D. D. Hostetler
}

March 1989

Prepared for

the U.S. Department of Energy

under Contract DE-AC06-76RLO 1830

Pacific Northwest Laboratory

Richland, Washington 99352

This document is PUBLICLY RELEASABLE B Stule

Authorizing Official

\section{DISCLAIMER}

Date: $5-23-67$

This report was prepared as an account of work sponsored by an agency of the United States Government. Neither the United States Government nor any agency thereof, nor any of their employees, makes any warranty, express or implied, or assumes any legal liability or responsibility for the accuracy, completeness, or usefulness of any information, apparatus, product, or process disclosed, or represents that its use would not infringe privately owned rights. Reference herein to any specific commercial product, process, or service by trade name, trademark, manufacturer, or otherwise does not necessarily constitute or imply its endorsement, recommendation, or favoring by the United States Government or any agency therepf. The views and opinions of authors expressed herein do not necessarily state or reflect those of the United States Government or any agency thereof. 


\section{DISCLAIMER}

This report was prepared as an account of work sponsored by an agency of the United States Government. Neither the United States Government nor any agency Thereof, nor any of their employees, makes any warranty, express or implied, or assumes any legal liability or responsibility for the accuracy, completeness, or usefulness of any information, apparatus, product, or process disclosed, or represents that its use would not infringe privately owned rights. Reference herein to any specific commercial product, process, or service by trade name, trademark, manufacturer, or otherwise does not necessarily constitute or imply its endorsement, recommendation, or favoring by the United States Government or any agency thereof. The views and opinions of authors expressed herein do not necessarily state or reflect those of the United States Government or any agency thereof. 


\section{DISCLAIMER}

Portions of this document may be illegible in electronic image products. Images are produced from the best available original document. 
This report documents a preliminary review and evaluation of instrument systems and sensors that may be used to detect ground-water contaminants in situ at the Hanford Site. Three main topics are covered in this report: 1 ) identification of a group of priority conteminants at Hanford that could be monitored in situ, 2) a review of current instrument systems and sensors for environmental monitoring, and 3) an evaluation of instrument systems that could be used to monitor Hanford contaminants.

Thirteen priority contaminants were identified in Hanford ground water, including carbon tetrachloride and six related chlorinated hydrocarbons, cyanide, methyl ethyl ketone, chromium (VI), fluoride, nitrate, and uranium. Based on transduction principles, chemical sensors were divided into four classes: optical, electrochemical, mass sensitive, and thermal. Within the first three classes, ten specific types of instrument systems were considered: fluorescence spectroscopy, surface-enhanced Raman spectroscopy (SERS), spark excitation-fiber optic spectrochemical emission sensor (FOSES), chemical optrodes, stripping voltammetry, catalytic surface-modified ion electrode, immunoassay sensors, resistancekapacitance, quartz piezobalance, and surface acoustic wave devices. Because the flow of heat is difficult to control, there are currently no environmental chemical sensors based on thermal transduction. The ability of these ten instrument systems to detect the thirteen priority contaminants at the Hanford Site at the required sensitivity was evaluated. In addition, all ten instrument systems were qualitatively evaluated for general selectivity, response time, reliability, and field operability.

With few exceptions, chemical sensors are in an early stage of development. Even prototype sensors have had little or no field testing. Despite broadly based activity in chemical sensor research and development at universities, national laboratories, and in industry, no environmental sensors capable of detecting all of the thirteen contaminants at Hanford are commercially available. However, these contaminants may be detectable by a variety of not-yet commercial instrument systems. The most promising instrument systems for detecting a range of Hanford contaminants 
were chemical optrodes, SERS, catalytic surface-modified ion electrodes, and masssensitive devices. All of the instrument systems evaluated can be used for fieldscreening applications. For in situ applications, chemical optrodes, resistance/ capacitance sensors, and mass-sensitive devices currently have an advantage over the other instrument systems. This advantage is the relatively simple instrumentation used with these systems. C'iemical optrodes, which combine small, rugged sensors with relatively simple above-ground instrumentation, ranked especially high in most of the categories evaluated. 


\section{ACKNOWLEDGMENTS}

The authors would like to acknowledge the help of several individuals during the preparation of this report. Critical reviews by Dr. John Evans and Dr. Jeff Griffen and editing by Ms. Laurel Grove greatly improved this document. In addition, numerous discussions with Dr. John Evans, Mr. Khris Olsen, Mr. Ron Schalla, and Dr. Don Goldman were very helpful. Dr. Michael Carrabba, Dr. Wayne Chudyk, Dr. Michael Angel, Dr. Johnny Thomas, and Dr. Joseph Wang provided valuable technical information, and we would like to thank them for their cooperation. 


\section{CONIENTS}

SUMMARY . . . . . . . . . . . . . . . . . . . . iii

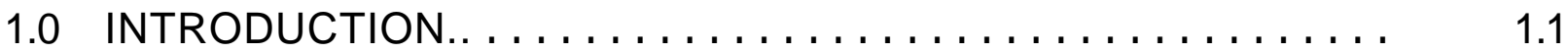

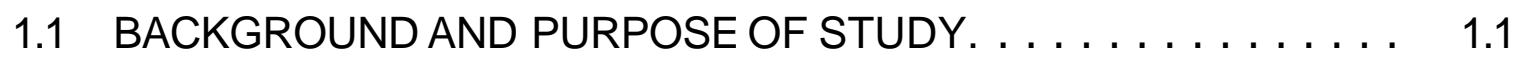

1.2 SCOPE OF REPORT. . . . . . . . .

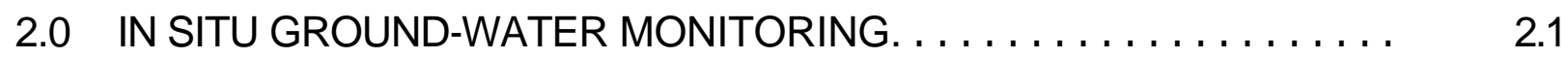

2.1 RATIONALE. . . . . . . . $\ldots \ldots \ldots \ldots \ldots \ldots \ldots \ldots .1$

2.1.1 Sample Integrity $\ldots \ldots \ldots \ldots \ldots \ldots \ldots \ldots \ldots \ldots \ldots$

2.1.2 Real-Time Monitoring Capability.............. 2.1

2.1.3 Rapid Field-Screening Capabilities. . . . . . . . . . . . . 2.2

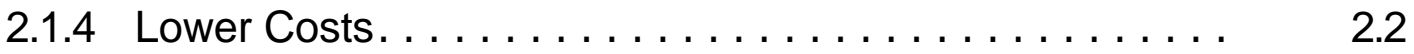

2.2 COMPLYING WITH CURRENT SAMPLING PROTOCOLS. . . . . . 2.3

3.0 TARGET CONTAMINANTS FOR IN SITU MEASUREMENTS. . . . . . . . 3.1

3.1 HANFORD SITE CONTAMINANT PROBLEMS. . . . . . . . . . 3.1

3.1.1 High-Priority Ground-Water Contaminants . . . . . . . . . . 3.1

3.1.2 Additional Contaminant Concerns. . . . . . . . . . . . 3.7

3.2 PHYSICOCHEMICAL PARAMETERS. . . . . . . . . . 3.9

4.0 INSTRUMENTATIONMETHODS FOR IN SITU MEASUREMENTS . . . 4.1

4.1 OPTICAL METHODS $\ldots \ldots \ldots \ldots \ldots \ldots \ldots \ldots \ldots \ldots$

4.1.1 In Situ Fluorescence Spectroscopy. . . . . . . . . . . . 4.5

4.1.2 Surface-Enhanced Raman Spectroscopy. . . . . . . . . . 4.11 



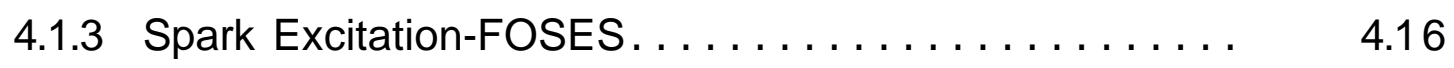

4.1.4 Chemical Optrodes................. 4.18

4.2 ELECtROChEMICAL METHODS .............. 4.26

4.2.1 Stripping Voltammetry $\ldots \ldots \ldots \ldots \ldots \ldots \ldots \ldots \ldots \quad 4.26$

4.2.2 Catalytic Surface-Modified Ion Electrode . . . . . . . 4.28

4.2.3 Immunoassay Sensors $\ldots \ldots \ldots \ldots \ldots \ldots \ldots \ldots \ldots \quad 4.30$

4.2.4 Resistance/Capacitance ............... 4.32

4.3 MASS-SENSITIVE SENSORS $\ldots \ldots \ldots \ldots \ldots \ldots \ldots \ldots .4 .33$

5.0 EVALUATION OF INSTRUMENT SYSTEMS AND SENSORS. . . . . . . 5.1

5.1 PRIMARY CONSIDERATIONS: DETECTABILITYAND

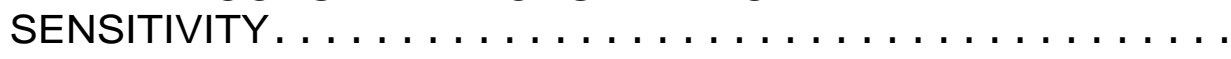

5.2 GENERAL CONSIDERATIONS IN EVALUATING INSTRUMENT

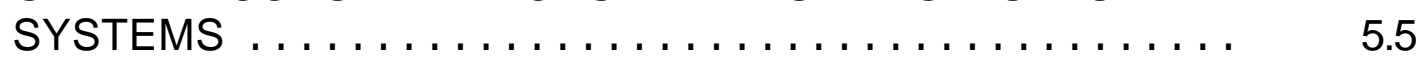

6.0 CONCLUSIONS AND RECOMMENDATIONS. . . . . . . . . . 6.1

6.1 REVIEW OF THE MAJOR ISSUES $\ldots \ldots \ldots \ldots \ldots \ldots \ldots \ldots \quad 6.1$

6.2 CONCLUSIONS....................... 6.3

6.2.1 Conclusions Regarding the Developing Technology of Chemical Sensing ................... 6.3

6.2.2 Conclusions Specific to Hanford Interests . . . . . . . 6.4

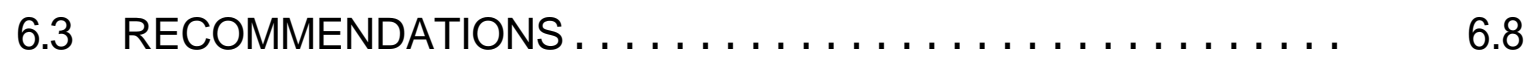

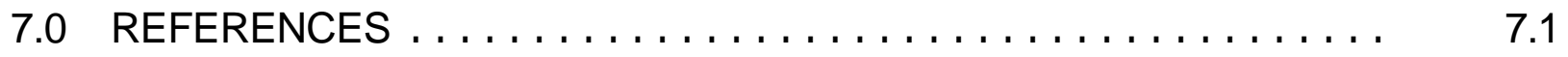




\section{FIGURES}

$1.1 \quad$ Scope of Report. . . . . . . . . . . . . .

3.1 Location of Hanford Site $\ldots \ldots \ldots \ldots \ldots \ldots \ldots \ldots \ldots \ldots \ldots \ldots .2$

3.2 Distribution of Tritium in Ground Water Resulting from 40 Years of Site Operation . . . . . . . . . $3.6 \ldots \ldots \ldots$

3.3 Nitrate Plume in Ground Water Across the Hanford Site . . . . . . . . 3.7

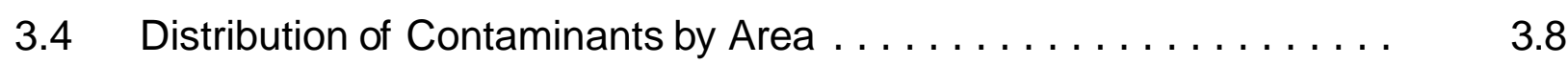

4.1 Generalized Instrument System for Detecting Contaminants in Ground Water. . . . . . . . . . . . . . . . . . . . . . . 4.1

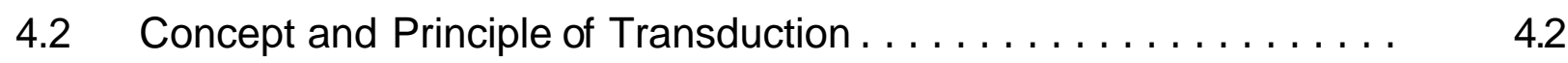

4.3 Four Primary Methods of Transduction in Chemical Sensors and the Instrument Systems Discussed in this Report . . . . . . . . . 4.4

4.4 Schematic Illustration of Tufts University's Fluorescence Spectrometer.

4.5 In Situ Fluorescence Emission Spectra Using a Fiber Length

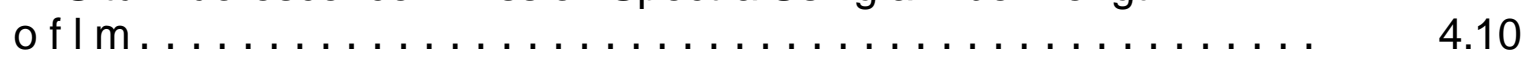

4.6 Fluorescence Signal Versus Concentration for a) Gasoline

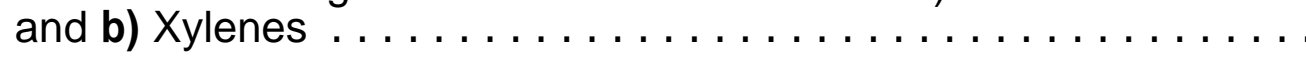

4.7 A Plot of Boxcar Averager Corrected Signal Versus Concentration of Phenol. . . . . . . . . . . . . . . . . . . 4.12

4.8 Basic Components of a Typical SERS Instrument System . . . . . . . . 4.13

4.9 SERS Spectra of an Ethanol Extract of Soil Contaminated

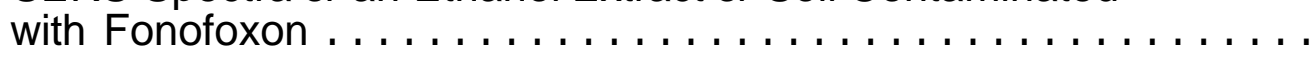

4.10 Instrument Design for Spark Excitation-FOSES . . . . . . . . . . 4.17

4.11 Schematic Illustration of EPNLLNL Chloroform Sensor . . . . . . . . 4.19 
4.12 Schematic Illustration of Refractive-Index Optrodes . . . . . . . . . . . . 4.24

4.13 Calibration Curve for $\mathrm{Cr}(\mathrm{V})$ Sensor Based on Stripping Voltammetry $\quad 4.27$

4.14 Flow Cell for the PDV 2000 Voltammeteric Analyzer. . . . . . . . . . . 4.28

4.15 Schematic Illustration of Westinghouse Immunoassay Sensor

Operation ...........................

4.16 Conceptual Drawings of a Piezobalance and Surface Acoustic Wave Devices . . . . . . . . . . . . . . . . . . . . .

5.1 Evaluation Matrix Illustrating Whether Hanford Contaminants Can Be Detected by the Individual Sensing Methods . . . . . . . . . 5.2

5.2 Evaluation Matrix of the Sensivity of the Instrument Systems

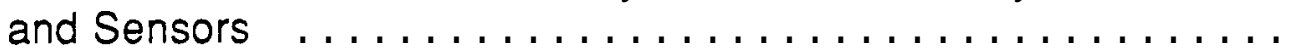




\section{TABLES}

3.1 High-Priority Contaminants in Hanford Ground Water for Which Field Screening and In Situ Monitoring Devices Would Be Desirable. ..........................

3.2 Additional Contaminants for Which Field-Screening Analysis Would Be Desirable. ........................

4.1 Limits of Detection for Ground-Water Contaminants. . . . . . . . . . . . 4.7

4.2 List of Refractive-Index Optrodes Being Developed for Environmental and Agricultural Applications. . . . . . . . . . . . . . . .

4.3 Past Applications of Amperometric Titrations . . . . . . . . . . . . . . . . . 4.29

6.1 Summary of Current Development Status for Instrument

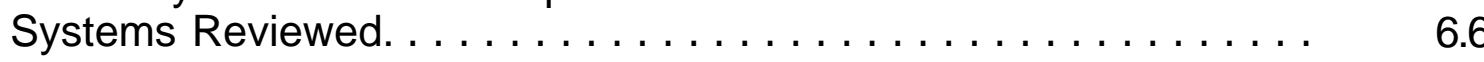

6.2 Evaluation of Current Development Status for Instrument Systems Reviewed. . . . . . . . . . . . . . . . . . . . 


\section{ABBREVIATIONS}

DCA 1,1-dichloroethane

DCE 1,2-dichloroethylene

DOE U. S. Department of Energy

DWS drinking water standard

Eh oxidation-reduction potential

EMSL Environmental Monitoring Systems Laboratories

EPA U. S. Environmental Protection Agency

FOSES fiber optic spectrochemical emission sensor

LLNL Lawrence Livermore National Laboratory

MCL maximum concentration limit

MEK methyl ethyl ketone

PCE perchloroethylene

PNL Pacific Northwest Laboratory

$\mathrm{ppb} \quad$ parts per billion

ppm parts per million

RCRA Resource Conservation and Recovery Act

SAW surface acoustic wave

SERS surface enhanced Raman spectroscopy

TCA 1,1,1-trichloroethane

TCE 1,1,2-trichioroethylene

TOC total organic carbon

$$
\text { xii/ xiii }
$$





$\begin{array}{ll}\text { TOX } & \text { total organic halogens } \\ \text { UV } & \text { ultraviolet } \\ \text { WBAS } & \text { Westinghouse Bio-Analytic Systems }\end{array}$




\subsection{INTRODUCTION}

\subsection{BACKGROUND AND PURPOSE OF STUDY}

The Site Investigation Technology Demonstration Project (Site Project) was established to set up two or more field-demonstration sites to develop and test state-ofthe-art monitoring, detection, sampling devices, and sample schemes. The need for this type of project has evolved because characterization of inactive waste sites is a very costly and critical part of the remedial investigation phase of the Superfund process. Little work has been done in this area because of the lack of waste sites dedicated to conducting research and development. Well-characterized demonstration sites are being established at the Hanford Site so new technologies can be compared in the field.

The In-Field Screening Task of the Site Project is investigating and testing stateof-the-art techniques for monitoring ground water in the field at the Hanford Site. The emphasis is on in situ monitoring technologies; however, many of the techniques being evaluated can also be used to screen samples in the field. The first part of this task was to define a set of high-priority contaminants at the Hanford Site that could be detected by in situ instrument systems. The second part of this task is to evaluate and recommend instrument systems that can be evaluated in the field at Hanford in 1989 and 1990. It should be noted that at this time there are no commercially available environmental sensors capable of detecting ground-water contaminants at the Hanford Site.

By providing instrument developers with the opportunity to field-test their sensors, we expect to accelerate both the development and application of these systems to solve environmental problems. In the next few years, sensors for environmental contaminants will become commercially available. At this time, only a chloroform optrode, TCE optrode, and in situ fluorescence spectroscopy have been tested under field conditions. 


\subsection{SCOPE OF REPORT}

The purpose of any hydrologic contaminant detection system is to reliably measure the concentration of selected contaminants in situ, thereby avoiding sampling problems typically associated with the measurement of environmental pollutants. "In situ" refers to the measurement of hydrologic contaminants in the saturated zone, directly in the sampling wells or boreholes. "Field screening" refers to the field measurement of ground-water contaminants from samples drawn or pumped from the well. This report documents a preliminary evaluation of instrument systems that may be able to detect contaminants in situ. Although the focus is on in situ instrument systems, most of the systems evaluated can also be applied for field-screening purposes. The evaluation has two major parts: the identification of priority groundwater contaminants at Hanford, and the identification of instrumentation for in situ detection of priority Hanford contaminants. Figure 1.1 illustrates the scope of this report.

First, priority contaminants at the Hanford Site were identified by identifying all known Hanford contaminants, reviewing available information on their distribution and

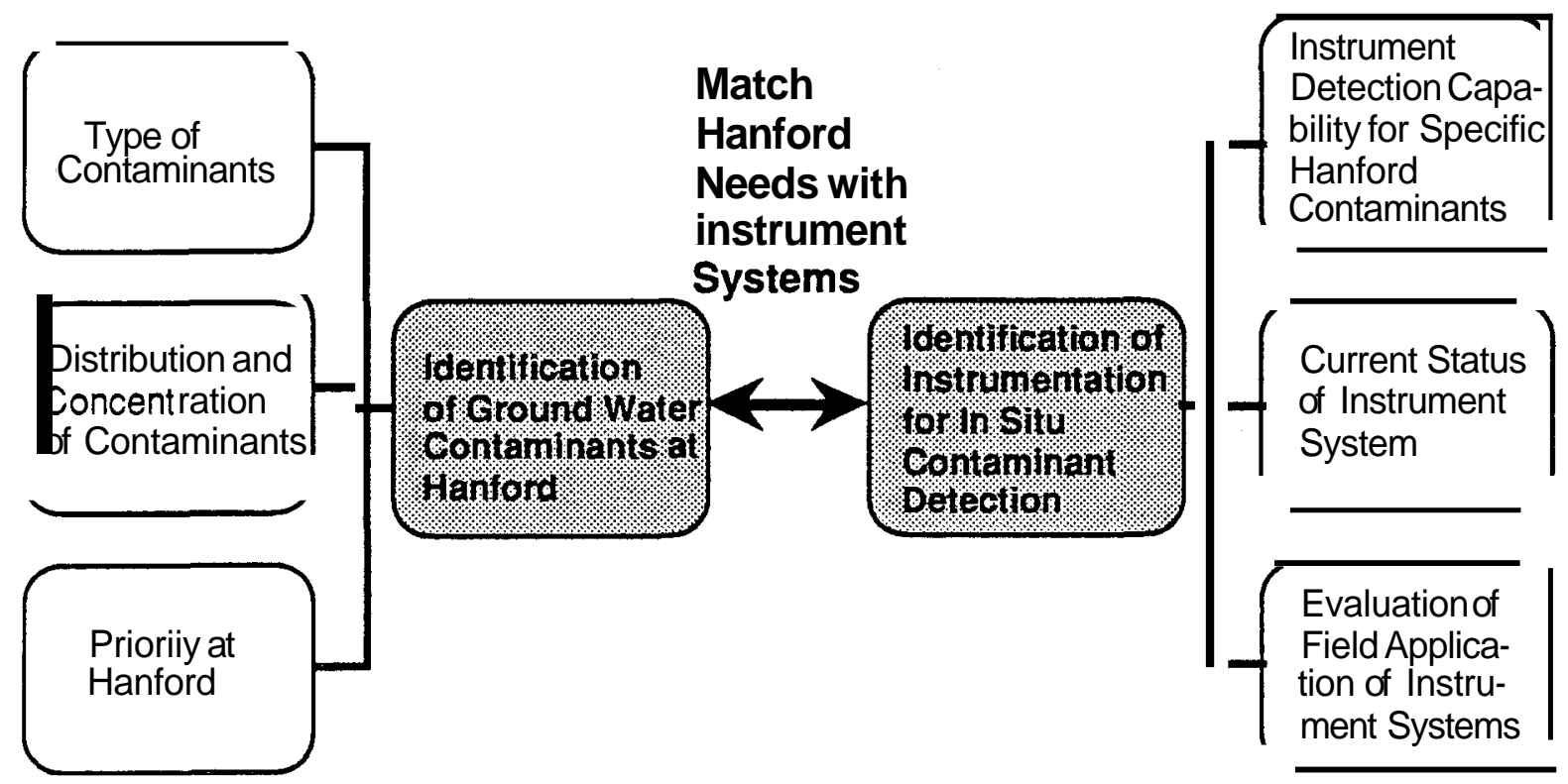

EIGURE 1.1. Scope of Report 
concentrations, and selecting a subset of high-priority contaminants. High priority was assigned primarily to those contaminants whose concentrations consistently exceeded the maximum concentration limit (MCL)set by law. Wide distribution of a contaminant also increased its priority. Organic, inorganic, and radionuclide contaminants alike were included in the identification process. Sections 2.0 and 3.0 describe the identification and selection process.

Second, instrument systems potentially capable of detecting contaminants in situ were identified by reviewing existing environmental instrument systems reportedly capable of detecting priority contaminants, assessing the current status of each instrument system's development, and then evaluating the potential field application of those systems at the Hanford Site. in the evaluation process (Section 5.0), specific instrument characteristics for review were established, the instrument systems identified in Section 4.0 were reviewed, an initial analysis based on available information was performed, and recommendations for future work were made. 


\subsection{IN-SITU GROUND-WATER MONITORING}

\subsection{RATIONALE}

There are at least four advantages to measuring ground-water contaminants in situ: 1) sample integrity, 2) real-time monitoring capability, 3) rapid field-screening capabilities, and 4) lower costs.

\subsubsection{Sample Integrity}

In a typical ground-water monitoring program, samples are collected in the field and returned to the laboratory for analyses. Removal of the sample from the monitoring well introduces handling problems (chain of custody) and can induce changes in sample composition, altering analytical results. Even under strict sampling protocols, problems can occur during the transport and storage of samples. Pumping to obtain a sample can alter the $\mathrm{pH}$ by as much as $1 \mathrm{pH}$ unit by changing the $\mathrm{CO}_{2}$ partial pressure. Investigators in Sweden have found a large difference between downhole (in situ) and surface flow-cell measurements of Eh (Peter Wikberg, personal communication). The change in pressure during traditional sampling also complicates the quantitation of volatile organic compounds. With current sampling techniques it is difficult, if not impossible, to assess other potential problems, such as ultraviolet photo-oxidation during sample storage.

\subsubsection{Beal-Time Monitorina Capability}

Ground water is a dynamic environment, subject to both physical and chemical processes. Fluctuating river stages or high-transmissivity zones affect contaminant mobilization and dilution. The microbial community in an aquifer can be stimulated by an abrupt change in available organic carbon. Real-time monitoring capabilities will provide a valuable research tool for studying these dynamic processes in an aquifer.

In situ monitoring capabilities will be invaluable during site remediation. Realtime monitoring will give immediate information on the effectiveness of remediation techniques. During remediation wells are often pumped in an on-and-off cycle instead of continuously, to allow time for contaminants to desorb from the sediment. In situ 
monitoring could be used in a feedback system to optimize the pumping cycle, and therefore could reduce pumping costs. Labor, time, and analytical costs would also be reduced during remediation by using real-time monitoring.

\subsubsection{Bapid Field-Screenina Cap}

In the case of a contaminant release, rapid assessment of point pollution releases is needed. To accomplish this usually requires an analytical laboratory to interrupt its schedule and work around-the-clock until the contaminant release has been delineated. The inherent time delays could be eliminated with in-field screening. Field sensors may also offer a low-cost method of delineating gaps in plumes in areas lacking compliance monitoring wells. These areas often have old, noncompliance wells without pumps. Contaminants in these wells could be rapidly measured using field sensors.

\subsubsection{Lower Costs}

Labor and analytical costs are expected to escalate as regulations covering contaminant release to the environment become more comprehensive. The U. S. Environmental Protection Agency (EPA), recognizing the high costs of long-term ground-water monitoring, has initiated a comprehensive program to develop field sensors. Such a program may lower costs, both for rapid field-screening (discussed above) and for long-term monitoring after a site is closed. In situ sensors, coupled with remote communication capabilities, would allow site operators to minimize labor and analytical costs.

A quarterly ground-water sampling scheme is employed for the 350 monitoring wells at the Hanford Site. However, some wells are sampled more than four times a year and others are sampled less. Complete laboratory analyses cost about $\$ 1000$ per well, which means that the monitoring budget for a single year can total several million dollars. A reliable in situ system could be used to monitor known contaminants, reducing the need for detailed laboratory analyses to only once or twice a year. Once the 
contaminants in a well have been identified, sensors specific to those contaminants would be installed to provide long-term monitoring.

\subsection{COMPLYING WITH CURRENT SAMPLING PROTOCOLS}

The EPA has established strict sampling and analysis protocols for ground-water contaminants. Whether or not in situ techniques can be substituted for laboratory analyses is a legal problem and will ultimately be determined through the legal system. The EPA has made a commitment to developing in situ sensor technologies at their Environmental Monitoring Systems Laboratories (EMSL). The EPA has realized that to adequately monitor sites with contaminated ground water requires more manpower and money than are available, as this excerpt from a recent EPA document illustrates:

The magnitude of the ground-water monitoring activities at Superfund sites is evident, and further growth is expected. The nation cannot afford to ignore this task and cannot reasonably afford to carry it out with the currently available tools without having to accept compromises in the scope, the quality, or both. Additionally, there are not enough trained personnel to implement the mandated monitoring effectively for the next decade and beyond. Current ineffective monitoring is mostly due to using a difficult and time consuming technology based on sophisticated sampling techniques with subsequent analysis in the laboratory. The EPA must take the lead in providing a reasonable solution to this monitoring dilemma. The EPA must lead the transition from analytical laboratory based monitoring to in situ, real-time monitoring (Eccles, Simon, and Klainer 1987).

With the EPA taking the lead, it will probably not be difficult to justify the use of in situ monitoring at the Hanford Site. However, we must be able to show that in situ monitoring can match the sensitivity of the current ground-water MCLs for individual contaminants. 


\subsection{TARGET CONTAMINANTS FOR IN SITU MEASUREMENTS}

The focus of this review is on specific organic, inorganic, and radionuclide contaminants found in ground waters at the Hanford Site. Informationfor the Hanford Site is largely based on the current Hanford Site-Wide Ground-Water Monitoring Program and several Resource Conservation and Recovery Act (RCRA) compliance projects.

\subsection{HANFORD SITE CONTAMINANT PROBLEMS}

The site-wide monitoring-well network at the Hanford Site is designed to meet the intent of U.S. Department of Energy (DOE) Orders 5480.1 and 5484.1 for environmental monitoring. DOE Order 5480.1 requires that DOE cooperate with the EPA and state, interstate, and local agencies in the prevention, control, and abatement of pollution. The order also lists permissible concentrations of radionuclides for the discharge of liquid effluent in controlled and uncontrolled areas.

Ground-water monitoring activities at the Hanford Site are also being conducted for compliance with RCRA and Washington Administrative Code 173-303. The projects include sampling programs at the $183-\mathrm{H}$ Solar Evaporation Basins in the $100 \mathrm{H}$ Area, the Transportable Grout Facility (directly east of the 200 East Area), 300 Area Process Trenches, and the Central Landfill (Evans, Mitchell, and Dennison 1988) (Figure 3.1). Most of the Hanford Site property outside the designated areas in Figure 3.1 is referred to as the 600 Area. The following discussion has been divided into highpriority ground-water contaminants (i.e., those contaminants that are consistently over the MCL and have wide distribution) and additional contaminants that may become problems in the future.

\subsubsection{Hiah-Priority Ground-Water Contaminants}

Several recent reports (Evans, Mitchell, and Dennison 1988; Law, Serkowski, and Schatz 1987; PNL 1987) describe the monitoring networks and results for monitoring programs at the Hanford Site. The following contaminants are discussed in 


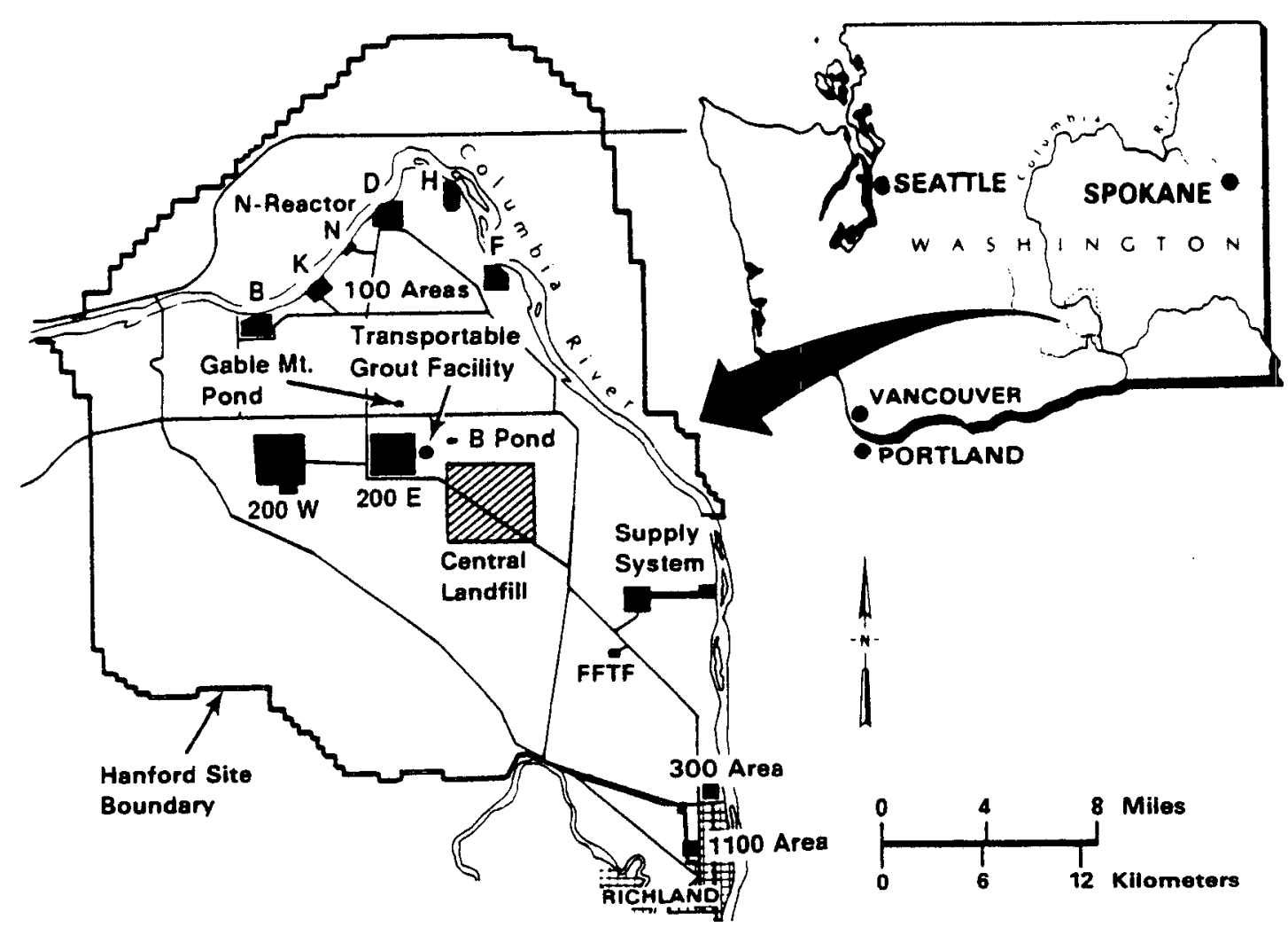

FIGURE 3_I _ Location of Hanford Site

detail because of their high concentrations, regulatory implications, or wide-spread distribution: 1) carbon tetrachloride in the 200 West Area; 2) cyanide to the north of the 200 East Area; 3) hexavalent chromium in the 1008, 100D, 100K, and 100 H Areas;

4) chlorinated hydrocarbons in the vicinity of the Central Landfill; 5) uranium at two disposal cribs in the 200 West Area; 6) tritium across the site; and 7) nitrate across the site. The discussion of these contaminants found in Evans, Mitchell, and Dennison (1988) is summarized below.

Carbon Tetrachloride. Carbon tetrachloride has been detected below most of the 200 West Area, except the southeast corner near the Reduction Oxidation Plant. The plume has spread into the 600 Area on the east and west sides of the 200 West Area, and north, near the fence line. The MCL for carbon tetrachloride is $5 \mathrm{ppb}$ (U. S. EPA, 1988). Evans, Mitchell, and Dennison (1988) reported a maximum concentration of 4,520 ppb near the Plutonium Finishing Plant in the 200 West Area. Trichloroethylene, 
ranging in concentration from 1,0 to $38 \mathrm{ppb}$, appears to be associated with the carbon tetrachloride plume.

Carbon tetrachloride contamination probably originated from a soil disposal column facility (crib) at the Plutonium Finishing Plant (Evans, Mitchell, and Dennison 1988). From 1955 through 1973, degraded solvents from various solvent-extraction processes were disposed of to the crib. Carbon tetrachloride was the primary carrier used in the solvent-extraction processes. Many of the cribs used by the Plutonium Finishing Plant are near the U Pond. A ground-water mound still exists beneath the now-decommissioned U Pond, causing ground water to flow radially outward. Evans, Mitchell, and Dennison (1988) speculated that this flow pattern might account for the distribution of contamination found beneath the 200 West Area.

Cvanide. Cyanide has been detected in a few wells in the 600 Area directly north of the 200 East Area and in the 200 East Area (maximum concentration detected was $1690 \mathrm{ppb}$ ). Cyanide has also been detected in concentrations up to $115 \mathrm{ppb}$ in four wells in the 200 West Area. There is currently no fixed MCL or drinking water standard (DWS) for cyanide. The cyanide detected was accompanied by increases in cobalt-60 and gross beta activity. Evans, Mitchell, and Dennison (1988) suggested that the usually immobile cobalt- 60 has been chemically complexed and mobilized by cyanide.

Cyanide is a waste product of the cesium precipitation that took place as part of uranium reclamation operations in the mid-1950s. The cyanide plume near the 200 East Area probably originates from the BY Cribs. Nickel ferrocyanide was the reagent used during the reclamation process. Liquor from this process was sent to the BY Cribs, BX Trenches, BC Cribs and BC Trenches, all located in the 200 East Area. During 1987 and 1988, the plume moved into the 600 Area, just north of the 200 East Area. Evans, Mitchell, and Dennison (1988) attribute this to increased liquid disposal to B Pond resulting from the restart of the Plutonium Uranium Extraction Plant (200 East Area) and decreased disposal to Gable Mountain Pond. These changes have caused some of the flow paths from beneath the 200 East Area to shift to the north. 
Recent speciation experiments performed on ground-water samples from three wells in the 200 East area have shown that approximately $1 / 3$ of the cyanide is present as free cyanide, while the remainder is complexed as either ferrocyanide or ferricyanide. The chemical form of the cyanide is significant for the development of chemical sensors.

Hexavalent Chromium. Hexavalent chromium has been found throughout the 100 Areas, with a maximum concentration of $1,690 \mathrm{ppb}$ (in the 100D Area). All wells in the $100 \mathrm{H}$ Area showed measurable concentrations of hexavalent chromium, in most cases above the DWS of $50 \mathrm{ppb}$. The source of the chromium is sodium dichromate, used to control oxidation of aluminum parts during operation of the production reactors in the 100 Areas, and chromic acid used to decontaminate dummy fuel elements. Waste materials from these processes were disposed of in a number of cribs and liquid-disposal facilities in the 100 Areas. The use of sodium dichromate was discontinued in the mid-1970s at the N Reactor, and no chromium contamination has been observed in the $100 \mathrm{~N}$ Area. In addition to the 100 Areas, some evidence of chromium contamination has been found in the 200 West Area and in at least eight wells in the 600 Area.

Chlorinated Hydrocarbons. Several chlorinated hydrocarbons, of which 1,1,1-trichloroethane was the most abundant, have been found near the central landfill (Evans, Mitchell, and Dennison 1988). The highest concentration of 1,1,1-trichloroethane was 56 ppb; 1,1,2-trichloroethylene, 1,1-dichloroethane, carbon tetrachloride, and perchloroethylene were found in lesser amounts. The areal distribution of the contaminants suggests that the Central Landfill is the source, although the origin of the contamination is unknown at this time. In addition to those in the central landfill area, wells downgradient of the 300 Area process trenches also contain detectable 1,2-dichloroethylene and trichloroethylene.

A trichloroethylene plume has been found in the 600 Area near the White Bluffs Acid Pickling Crib (36 ppb; adjacent to 100 F Area). Mixed low-level chlorinated hydrocarbon contamination (up to $10 \mathrm{ppb}$ of 1,1,1-trichloroethane) has been observed in the 1100 Area. 
Uranium. Uranium concentrations in ground water near two disposal cribs in the 200 West Area increased from 200 to 72,000 pCi/L over a 2-month period in 1985. Perched water resulting from liquid discharges to a nearby crib probably provided the liquid that carried the uranium from the unsaturated zone beneath the two disposal cribs to the water table. Unsealed well casings may have provided a pathway to the ground water. To prevent further contaminaiion, the unsealed wells were grouted and the disposal of waste water to disposal cribs was discontinued. Uranium was removed from pumped ground water from June to November 1985, reducing the concentration from 106,000 to $25,000 \mu \mathrm{g} / \mathrm{L}$. Since 1985 uranium concentrations have remained constant, although the plume continues to spread with ground-water movement (Evans, Mitchell, and Dennison 1988). Significant amounts of uranium contamination have also been found in the 100H Area (307 ppb), 100F Area (609 ppb), 200 East Area (144 ppb), and 300 Area (110 ppb).

Tritium. Tritium is found in ground water across the Hanford Site. It appears to be the most mobile radionuclide at the Hanford Site. Tritium contamination occurs in both the fuel production and reprocessing areas. Tritium concentrations greater than the DWS of $20,000 \mathrm{pCi} / \mathrm{L}$ have been detected in the $1008,100 \mathrm{~F}, 100 \mathrm{~K}, 100 \mathrm{~N}, 200$ East, 200 West, and 600 areas. A contour map of the distribution of average tritium concentrations, resulting from 40 years of Site operations, is shown in Figure 3.2. Evans, Mitchell, and Dennison (1988) have provided a detailed description of tritium monitoring during 1987.

Nitrate Nitrate is not considered a hazardous substance under CERCLA scoring for Superfund remedial action. However, nitrate is a concern at Hanford because of its wide distribution and clear association with the Hanford operations. The DWS for nitrate is $45 \mathrm{ppm}$. Nitrate exceeds the DWS in all of the 100 Area wells, except those in the 100B Area, and in the 200 Areas. Nitrate is present in process condensate and other liquid wastes discharged to the ground. It originated from nitric acid, used extensively in chemical reprocessing and decontamination operations. Figure 3.3 shows the extent of the nitrate plume across the Hanford Site. Evans, Mitchell, and Dennison (1988) describe in detail the nitrate monitoring results. 


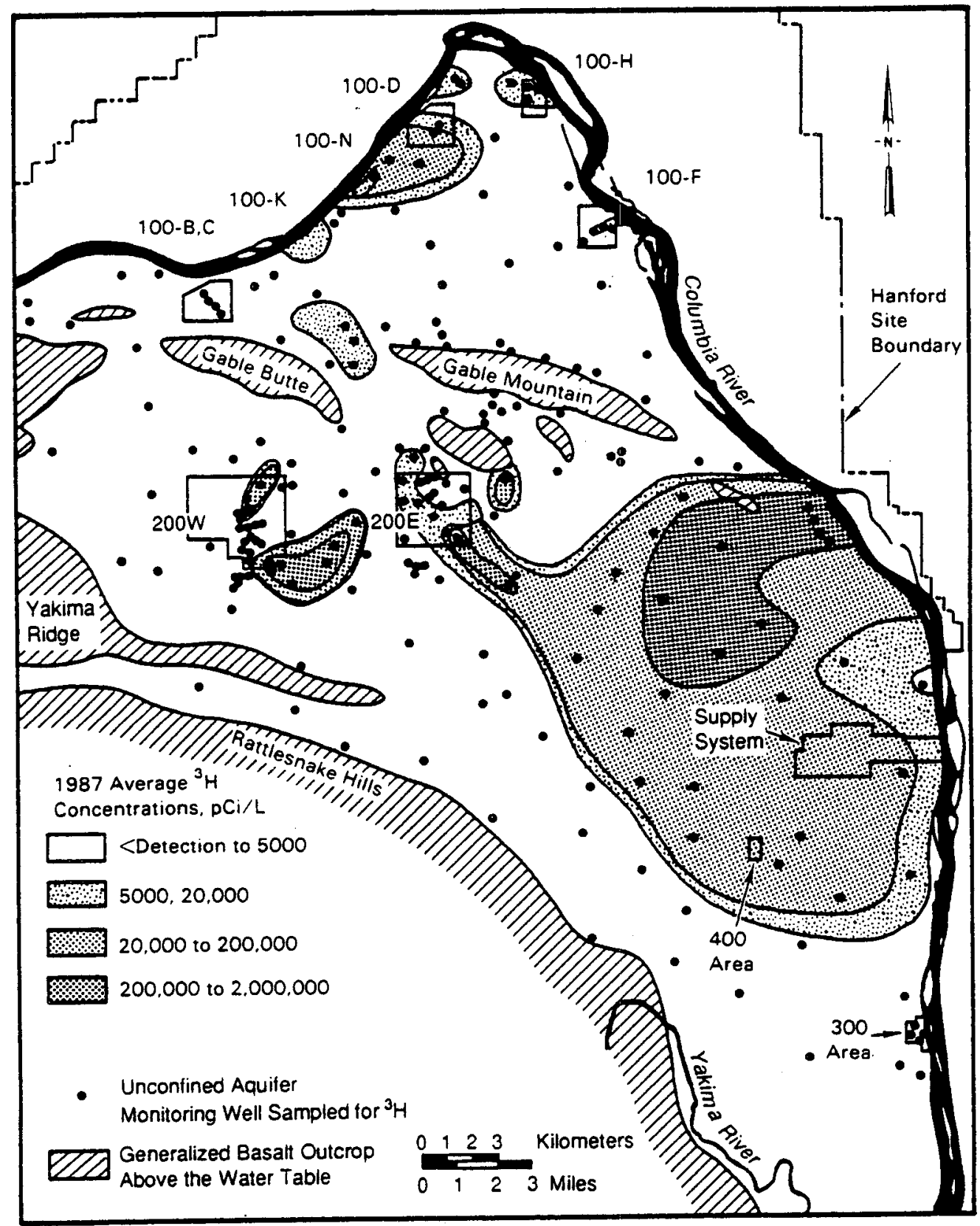

FIGURE 3.2. Distribution of Tritium in Ground Water Resulting from 40 Years of Site Operation (from PNL 1987)

The major contaminants at Hanford are summarized by area in Figure 3.4. Only tritium and nitrate are currently site-wide problems. Chlorinated hydrocarbons, uranium, cyanide, and hexavalent chromium are limited mainly to processing or disposal areas. 


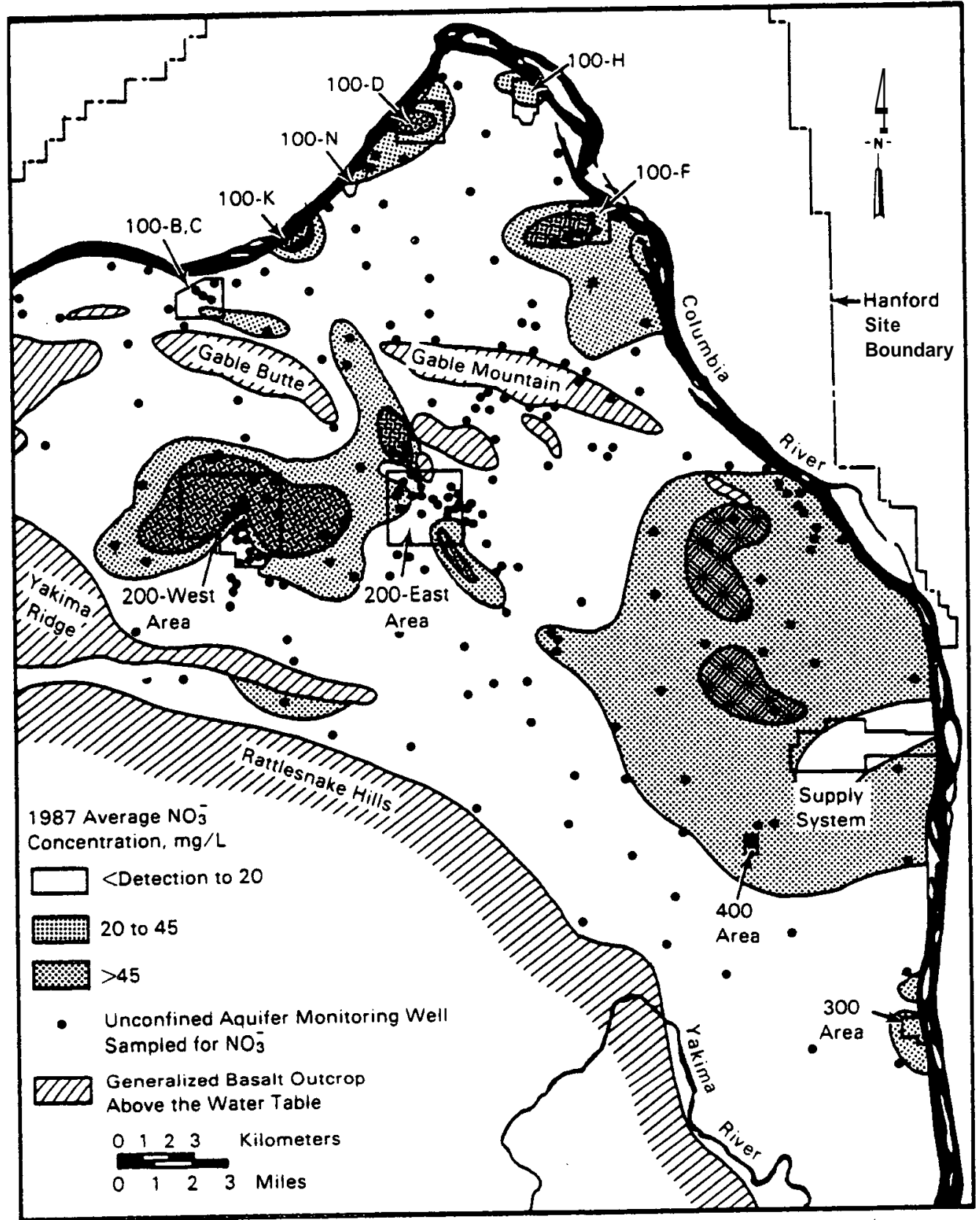

EIGURE 3.3. Nitrate Plume in Ground Water Across the Hanford Site (from PNL 1987)

\subsubsection{Additional Contaminant Concerns}

Several other contaminants not mentioned above have also been found in ground waters at Hanford and may be related to site operations. These contaminants 


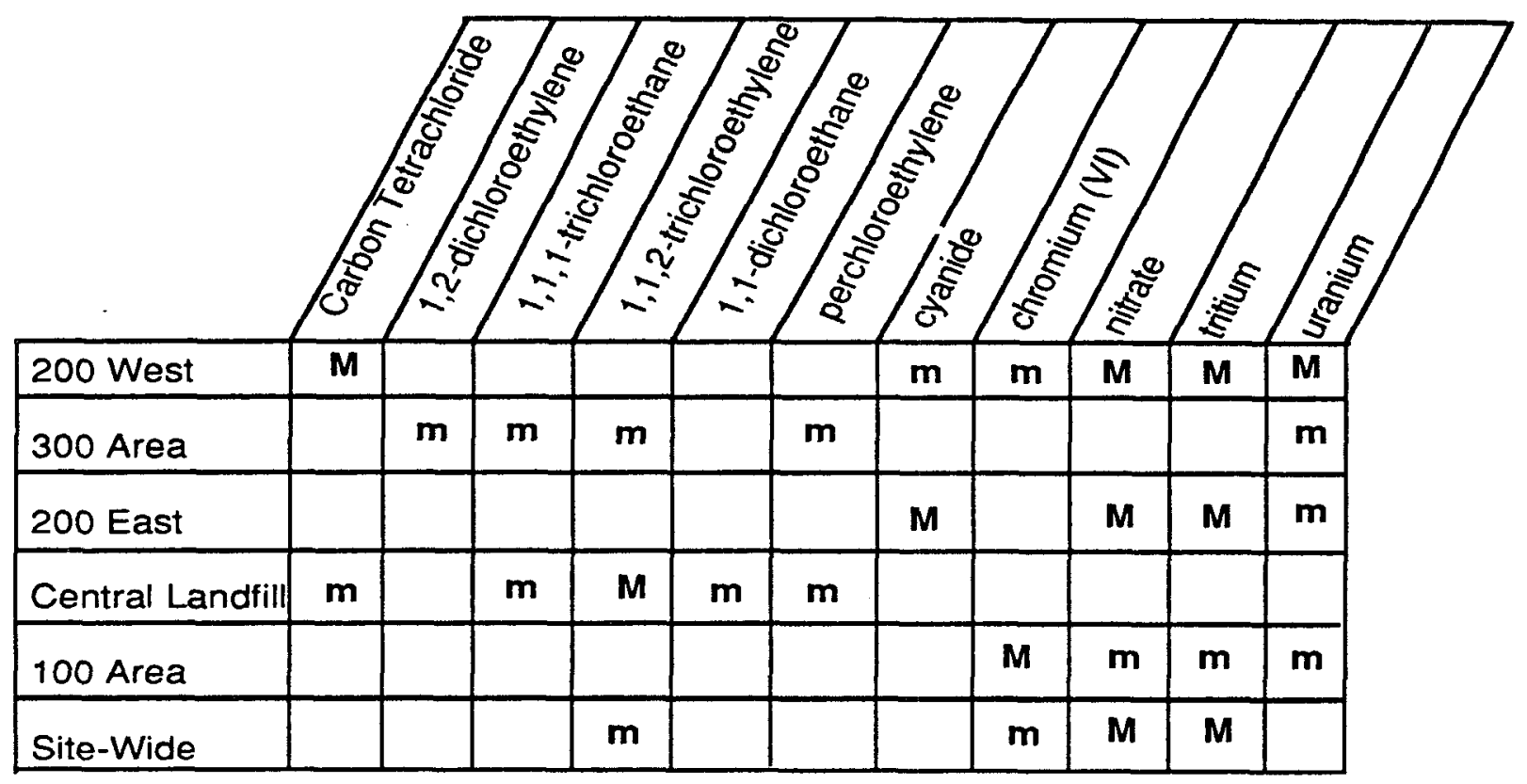

EIGURE 3.4. Distribution of Contaminants by Area. $M=$ major contaminant, $\mathrm{m}=$ minor contaminant.

are discussed individually below. Occasionally acetone, methylene chloride, and Nnitroso-dimethylamine have been detected, but it is suspected that these species are from laboratory contamination during sample handling.

Ammonia has been detected in 29 wells in the $100 \mathrm{~N}$ and 200 East Areas. Its probable source is a decontamination solution containing ammonium phosphate. The maximum concentration measured is $3,630 \mathrm{ppb}$. Given that ammonia is rapidly converted to nitrate in the oxygen-rich ground waters found in the unconfined aquifer at Hanford, ammonia species will probably only be found near the source of input.

Fluoride has been detected at elevated levels, up to $12,500 \mathrm{ppb}$ in one well in the 200 West Area. The contaminated wells are downgradient from 216-Z-9 crib, which has received approximately 210 metric tons of aluminum fluoride nitrate over the course of Hanford operations. 
Methyl Fthvl Ketone has been detected in one well at a maximum level of $50 \mathrm{ppb}$. The source of this contaminant is unknown, although it may be a degradation product of hexone (methyl isobutyl ketone).

Selenium has been detected five times in one well in the 200 West Area at levels five times as great as the DWS (10 ppb). A well in the 600 Area has also been shown to have selenium concentrations above the DWS. No use of selenium at the Hanford Site has been documented.

Total Organic Halogens (TOX) have been detected in several wells in the 100 Areas; however, specific chlorinated hydrocarbons have not been detected individually. This anomaly is being studied further.

Table 3.2 contains a list of the highest-priority pollutants in the Hanford ground waters. These priority pollutants were chosen because of their concentrations, regulatory implications, and/or wide-spread distribution. This list forms a basis for selecting in situ devices for development for ground water monitoring at Hanford. High priority will be given to testing and research and development of sensors for these contaminants. In addition to the high-priority contaminants listed in Table 3.2, other organic, inorganic, and radionuclide species are found in the process waste stream and in mixed hazardous waste (Table 3.3). Although these contaminants are not typically found in the ground water, rapid, in-field screening for these constituents would allow a quick assessment of point releases of pollution.

\subsection{PHYSICOCHEMICAL PARAMETERS}

In addition to the above contaminants, several physicochemical parameters need to be monitored in situ. These parameters, including $\mathrm{pH}$, temperature, Eh, dissolved oxygen, pressure, and conductivity, must be monitored to adequately evaluate the instruments being tested. As mentioned previously, pumping to obtain samples can alter the $\mathrm{pH}$ of the sample by as much as $1 \mathrm{pH}$ unit because it changes the $\mathrm{C} 02$ partial pressure. Accurate $\mathrm{pH}$, Eh, and temperature measurements are especially important for modelling geochemical speciation in an aquifer and will be critical in evaluating 
IAB $F$ 3.1. High-Priority Contaminants in Hanford Ground Water for Which Field Screening and In Situ Monitoring Devices Would Be Desirable

Contaminant

Chlorinated Hydrocarbons:

Carbon tetrachloride

1,1,2-trichloroethylene (TCE)

Perchloroethylene (PCE)

1,1-dichloroethane (DCA)

1,1,1-trichloroethane (TCA)

1,2-dichloroethylene (DCE)

Chloroform

Cyanide

Chromium (VI)

Fluoride

Methyl Ethyl Ketone

Nitrate

Tritium

Uranium
MCL or Action Level (around water)
Range of Concen-

trations at Hanford

\begin{tabular}{ll}
$5 \mathrm{ppb}$ & $<5-5,550 \mathrm{ppb}$ \\
$5 \mathrm{ppb}$ & up to $38 \mathrm{ppb}$ \\
--- & up to $-10 \mathrm{ppb}$ \\
$-200 \mathrm{ppb}$ & up to $-5 \mathrm{ppb}$ \\
\hdashline $100 \mathrm{ppb}$ & up to $-110 \mathrm{ppb}$ \\
$?(\sim 200 \mathrm{ppb})$ & up to $-50 \mathrm{ppb}$ \\
$50 \mathrm{ppb}$ & $\sim 15-1,690 \mathrm{ppb}$ \\
$2000 \mathrm{ppb}$ & $<50-1,690 \mathrm{ppb}$ \\
----- & $<2000-12,500 \mathrm{ppb}$ \\
$45 \mathrm{ppm}$ & up to $50 \mathrm{ppb}$ \\
$20,000 \mathrm{pCi} / \mathrm{L}$ & $<45->3000 \mathrm{ppm}$ \\
& $<20,000-$ \\
$(10-40 \mathrm{pCi} / \mathrm{L})$ & $>2,000,000 \mathrm{pCi} / \mathrm{L}$
\end{tabular}

TABLE 3.2. Additional Contaminants for Which Field-Screening Analysis Would Be Desirable. $\mathrm{TOC}=$ total organic carbon, $\mathrm{TOX}=$ total organic halogens.

\begin{tabular}{|c|c|c|}
\hline Organic & Inorganic & Radionuclide \\
\hline Acetone & Mercury & $90 \mathrm{Sr}$ \\
\hline Methylene chloride & Selenium & 1291 \\
\hline TOC & Sulfate & 99TC \\
\hline $\begin{array}{l}\text { TOX } \\
\text { Tributyl phosphate } \\
\text { Kerosene }\end{array}$ & $\begin{array}{l}\text { Lead } \\
\text { Cadmium } \\
\text { Bismuth } \\
\text { Copper }\end{array}$ & $\begin{array}{l}14 \mathrm{C} \\
137 \mathrm{Cs} \\
60 \mathrm{Co} \\
106 \mathrm{Ru} \\
1311 \\
\text { Total alpha and beta } \\
\text { iso } \mathrm{U} \text { and iso } \mathrm{Pu}\end{array}$ \\
\hline
\end{tabular}


differences in concentrations of species measured in situ versus concentrations of species measured in the laboratory. Pressure will be monitored to provide accurate depth in water.

The oxidation-reduction potential (Eh) often determines the mobility of contaminants in the subsurface. Investigators in Sweden have found a large difference between downhole (in situ) and surface flow cell measurements of Eh (Peter Wikberg, personal communication). Accurate Eh measurements will be essential during biological remediation of contaminated ground water, which involves the degradation of contaminants by microorganisms. In the absence of oxygen, several other constituents act as electron acceptors for microorganisms, including $\mathrm{NO}_{3}{ }^{-}, \mathrm{Mn}^{2+}$, $\mathrm{FeOOH}$, and $\mathrm{SO}_{4}{ }^{2-}$. Pseudomonas denitrificans can degrade some classes of organic contaminants using $\mathrm{NO}_{3}$ - as a terminal electron acceptor. Careful measurements of the nitrate/nitrite oxidation-reduction pair will give an indication of in situ metabolic activity of these microorganisms. 


\subsection{INSTRUMENTATIONMETHODS FOR IN SITU MEASUREMENTS}

Before instrument systems can be evaluated, they must be defined. There is a wide variety of instrument systems. Some are simple and others quite complicated, depending on what they measure and how the measurement is performed. Figure 4.1 illustrates a ceneralized instrument system. The basic components of an instrument system are highlighted. Auxiliary components are often present in newer instrument systems, and example components are shown in the figure.

In general, the instrument systems for in situ monitoring of ground water are under development and have not been demonstrated in the field. This report focuses on the transducer and its relationship to the sensed environment containing the contaminant of interest. The transducer is the heart of the instrument system. The transducer must be able to detect the contaminant in its environment, before an entire, fieldable instrument system can be developed for general use.

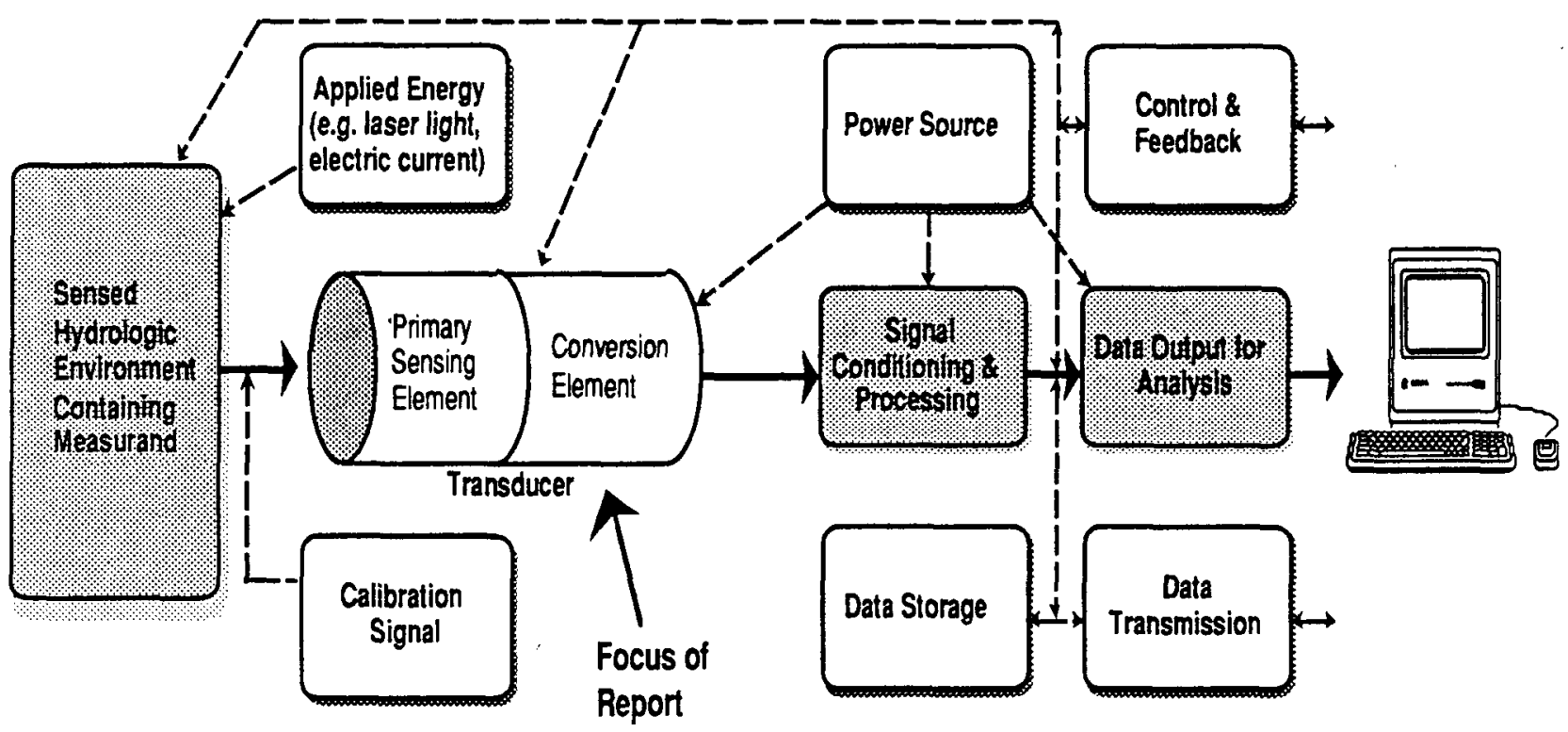

FIGURE 4.1. Generalized Instrument System for Detecting Contaminants in Ground Water 
Transduction is simply the conversion of sensed energy into an alternate form of energy. The alternate form is usually electrical for interfacing with electronic components and digital computers. To measure the concentration of a contaminant, the primary sensing element must somehow interact with the contaminant as a function of its concentration. This interaction must then be converted to electrical energy for transmission to signal-pro jessing components in a digital computer or device. In some systems, multiple transductions occur (e.g., in optical methods, light that is modulated in some fashion is transduced again, this time into electrical energy). Figure 4.2 illustrates both the general concept of transduction and the principle as it applies to sensing contaminants.

Concept of Transduction

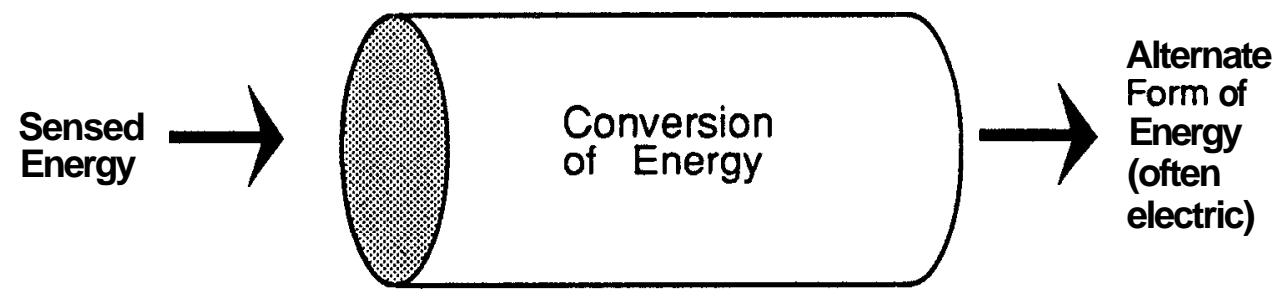

Principle of Transduction

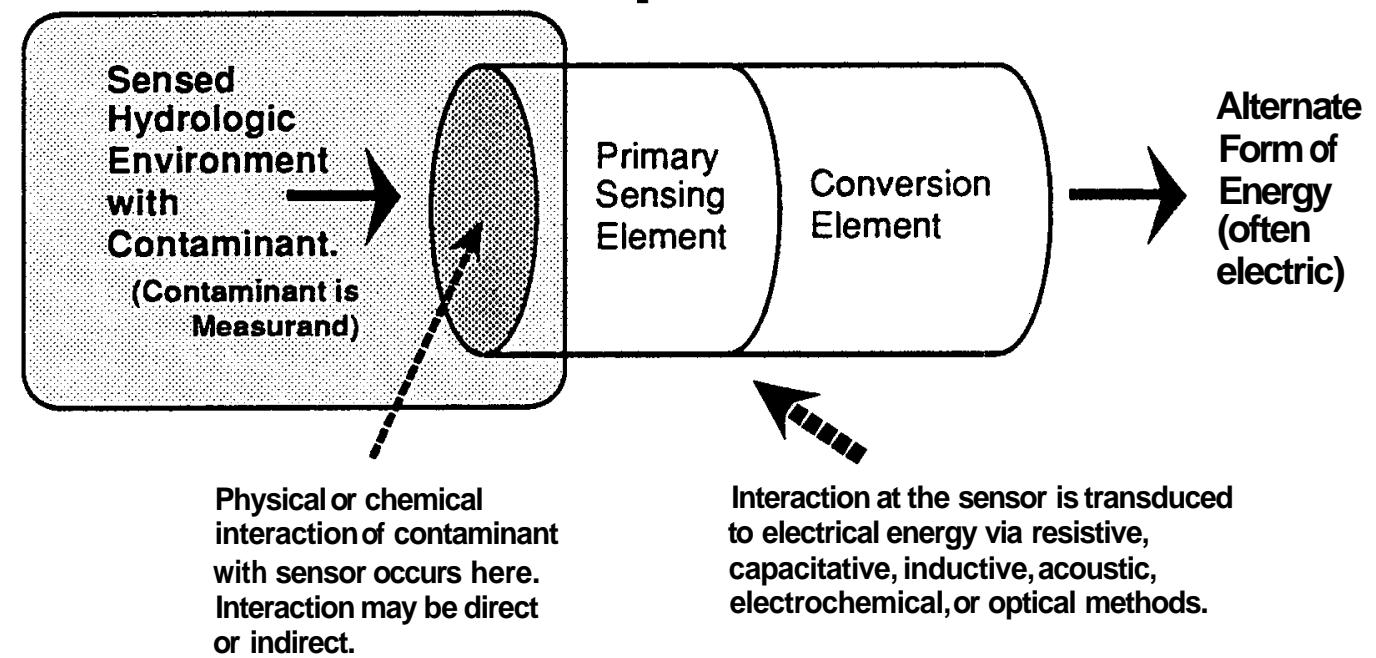

FIGURE 4.2. Concept and Principle of Transduction 
There are many ways to categorize instrument systems and sensing techniques. Instrument systems are categorized in this report based on the methods employed at the primary sensing element or transducer (Figure 4.3). Recently Janata and Bezegh (1988) categorized chemical sensors by four transduction methods: optical, electrochemical, mass, and thermal. Optical methods use optical fibers as a light pipe. The selectivity of optical methods is influenced by absorption, fluorescence, luminescence, and a broad range of wavelengths (Janata and Bezegh 1988). In electrochemical methods, the interaction of chemistry and electricity produces a measurement of cell voltage, cell current, or cell admittance. Mass methods use changes in mass to sense concentration. In thermal methods, the heat of chemical reactions is detected. However, because the flow of heat is hard to control, there are currently no environmental chemical sensors based on thermal transduction.

The transduction or sensing techniques described in this report are shown in Figure 4.3. Optical methods include in situ fluorescence spectroscopy, surfaceenhanced Raman spectroscopy (SERS) spark excitation-Fiber Optic Spectrochemical Emission Sensors (FOSES), and chemically based optrodes. Electrochemical methods include stripping voltammetry, catalytic surface-modified ion electrodes, immunoassay sensors, and resistance/capacitance techniques. Mass-sensitive devices include quartz piezobalance and surface acoustic wave (SAW) sensors.

\subsection{OPTICAL METHODS}

All of the optical methods use fiber optics to varying degrees. Fiber optic systems involve the transmission of light through a glass or plastic fiber. In the 1930s simple glass fibers were first used to transport images. By the 1950s fiber optic technology was being used in the areas of image transmission, light distribution, and remote sensing (Martin 1987). However, the glass fibers were very expensive and relatively inefficient. Therefore, early fiber optic applications were inhibited by cost and attenuation. High-quality glass fibers were several times as expensive as cables used in telecommunications, and the signal attenuation losses were so great that about 


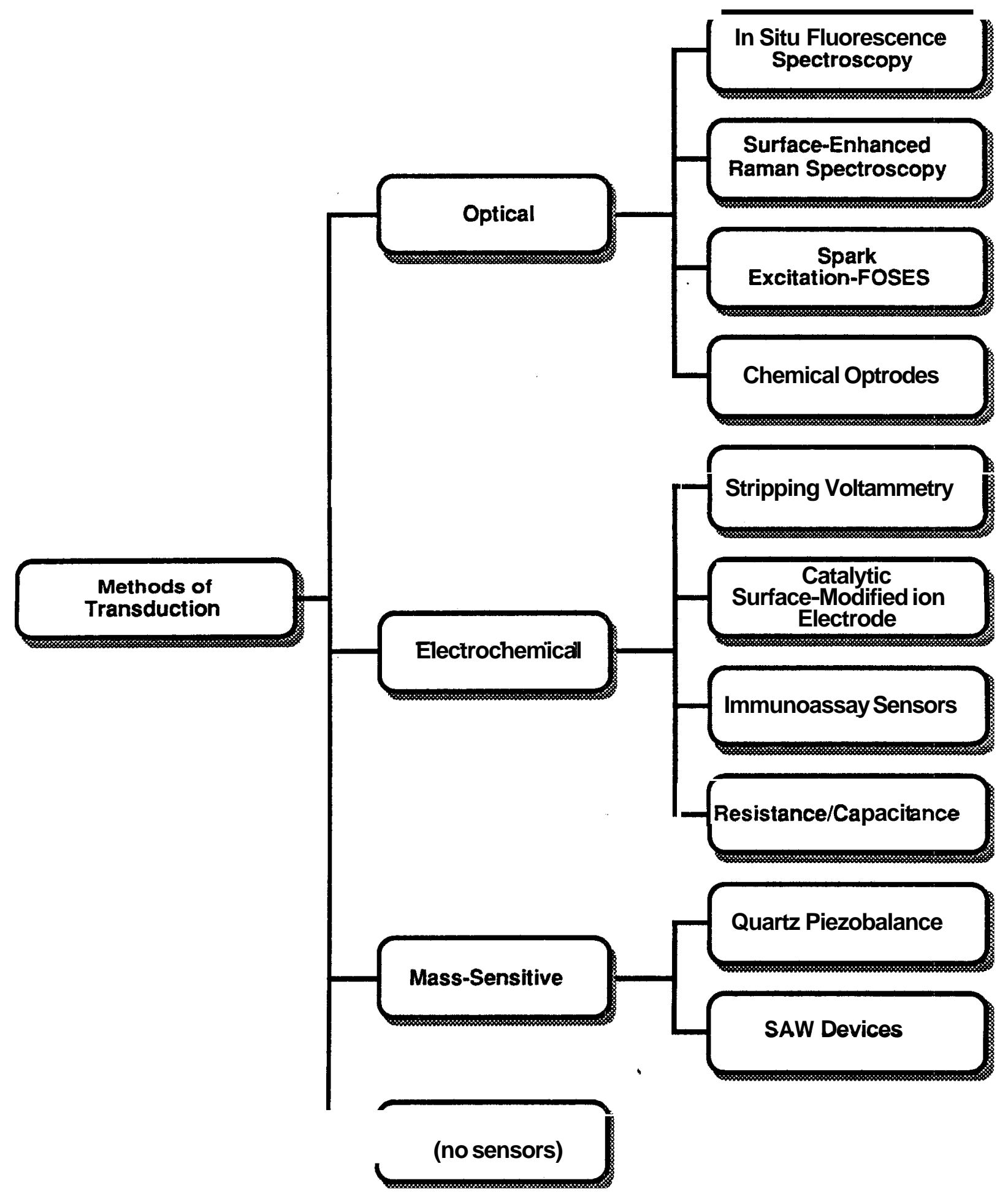

FIGURE 4.3. Four Primary Methods of Transduction in Chemical Sensors and the Instrument Systems Discussed in this Report 
one-half of the light entering a fiber would be lost within the first three meters. Today, low-cost fused-silica fibers are available that have low attenuation losses (Martin 1987).

The principle of fiber optic light transmission is relatively simple. Light is injected into a glass or plastic fiber and is reflected (or bounces back and forth between the walls of the fiber) until it exits at the other end of the fiber. In contrast to the simplicity of the principle, the manufacturing of glass fibers and their application in instrument systems are complex and have undergone decades of developmental research.

\subsubsection{Jn Situ Fluorescence Soectroscopv}

The idea of in situ monitoring of organic contaminants in ground water using fiber optic fluorimetry has only emerged since 1983. Although field devices for in situ fluorescence spectroscopy have been built and tested by researchers at Tufts University, no commercial field instruments are currently available.

Many organic chemicals are photoluminescent; that is, they reemit radiation when excited by electromagnetic radiation. The luminescent process in fluorescence ceases almost immediately when irradiation is discontinued. The advantage of fluorescence spectroscopy is its sensitivity, usually in the ppb range or lower. This sensitivity is at least an order of magnitude greater than the sensitivity of the commonly used absorption methods.

The limitation of fluorescence spectroscopy is that not all compounds fluoresce. Both molecular structure and chemical environment are influential in determining whether a substance will fluoresce. The intensity of the fluorescence will also determine whether a compound can be detected. The most intense fluorescent behavior is in compounds that contain aromatic functional groups with low energy $\pi$ to $\pi^{\star}$ transition levels (Skoog and West 1980). A limited number of compounds containing aliphatic and alicyclic carbonyl structures or highly conjugated double-bond structures may also exhibit fluorescence. The quantum efficiency of fluorescence in unsubstituted aromatic hydrocarbons increases with the number of rings and their degree of condensation. For example, simple heterocycles such as pyridine, furan, thiophene, 
and pyrrole do not fluoresce, while multiring structures normally do (Skoog and West 1980). Nitrogen heterocycles do not typically exhibit fluorescence; however, fusion of benzene rings to a heterocyclic nucleus results in fluorescence. As a result, fluorescence is observed for such compounds as quinoline, isoquinoline, and indole.

Fluorescence generally decreases with halogen (Le., chloride) substitution. The simple chlorinated hydrocarbons found in Hanford ground waters will not exhibit fluorescence. Carboxylic acid or carbonyl groups substituted on an aromatic ring will inhibit fluorescence. Fluorescence is favored in compounds that have rigid structures. For example, fluorene has greater fluorescence intensity than biphenyl. The bridging methylene group in fluorene increases the rigidity of this compound (Skoog and West 1980). Another example of structural rigidity that has been applied to fiber optic sensors is the adsorption of fluorescing dyes to solid surfaces. The added rigidity provided by the solid surface results in greater fluorescence.

Temperature also affects the quantum efficiency of fluorescence of most molecules, with fluorescence decreasing as temperature increases. The fluorescence of an aromatic compound with basic or acidic functional groups is usually $\mathrm{pH}$ dependent (Skoog and West 1980). Whether the compound is ionized or nonionized will affect the wavelength and emission intensity of the fluorescence; therefore, analytical procedures based on fluorescence often require close control of $\mathrm{pH}$.

In the last few years, a number of researchers have been investigating the feasibility of using remote fiber fluorimetric analysis for monitoring ground-water contamination. Hirschfeld et al. (1983) first suggested the use of fiber optics for monitoring ground-water contaminants. Investigations have emphasized laserinduced fluorescence monitoring because of the inherent sensitivity of fluorescence methods. Even though approximately $90 \%$ of all chemical compounds are nonfluorescent and cannot be directly detected by fluorimetry, high sensitivity can be achieved with those compounds that do fluoresce. Hirschfeld et al. (1983) demonstrated that fluorescent dye tracers could be detected at ppb levels even at $1000 \mathrm{~m}$ range. Another approach, one that takes advantage of the sensitivity of fluorescence methods, involves imbedding a chemical in the optrode. The chemical will react with a 
specific contaminant and produce a fluorescence signal. In this case the contaminant itself need not be fluorescent. Chemical optrodes using this approach will be discussed later.

The development and testing of field fluorimetry instrumentation has mainly been done by researchers at Tufts University. They have focused their research on naturally fluorescing compounds, such as aromatic gasoline compoirents. Several of the EPA's priority pollutants (phenol; o-cresol; toluene; o-chlorophenol; p-nitrophenol; 2,4-dinitrophenol, and xylenes), as well as humic acids, have been detected at environmentally significant concentrations using this method (Chudyk et al. 1985a). Chudyk et al. (1985a) achieved detection limits near or below 1 ppb at a distance of 25 m working with both simulated and actual contaminated ground-water samples. The contaminants and the limits of detection are listed in Table 4.1.

Investigators at Tufts University have designed and have tested, both in the laboratory and in the field, a prototype mobile instrument for remote laser-induced, fluorescence monitoring of ground water. The instrument consists of a portable,

TABLE 4.1. Limits of Detection for Ground-Water Contaminants (from Chudyk et al. 1987)

\begin{tabular}{llllr}
\multicolumn{1}{c}{ Contaminant } & & $\begin{array}{c}\text { Limit of } \\
\text { Detection (ppb) }\end{array}$ & $\begin{array}{c}\text { Simulated } \\
\text { Well Depth (m) }\end{array}$ & $\begin{array}{r}\text { DWS } \\
\text { (ppb) }\end{array}$ \\
& 10 & 25 & \\
o-Cresol & 9.4 & 20 & \\
Humic acid & 1 & 25 & \\
Toluene & 0.1 & 25 & 440 \\
Xylenes & 8.7 & 20 & \\
Unleaded gasoline & 0.074 & 20 & \\
Landfill leachate & 760 (as TOC) & 25 & \\
Barkpile leachate & 34 (as TOC) & 25 &
\end{tabular}


computer-controlled fluorimeter with a frequency-quadrupled Nd:YAG laser as an ultraviolet (UV) excitation source, a detachable fiber optic sensor, and a detection module containing two photomultiplier tubes and a dual-channel boxcar averager for signal recovery (Kenny et al. 1989). This device is illustrated in Figure 4.4. The instrumentation is built into a mobile unit that weighs about $230 \mathrm{~kg}$ and fits into a small truck or van. Given recent developments in-instrumentation, the investigators believe that a similar instrument could be constructed today, with the same or better capability, at less than half the size and weight.

A major obstacle to using sophisticated instrumentation is the fact that ambient field conditions are less stable than those $n$ the laboratory. Kenny et al. (1989) have

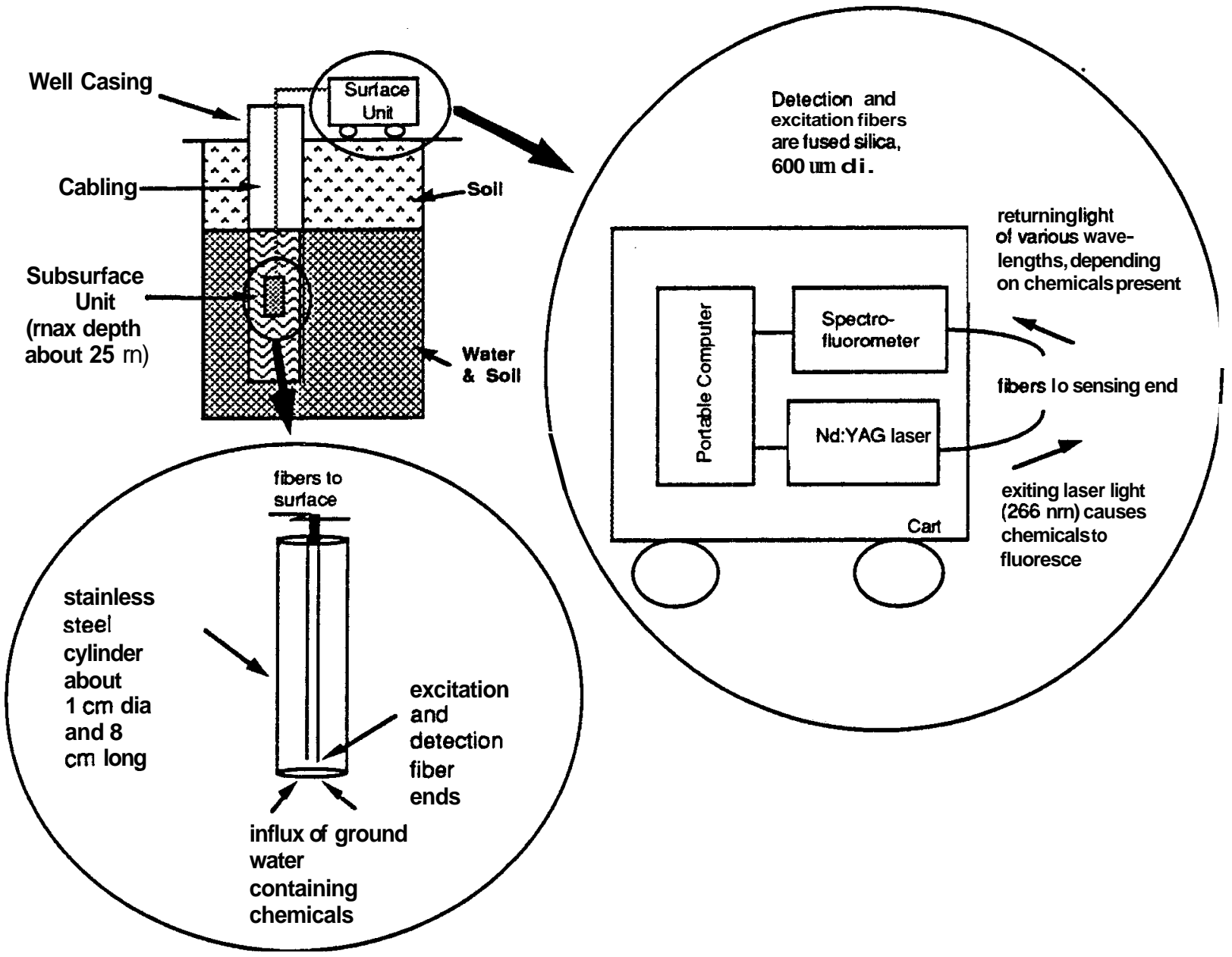

FIGURE 4.4. Schematic Illustration of Tufts University's Fluorescence Spectrometer 
achieved good efficiency (25\%) in converting the laser fundamental to green, but they have not yet achieved very good conversion of green to UV $(0.1 \% ; 10 \%$ or better is routinely achievable with laser systems). Although they foresee no problems in achieving the 1-2 mJ per pulse of UV output specified by the laser manufacturer, with the current energies of about $10 \mu \mathrm{J}$, they have had to use shorter fiber lengths $(10 \mathrm{~m})$ and higher detection limits (sub-ppm) than in their earlier laboratory work. Under field conditions, the temperature stability of the laser, the frequency-doubling crystals, and the boxcar can be a major problem. Temperature regulation has so far been systematically integrated into the prototype instrument for only the frequency-doubling crystals.

Most of the data published by the researchers at Tufts University are from laboratory experiments. In Figure 4.5 emission spectra of the principal compounds are shown. These spectra were generated with a fiber length of $1 \mathrm{~m}$. The fluorescence responses versus concentration for gasoline and xylenes for another laboratory experiment are shown in Figure 4.6 (Chudyk et al. 1985b). In this experiment, they simulated a well depth of $20 \mathrm{~m} ; 20 \mathrm{~m}$ of fiber optic cable was used between the laser and the sample. The limit of detection was less than $1 \mathrm{ppb}$ for gasoline and less than $10 \mathrm{ppb}$ for xylenes. In Figure 4.7, a plot of boxcar averager corrected signal versus concentration of phenol is shown (Kenny et al. 1989). This phenol curve was generated in the laboratory with the prototype field instrument at an instrument/analyte distance of $10 \mathrm{~m}$. The lower curve is the baseline signal; the upper curve is raw data from the fluorescence detector. This experiment was run at low power $(7 \mu \mathrm{J})$ and the limit of detection was 150 ppb.

Although in situ fluorescence is the most-tested technique for environmental monitoring, it has a few serious drawbacks. The sensitivity of the instrument at depths of $200 \mathrm{ft}$, which are common for ground water at Hanford, is questionable. Simulated well depths of $25 \mathrm{~m}$ have shown good sensitivity under laboratory conditions (Table 4.1); however, as discussed above, temperature stability of the laser, frequencydoubling crystals, and boxcar under field conditions is a major problem. As will be discussed in Chapter 6, few of the major Hanford contaminants will fluoresce and, therefore, this technique is not generally applicable. 


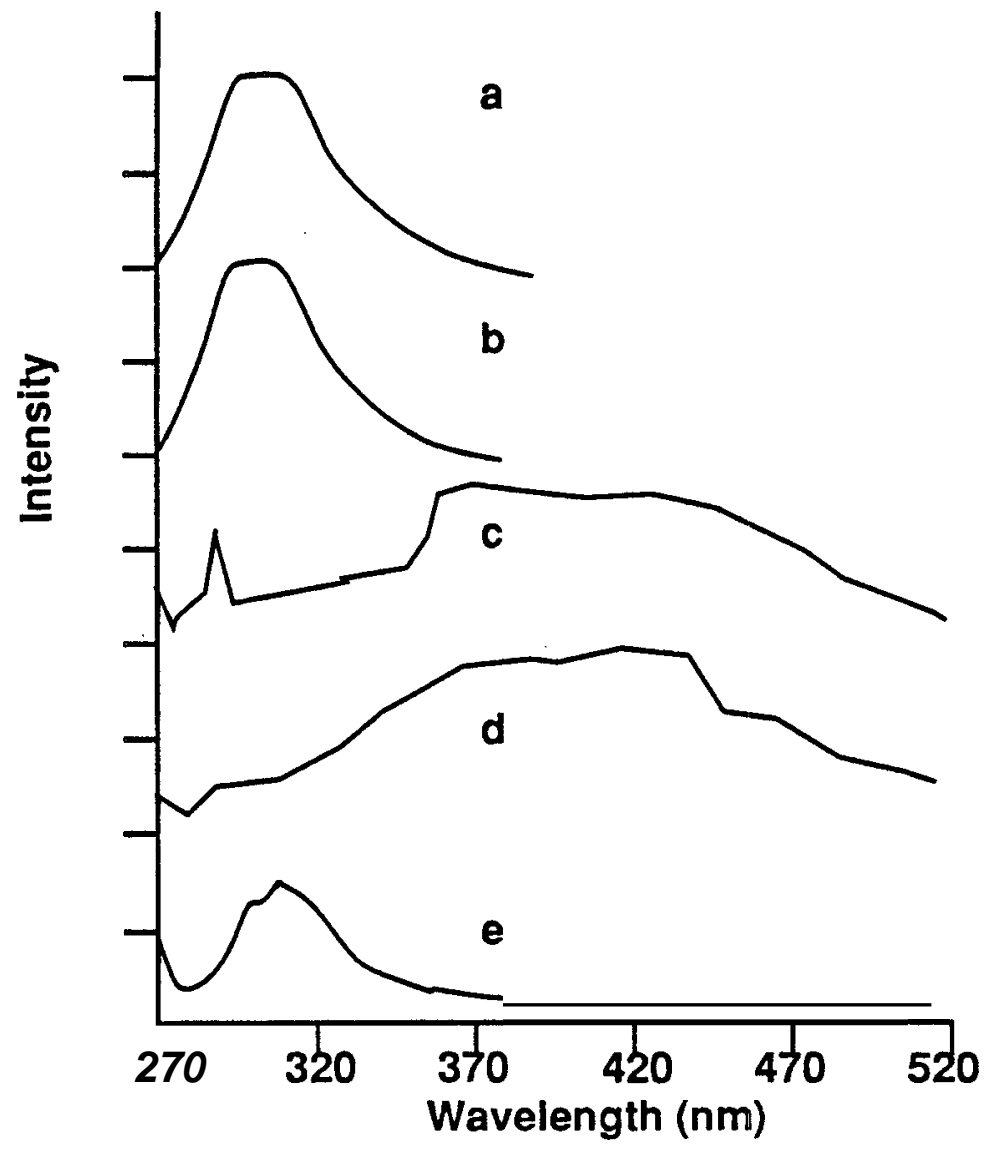

FIGURE 4.5. In Situ Fluorescence Emission Spectra Using a Fiber Length of $1 \mathrm{~m}$. a) phenol, $94 \mathrm{mg} / \mathrm{L}$; b) o-cresol, $108 \mathrm{mg} / \mathrm{L} ; \mathrm{c}$ ) humic acid, $10 \mathrm{mg} / \mathrm{L} ; \mathrm{d}$ ) bark leachate, undiluted; and e) landfill leachate, 10 -fold dilution (from Chudyk et al. 1985a).

A few variations of fluorescence and phosphorescence instrumentation have been used to measure uranium. These techniques hold promise at the Hanford Site for field-screening applications. Malstrom and Hirschfeld (1983) described a fluorescence method for determining uranium in process streams. Uranyl fluorescence depends upon uranium concentration, temperature, quenching (interference from $\mathrm{Fe}$, Al, etc.), and nitric acid concentration. Since their objective was to determine concentrations in process streams, they used a concentration range from $0.2 \mathrm{~g} / \mathrm{L}$ to $10 \mathrm{~g} / \mathrm{L}$. Baldwin and Stromatt at Pacific Northwest Laboratory (PNL) have used diode array 
COMPONENT A

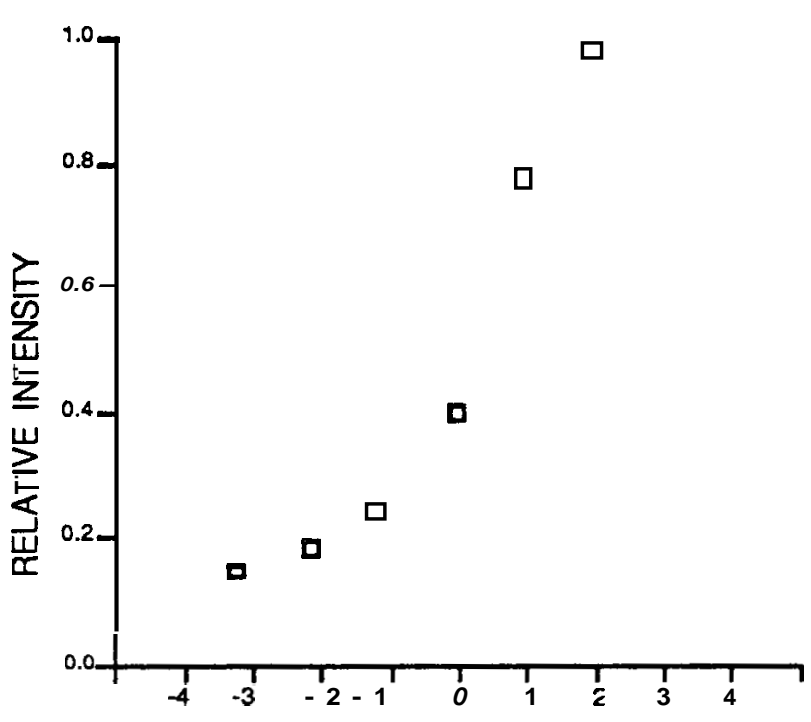

$\log C$
COMPONENT B

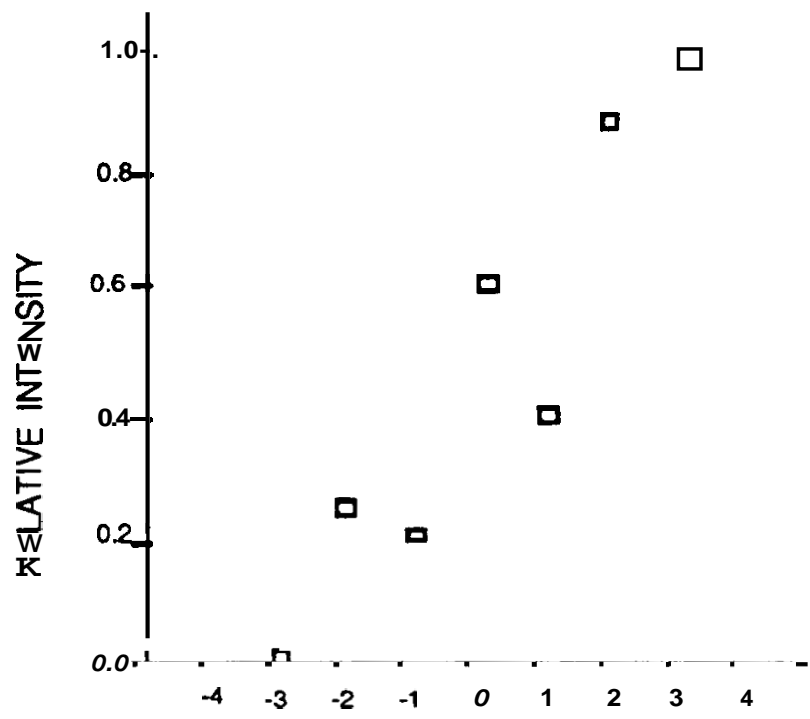

$\log C$

FIGURE 4.6. Fluorescence Signal Versus Concentration for a) Gasoline and b) Xylenes (from Chudyk et al. 1985b)

spectrophotometry to determine plutonium, uranium, and nitrate in process streams. With a $50-\mathrm{mm}$ cell, the detectable concentration range would be $0.1 \mathrm{~g} / \mathrm{L}$ to $1 \mathrm{~g} / \mathrm{L}$, too high for typical ground-water concentrations.

A kinetic phosphorescence analyzer (KPA) built by Chemchek Instruments, Inc. (Richland, WA) can be used as a field-screening device for uranium. The KPA system uses a dye laser and samples are measured in a cuvette. To enhance the phosphorescence, a solution is added to the sample to form an uranyl complex. The KPA system has a linear analytical range from 0.02 to $5,000 \mathrm{ppb}$ uranium. A similar instrument is available through Scintrex, Inc. (Concord, Ontario, Canada).

\subsubsection{Surface-Enhanced Raman Spectroscopy}

Several researchers at national laboratories, universities, and private institutions are investigating the use of Raman spectroscopy via fiber optics as a method for 


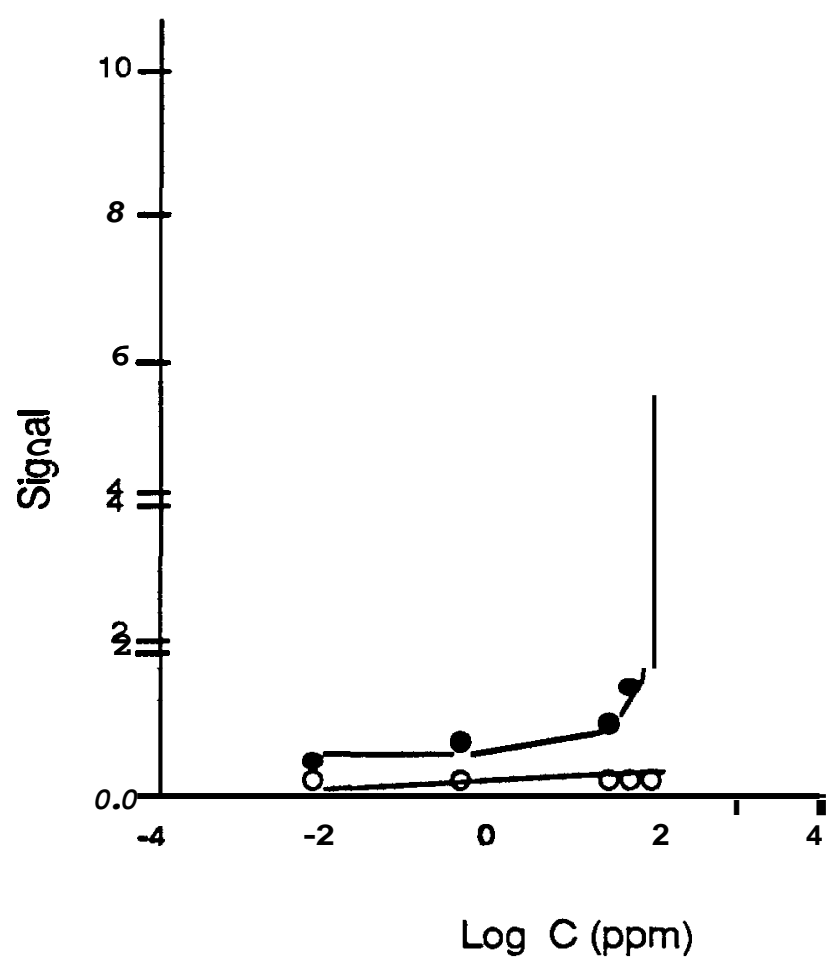

FIGURE 4.7. A Plot of Boxcar Averager Corrected Signal Versus Concentration $(\log C)$ of Phenol. This curve was generated in the laboratory at an instrument/analyte distance of $10 \mathrm{~m}$. The lower curve is the baseline (from Kenny et al. 1989).

detecting contaminants in ground water. Raman scattering was discovered in 1928 by the Indian physicist C. V. Raman. He found that the wavelength of a small fraction of the radiation scattered by certain molecules differs from that of the incident beam and, furthermore, that the shifts in wavelength depend upon the chemical structure of the molecules responsible for the scattering (Skoog and West 1980). Raman spectra are obtained by irradiating a sample with visible monochromatic radiation and measuring the scattered radiation at some angle (usually $90^{\circ}$ ). The intensities of Raman lines are usually less than $0.01 \%$ of the source; such weakness creates sensitivity problems. However, an important advantage of Raman spectra is that water does not cause interference, so Raman spectra can be obtained from aqueous solutions. 
Numerous methods have been employed to enhance the relatively weak Raman signal. Resonance Raman spectroscopy uses a tunable laser to excite a compound in the UV region of the spectrum. A laser source with a frequency near or coincident with an electronic absorption peak of a substance enhances the Raman scattering associated with this substance. Thus, resonance Raman spectroscopy results in a significant increase in sensitivity and se!ectivity. Another technique, known as surfaceenhanced Raman spectroscopy (SERS), was discovered unexpectedly in the early 1970s. The Raman signal from pyridine adsorbed on a roughened silver electrode was approximately six orders of magnitude larger than the signal from a pyridine molecule in solution. The enhancement in sensitivity is attributed to both electromagnetic and chemical interactions between the adsorbate and the metal surface (Van Duyne, Haller, and Altkorn 1986). Basic components of a typical SERS instrument system are shown in Figure 4.8. A third technique, known as Coherent Anti-Stokes Raman Spectroscopy, can overcome some of the drawbacks of conventional Raman spectroscopy, such as its low efficiency, its limitation to the visible and near-ultraviolet regions, and its susceptibility to interference from fluorescence (Skoog and West

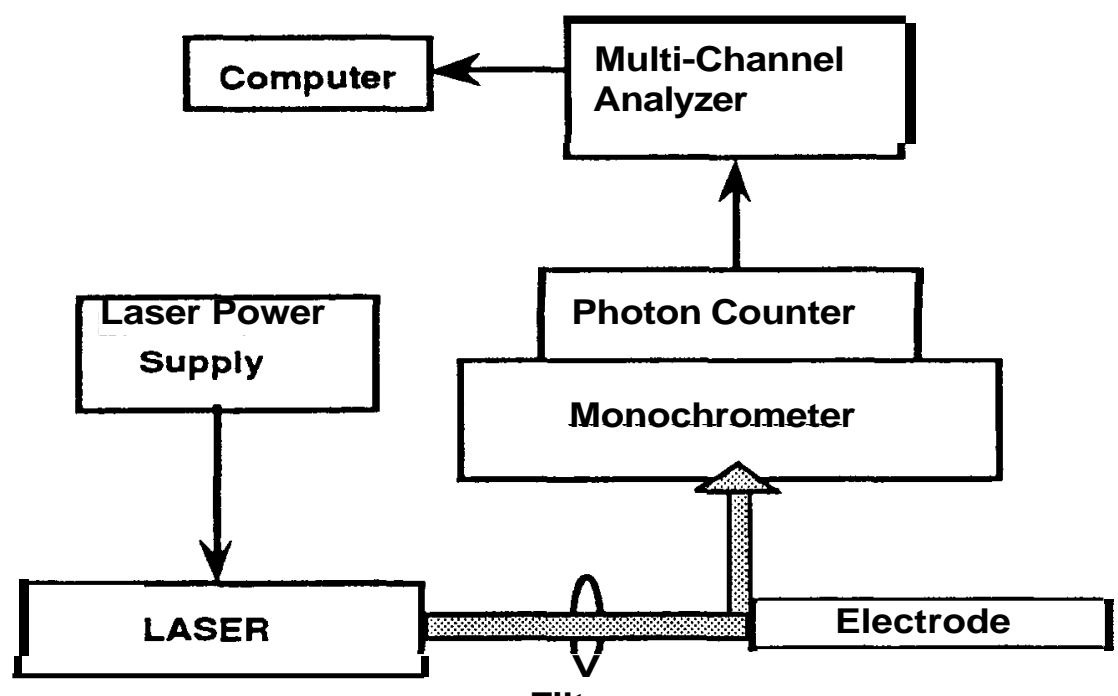

Filters

FIGURE 4.8. Basic Components of a Typical SERS Instrument System 
1980). However, only the SERS technique is currently being developed for in situ monitoring of contaminants.

Researchers at Oak Ridge National Laboratory have investigated the practicality of SERS as an analytical method for the detection of trace amounts of various organic compounds (Moody, Vo-Dinh, and Fletcher 1987; Alak and Vo-Dinh 1987; Vo-Dinh et al. 1984). They have generated SERS spectra for a variety of organic compounds of environmental interest, including benzo(a)pyrene and several organophosphorus insecticides, such as methylparathion, fonofoxon (fonofos oxygen analogue), chlorfenvinphos, cyanox, diazinon, formothion, dimethoate, and trichlorfon. In these studies, a small volume of material in solution was evaporated on the SERS substrate (Alak and Vo-Dinh 1987). Alak and Vo-Dinh also contaminated a soil sample with fonofoxon and generated a SERS spectrum of the ethanol extract of this soil. A concentrate of this extract was evaporated on the SERS substrate. The resulting spectra are shown in Figure 4.9.

For in situ monitoring of ground-water contaminants, Carrabba, Edmonds, and Rauh (1987) have perhaps taken a more realistic approach. Their SERS device is designed to measure contaminants in aqueous systems and, therefore, may eventually be used to monitor contaminants in ground water. A detection limit for pyridine of $8.5 \mathrm{pg}$ was determined using a roughened silver electrode. They were also able to qualitatively determine a two-component mixture of contaminants, pyridine and quinoline at the ppm level (Carrabba, Edmonds, and Rauh 1987). At a recent DOE workshop on in situ monitoring techniques, Carrabba (1988) presented new analytical results of SERS spectra of chlorinated hydrocarbons, in particular, carbon tetrachloride, 1,2-dichloroethane, chloroform, and trichloroethylene. More laboratory testing is necessary to determine the sensitivity for these compounds in aqueous systems. Future advances in SERS may utilize probes with selective polymer coatings that pre-concentrate a specific contaminant, further enhancing sensitivity.

In addition to the detection of organic compounds, SERS has been used to measure chromate, molybdate, tungstate, and cyanide (Feilchenfeld and Siiman 1986; Kellogg and Pemberton 1987). Although the sensitivity of these measurements was 


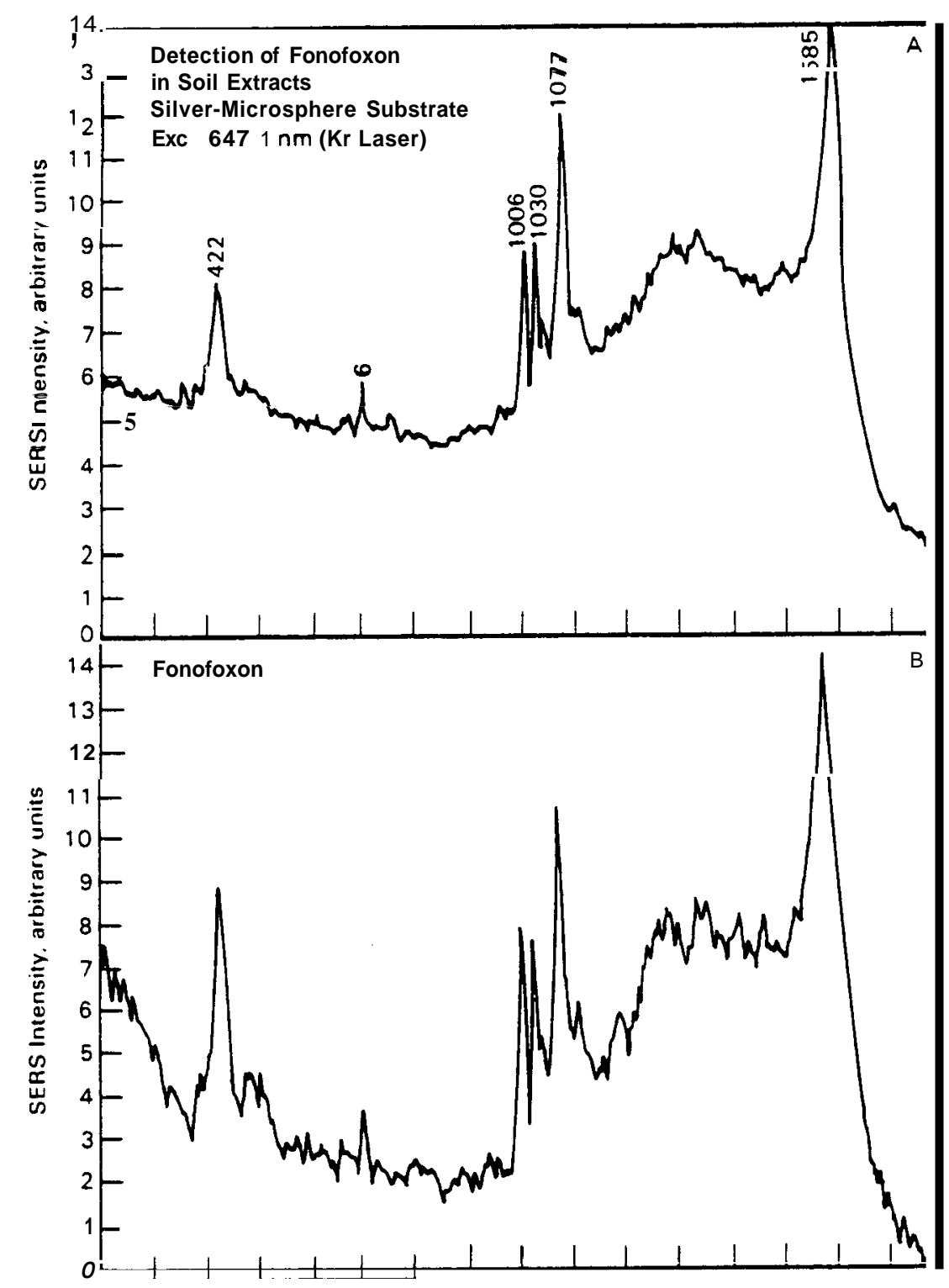

FIGURE 4.9. SERS Spectra of an Ethanol Extract of Soil Contaminated with Fonofoxon (from Alak and Vo-Dinh 1987)

not investigated, the capability of measuring chromate and cyanide may have future applications at the Hanford Site.

The SERS technique will have to overcome several obstacles before it can be used for environmental monitoring. The sensitivity of this technique for target contaminants will have to be demonstrated in the laboratory, before we can seriously consider field testing. The susceptibility of the SERS probe to contamination and the effect of 
competing inorganic and organic compounds in ground water must also be addressed. These problems can be addressed using actual ground-water samples in the laboratory SERS setup. Finally, the SERS technique uses a laser source that may be affected by environmental conditions. Carrabba's recent results with chlorinated hydrocarbons justify the continuing development of this technique, at least until the above concerns are answered.

\subsubsection{Spark Excitation-EOSES}

Emission spectroscopy refers to a type of atomic spectroscopy that employs an energetic excitation source, such as an electrical spark. The electrical spark must provide sufficient energy to vaporize the sample. It is assumed that the distribution of the elements in the vapor during this process is reproducibly related to their concentrations. The spark source must supply sufficient energy to electronically excite the elemental species in the sample. In the spark excitation-FOSES technique, a species is excited either with an electrical spark or via a radio frequency field (helium afterglow). The spark excitation mode could be used in ground water, while the helium afterglow method is more appropriate for detection in the vadose zone.

Griffin et al. (1988) described several advantages of the electrical spark as an excitation source for real-time environmental sensing. The spark simultaneously provides sample vaporization, molecular dissociation, and elemental electronic excitation. The electrical spark is an elemental detector in the sense that molecular species are entirely dissociated and emission spectra can be observed for atoms and ions. This limits the use of the spark excitation method to primarily elemental or ionic contaminants. It is possible, however, that this technique may provide a "fingerprint" of a particular ground water that would be valuable for detecting changes in contaminant levels. Another advantage of the electrical spark method is that sparks are relatively easy to generate and are well suited for remote environmental probes. Shortcomings listed by Griffin et al. (1988) include up to 50\% variability in optical emission from spark to spark and severe Stark broadening of spectral lines that effectively lowers wavelength resolution in the emission spectra. 


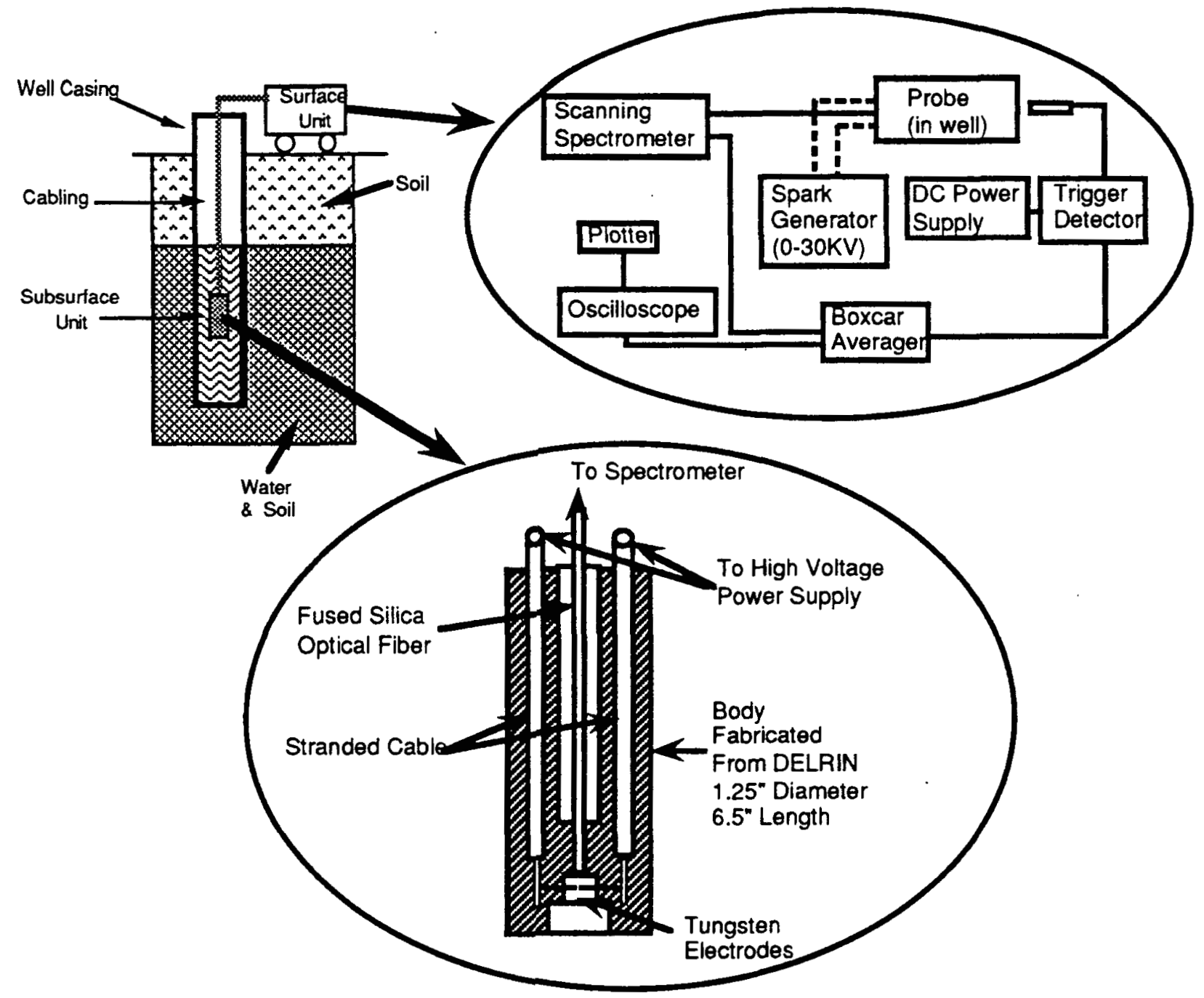

FIGURE 4.10. Instrument Design for Spark Excitation-FOSES

A simplified version of the instrumental configuration of the spark excitationFOSES is shown in Figure 4.10. The sensor system consists of a probe head containing the excitation components and optics; a detection system consisting of a spectral discriminator (filters and spectrometer) and an optical detector; and a data acquisition/analysis system suitable for data processing and storage. Evaluation of the spark excitation-FOSES in aqueous systems is planned for 1989 (Griffin et al. 1988). If the shortcomings can be overcome, then this may prove to be a valuable technique in environmental monitoring. 


\subsubsection{Chemical Optrodes}

Chemical optrodes are sensors in which the optic fiber has a specific chemistry at the fiber tip. In general, the fiber will be enclosed in a chemical jacket that monitors a particular chemical reaction. A variation of this is when the fiber has a jacket, or coating, that interacts physically with a chemical species (i.e., by absorption or diffusion into the jacket). This is an indirect means of sensing chemical change. The chemical optrodes create both a highly specific and a highly sensitive sensor through selective chemical reactions.

In a typical chemical optrode, a reagent immobilized at the fiber tip reacts with the contaminant in such a way that an optical signal is produced or an existing optical signal is modified. The strength of the optical signal is proportional to the contaminant concentration. A light beam is sent down the fiber and the return light is monitored. Optrodes have an advantage over electrochemical methods such as potentiometric electrodes because optrodes are less sensitive to surface contamination. This is an important feature for long-term in situ monitoring.

Many of the early chemical optrodes were based on fluorescence. As mentioned previously, fluorescence methods are much more sensitive than absorption methods. Laser-induced fluorescence is the most sensitive spectrophotometric analytical technique available (Angel 1987). An organochloride sensor has been developed by Lawrence Livermore National Laboratory (LLNL) in conjunction with the EPA. This sensor is based on the Fujiwara reaction, in which basic pyridine reacts with organochlorides to produce an intensely fluorescent product. Pyridine and $10 \mathrm{M} \mathrm{KOH}$ are inserted in a capillary tube that also contains the tip of the fiber optic. Although a mylar membrane was originally used to seal the capillary, it has since been found that an air pocket in the capillary tube serves the same purpose. Organic vapors move across the air pocket or membrane and react with the basic pyridine, resulting in a fluorescent red product.

The organochloride sensor has been modified and field-tested by the EPA (Herron et al. 1987) for chloroform. The modified sensor shown in Figure 4.11 uses 


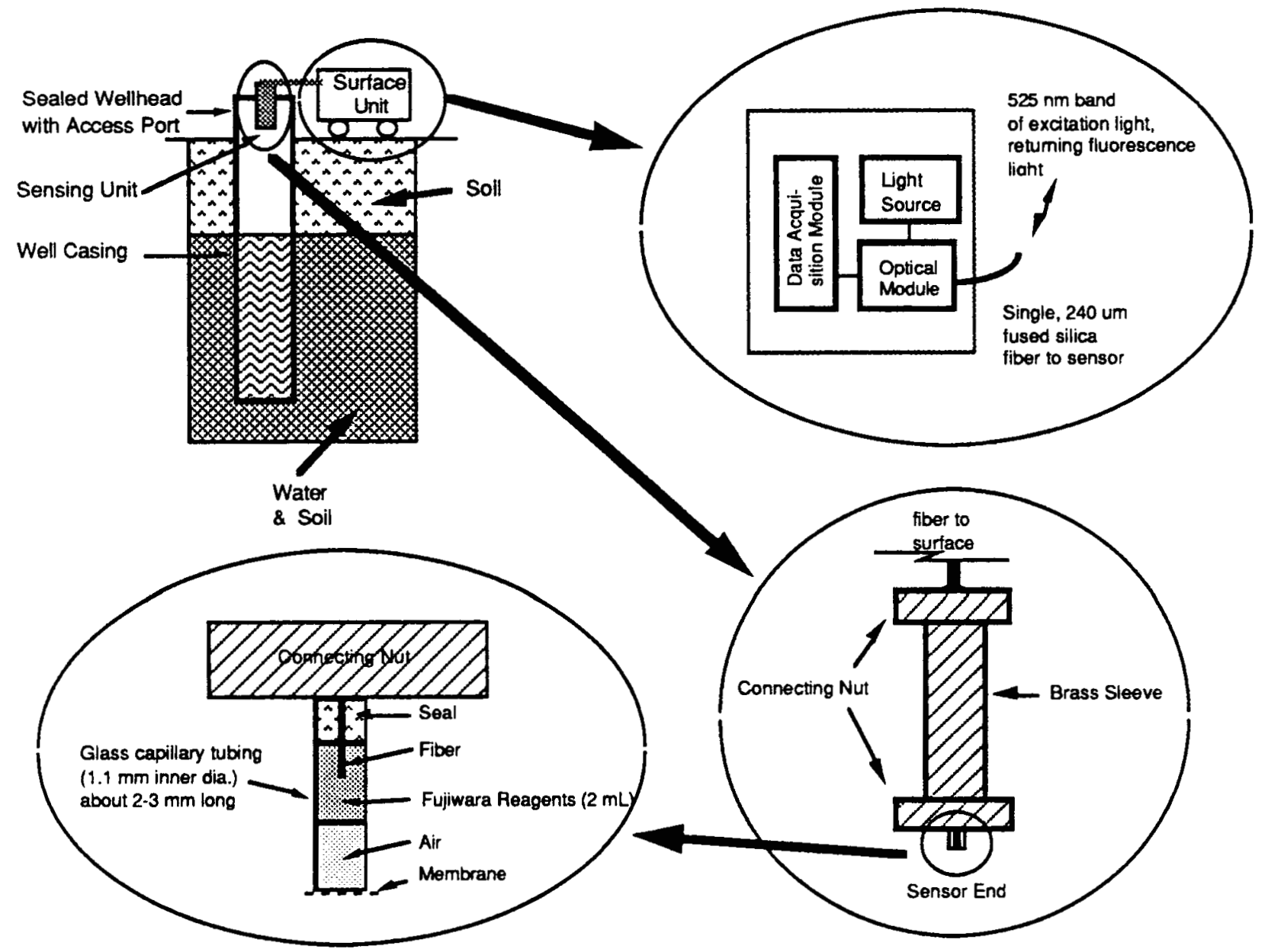

FIGURE 4.11. Schematic of EPNLLNL Chloroform Sensor

tetra-propyl ammonium hydroxide (TPAH) as the organic base instead of pyridine and $10 \mathrm{M} \mathrm{KOH}$. The sensor has also been encased in a brass sleeve for field use. The measurement time has been reduced from several hours to 15 to 20 minutes. The field test of the chloroform sensor was conducted at Henderson, Nevada. The EPA decided to use this sensor only in the gas phase by monitoring the well head space; therefore, the amount of chloroform in the ground water was calculated using Henry's Law. The EPA concluded that the sensor provided good sensitivity to gaseous chloroform in a well head space and that it had a linear response function over approximately two orders of magnitude of gaseous chloroform. The limit of detection for this 
system was about $1.2 \mathrm{ng} / \mathrm{mL}$ for gaseous chloroform, and the maximum concentration was about $100 \mathrm{ng} / \mathrm{mL}$. Based on Henry's Law, this would correspond to an aqueous chloroform concentration range between $7.5 \mathrm{ng} / \mathrm{mL}$ and $600 \mathrm{ng} / \mathrm{mL}$ (ppb). The well was not purged in the field tests before sampling. Purging the well disturbs the gas layer in the well head, and because the chloroform sensor is a gas-phase sensor, the EPA concluded that the purging procedure was inappropriate. After purging and removal of a bladder pump, the chloroform concentration takes approximately 1.5 to 2 hrs to reach equilibrium (Herron et al. 1987).

Mike Angel at LLNL has recently developed a new type of optrode for TCE. This optrode uses a reagent that turns color in the presence of TCE. White light is transmitted down the fiber optic to the sensor and is reflected off a white teflon membrane. A second fiber transmits the reflected light back to the surface instrument, which measures adsorption at 530 and $610 \mathrm{~nm}$. The measurement takes approximately 10 to 20 minutes, and the detection limit for TCE is about 2 to $4 \mathrm{ppb}$. A new sensor is required for each measurement; however, there is less than $10 \%$ variability between optrodes.

Numerous other chemical optrodes have been developed or are being planned. The chloroform and TCE sensors are so far the only optrodes specifically developed for ground-water contamination that have been field-tested. In the remainder of this . section, other chemical optrodes will be reviewed. Many of these optrodes were designed for high-concentration, process-stream applications. It may or may not be possible to modify these optrodes for the low concentrations typically found in ground water. Other optrodes have been developed for measuring physical and chemical properties of the blood stream. When appropriate (i.e., pH measurements), these optrodes will be described. Thorough reviews of chemical optrodes are presented by Angel (1987) and Seitz (1984), and the reader is referred to those reviews for more information.

Several kinds of chemical optrodes for ammonia have been developed (David et al. 1976; Giuliani et al. 1983; Wolfbeis and Posch 1986; Arnold and Ostler 1986; Rhines and Arnold 1988). The optrode developed by David, Willson, and Ruffin 
(1976) consisted of a quartz rod coated with a polymer/ninhydrin reagent. With this optrode, ammonia is detected colorimetrically. Giuliani, Wohltjen, and Jarvis (1983) described a reversible fiber optic sensor based on a thin, solid film of oxazine perchlorate dye on a glass capillary. Wolfbeis and Posch (1986) developed a fluorometric-based fiber optic sensor for aqueous ammonia determinations. In their sensor, a fluorescent $\mathrm{pH}$ indicator was trapped in a polymeric membrane at the tip of a bifurcated fiber optic bundle. Rhines and Arnold (1988) built an ammonia-gas sensor based on the entrapment of an indicator solution behind a gas-permeable membrane. The indicator solution is composed of ammonium chloride and a chromophoric or fluorophoric pH indicator. Only the sensor developed by Wolfbeis and Posch (1986) operates under aqueous conditions.

A chemical optrode for determining sulfide concentrations in aqueous solutions was developed by Martinez, Moreno, and Camara (1986). In this optrode, hydrogen sulfide reacts with $\mathrm{N}, \mathrm{N}$-dimethyl-p-phenylenediamine, which is immobilized on cationic Dowex ${ }^{\circledR} 5 \mathrm{~W}-\mathrm{X} 8$. This reaction yields methylene blue, which is measured optically. The reaction is irreversible, so an optical cell rather than a solid-state sensor can be used to monitor the methylene blue concentration. This allows addition of new Dowex $50 \mathrm{~W}-\mathrm{X} 8$ to the optical cell for the next measurement. Martinez et al. obtained a linear calibration curve within the range $0.05-0.6 \mathrm{mg} / \mathrm{L}$ sulfide.

A chemical optrode for halides was described by Urbano, Offenbacher, and Wolfbeis (1984). This sensor is based on dynamic fluorescence quenching of acridinium and quinolinium indicators, that have been immobilized via spacer groups on a glass surface. The concentration of halides in solution is determined from the decrease in fluorescence intensity resulting from the quenching process. Urbano, Offenbacher, and Wolfbeis were able to vary the sensitivity toward different halides to some extent by the choice of the indicator. The detection limits were $0.15 \mathrm{mM}$ for iodide, $0.40 \mathrm{mM}$ for bromide, and $10.0 \mathrm{mM}$ for chloride; the errors of determination were $1 \%$ for iodide, $1.5 \%$ for bromide, and $3-5 \%$ for chloride. The sensor was

@Trademarkof the Dow Chemical Co., Midland, Michigan 48640. 
reversible, and no interferences were observed with sulfate, phosphate, perchlorate, and nitrate in concentrations up to $1 \mathrm{M}$.

Several optrodes have been developed for measuring temperature, especially high temperatures. Milanovich and Hirschfeld (1983) have described a temperature optrode that makes use of the fact that many lanthanides and some transition metals exhibit narrow-iine fluorescence emission when sequestered in glass or crystal-like media. In fluorescence, this transition is a doublet and the ratio of intensities is a function of temperature. Tenge, Grunke, and Honigs (1987) built a fiber optic "chemfuse" temperature sensor. This is essentially an on/off temperature sensor for determining abrupt temperature changes in process streams. This type of sensor has limited application to ground-water monitoring.

Numerous pH sensors have also been developed. An absorbance-based pH sensor has been described by Peterson et al. (1980).Phenol red (a pH-sensitive dye) is covalently bound to polyacrylamide microspheres, providing a fixed dye concentration. Because this optrode was developed for in vivo blood gas monitoring, its range is only $7.0-7.4 \mathrm{pH}$, with a precision of $\pm 0.01 \mathrm{pH}$ unit. Saari and Seitz (1982) have described a pH sensor that uses fluoresceinamine covalently bound to cellulose. The $\mathrm{pH}$ is measured by monitoring the fluorescence at a single wavelength. Eccles, Simon, and Klainer (1987)reported on a similar optrode for measuring pH. They immobilized a $\mathrm{pH}$-sensitive dye, fluorescein, to a surface amplification polymer. This $\mathrm{pH}$ sensor has a response time of a few seconds and a range of roughly 4 to $8 \mathrm{pH}$, and the response is completely reversible. Yet another $\mathrm{pH}$ optrode has been reported by Jordan, Walt, and Milanovich (1987). This pH optrode is based on energy transfer; a fluorescent dye, eosin, is used as the donor molecule and a $\mathrm{pH}$-sensitive dye, phenol red, is used as the acceptor molecule. The dyes are co-immobilized on the end of an optical fiber in a polymer film. Eosin fluorescence is excited at $\mathbf{4 8 8} \mathrm{nm}$ and the resulting eosin emission is absorbed by phenol red. This absorption transfers energy efficiently and without radiation, from the eosin to the phenol red, resulting in a decrease of the eosin emission. The absorbance wavelength is affected by $\mathrm{pH}$. The range of $\mathrm{pH}$ has been reported as 6-8, with a precision of better than $0.01 \mathrm{pH}$ units. 
The refractive-index optrode is another type of chemical optrode that is based on a somewhat different operating procedure. The chemical optrodes described so far generally measure the product of a reaction between the contaminant and a specific chemical immobilized in the sensor tip. Refractive-index optrodes are based on refractive index matching in which the amount of light refracted changes as the analyte interacts with the reactive surface. The alteration in light intensity can be related directly to the concentration of the contaminant.

A refractive-index optrode for measuring gasoline has been described by Klainer, Dandge, and Goswami (1988). This sensor consists of a bare fiber optic core with a thin cladding of an organic or inorganic compound on its side (Figure 4.12). Fibers typically have cladding that prevents light from escaping through the sides of the fiber. A special coating on the side of the fiber, that replaces a short span of the cladding, is closely matched to the index of refraction of the target contaminant. Specific, sensitive measurements are possible if the coating has two characteristics: 1) a refractive index closely matched to the contaminant of interest, and 2) a high specific affinity for the target contaminant. In one design of the gasoline sensor, a dye is immobilized to form a fluorescent tip. An excitation signal is transmitted through the fiber tip and the fluorescence emission is used as a constant-intensity light source. A coating of a proprietary material is immobilized for a $2-\mathrm{cm}$ length on the sides of a fiber core. In the absence of gasoline, the returning light has a high intensity (i.e., all of the light is propagated through the fiber). When gasoline is present, it is attracted to the coated material, increasing the refractive index at the surface of the core. As the refractive index of the coating changes and approaches that of the core, light leaks out the sides of the fiber. When the refractive index of the coating exceeds that of the core, the intensity of the return signal decreases to zero.

The gasoline sensor responds to liquids, vapors, dissolved gasoline, and gasoline-water emulsions. Klainer, Dandge, and Goswami (1988) have reported a wide dynamic range for the sensor, from percents to $<10 \mathrm{~nL} / \mathrm{L}$. This sensor can operate in either the alarm or the quantitation mode. The gasoline sensor was developed by ST\&E and is marketed through FiberChem, Inc., in Albuquerque, New 


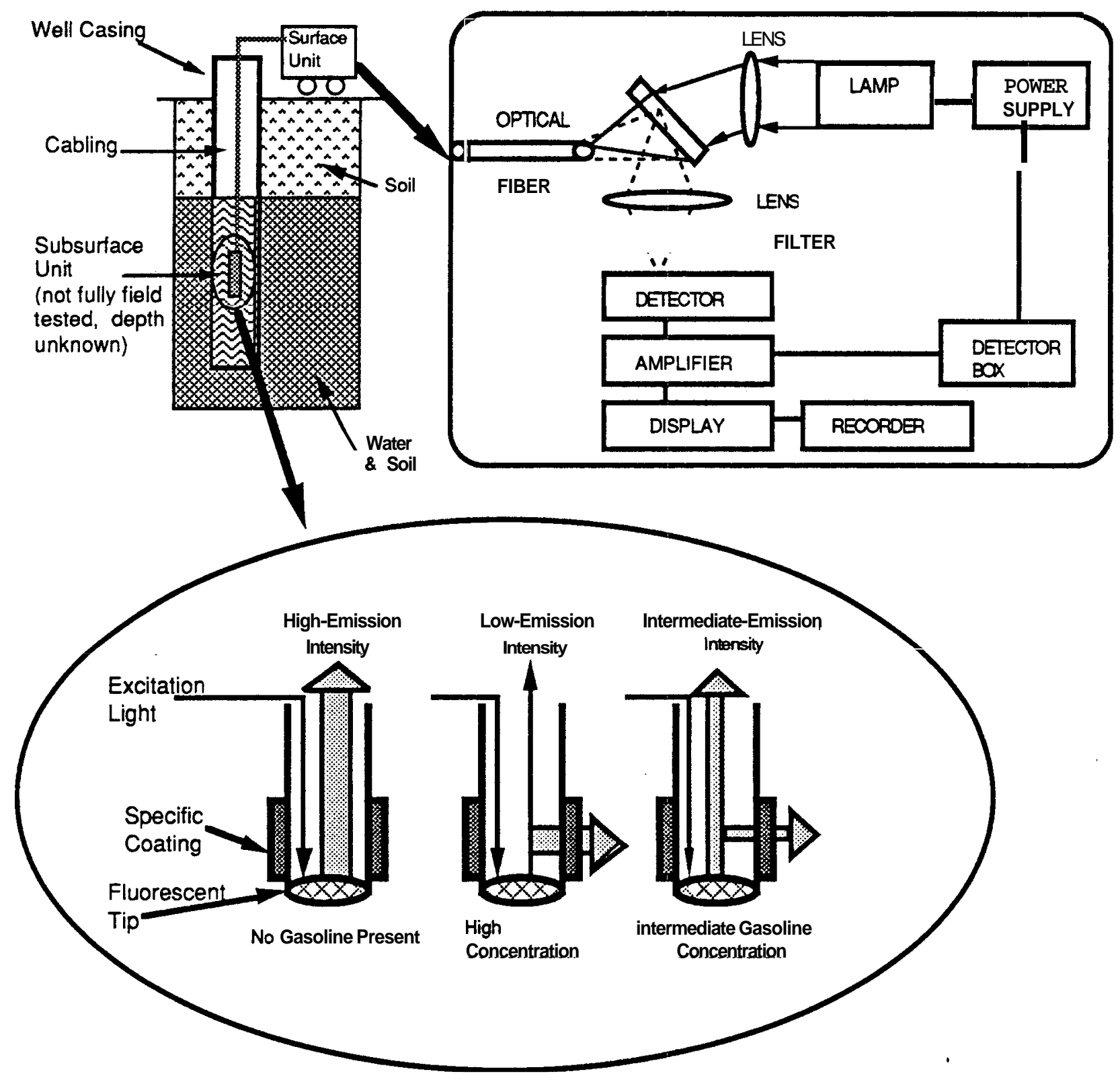

F IGURE 4.12. Schematic Illustration of Refractive-IndexOptrodes. The operating principle of the optrode is also illustrated and described in the text.

Mexico. ST\&E and FiberChem will be developing and marketing sensors based on refractive index for the constituents listed in Table 4.2.

Several chemical optrodes have been discussed in this section. Among them, only the chloroform, TCE, and refractive-index optrodes are being developed 
TABLE 4.2. List of Refractive-Index Optrodes Being Developed for Environmental and Agricultural Applications. The date represents the expected availability.

\begin{tabular}{|c|c|c|c|}
\hline Constituent & Date Available & Constituent & Date Available \\
\hline Kerosine & May 1988 & Jet Fuel & May 1988 \\
\hline & Sept 1988 & Carbon dioxide & Sept 1988 \\
\hline Oxygen & Sept 1988 & Nitrat€s & April 1989 \\
\hline Phosphates & April 1989 & Sulfates & April 1989 \\
\hline Cvanide & early 1989 & TCE & early 1989 \\
\hline Lead & early 1989 & Arsenic & early 1989 \\
\hline Chromium & early 1989 & & \\
\hline
\end{tabular}

specifically for environmental monitoring. If a specific chemistry can be developed, then optrodes are an attractive alternative for in situ environmental monitoring; however, developing specific chemistry for different chlorinated hydrocarbons may be extremely difficult. Chemical optrodes can be both highly specific and highly sensitive. The "aboveground" instrumentation is generally a tungsten lamp and spectrophotometer, and this simple instrumentation is another advantage. Finally, optical fibers can be multiplexed, allowing the monitoring of several adjacent wells.

Chemical optrodes are still being developed, and although some testing in the field may be possible in late 1989, a chemical optrode monitoring system may not actually be deployed until the mid-1990s. Chemical optrodes generally have a finite lifetime, because immobilized reagents in the optrode are used up during the reaction with the contaminant. The higher the contaminant concentration, the shorter the lifetime of the optrode. Field testing in the next few years will ultimately determine the lifetime and general applicability of chemical optrodes for environmental monitoring.

\subsection{ELECTROCHEMICALMETHODS}

In this section, we describe sensors that produce an electrical signal in response to a chemical reaction. Four kinds of devices are discussed: 1) stripping voltammetry, 2) catalytic surface-modified ion electrodes, 3) immunoassay sensors, and 4) resistancekapacitance sensors. Both stripping voltammetry and catalytic surfacemodified ion electrodes have been shown to be inherently sensitive in laboratory 
chemical analyses. Immunoassay sensors are relatively new and will require significant development before they can be used for environmental monitoring. Several resistancekapacitance sensors are currently being marketed for environmental use.

\subsubsection{Stripping Voltammetry}

The terms voltammetry and polarography are often used interchangeably. Voltammetry includes a group of electroanalytical methods in which information about the analyte is derived from current-voltage curves. Polarography is a type of voltammetric method in which a dropping mercury electrode is used. Stripping voltammetry is a modification of classic polarography. In stripping voltammetry, the analyte (or contaminant) is collected by electrodeposition at a mercury or solid electrode; the analyte is then redissolved (or stripped) from the electrode to produce a more concentrated solution than originally existed. The analysis can be based on electrical measurements made during the stripping process or electroanalytical measurement of the more concentrated solution (Skoog and West 1980). In trace analysis, stripping voltammetry can be used to determine minute amounts of a contaminant because it concentrates the analyte. Stripping voltammetry most commonly uses a micro mercury electrode for the deposition process, then measures the analyte by anodic voltammetry. Platinum electrodes have also been used.

Joseph Wang of New Mexico State University has built a chromium (VI) sensor based on adsorptive stripping voltammetry. Adsorptive stripping voltammetry is a technique in which the analyte is concentrated by adsorption onto the working electrode, and then the surface species are measured voltammetrically. Wang investigated two voltammetric techniques for determining $\mathrm{Cr}(\mathrm{VI})$ : 1) anion-exchange accumulation followed by voltammetric quantitation at polyvinylpyridine-coated electrodes, and 2) formation of an appropriate chelate of chromium and adsorptive accumulation of the chromium-chelate complex, followed by voltammetric measurement. Wang found the second design most effective; with it, he was able to detect $\mathrm{Cr}(\mathrm{VI})$ at the 2- to 7-ppb range, well below the current DWS (Figure 4.13). This sensor, either with a PDV 2000 portable digital voltammeter (made by Chemtronics) or with an EG\&G PAR Voltammetric Analyzer, could be used for screening ground-water grab 


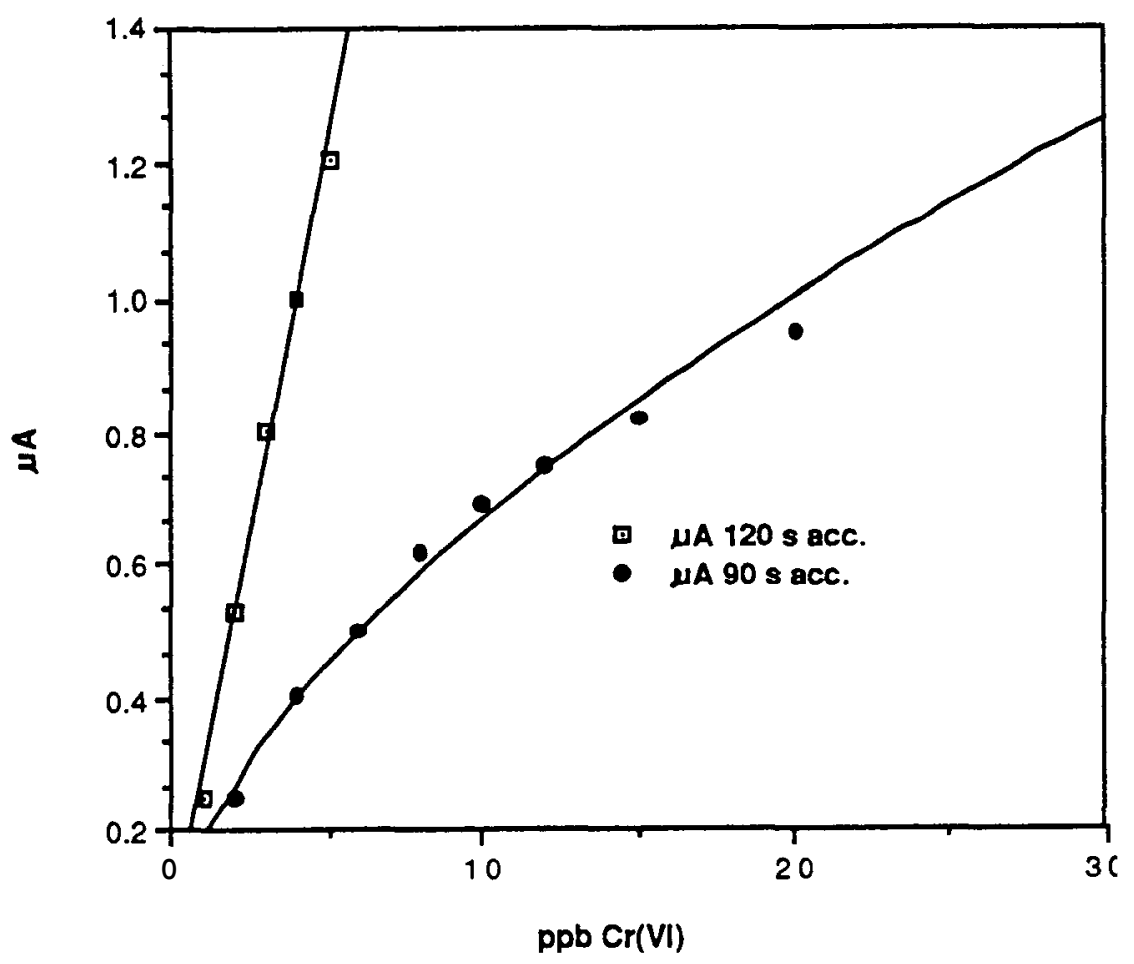

EIGURE 4.13. Calibration Curve for $\mathrm{Cr}(\mathrm{VI})$ Sensor Based on Stripping Voltammetry. Samples were allowed to accumulate for either 120 or 90 seconds.

samples in the field. The flow cell used for the PDV 2000 field unit is illustrated in Figure 4.14. Modification of this type of flow cell would make downhole, in situ measurements possible. Wang plans to build such a downhole flow cell for the $\mathrm{Cr}(\mathrm{VI})$ sensor. Field tests of the $\mathrm{Cr}(\mathrm{VI})$ sensor will begin in mid-1989 at the Hanford Site.

One advantage of stripping voltammetry is its sensitivity, the fact that it is capable of detecting contaminants well below their MCLs. In addition, with a dropping mercury electrode, a clean new surface is generated for each measurement, so the electrode should not be contaminated in field deployment. Stripping voltammetry has traditionally been limited to metals, in particular such heavy metals as $\mathrm{Pb}, \mathrm{Cu}, \mathrm{Zn}$, and $\mathrm{Cd}$, which narrows its applicability to only a few of the Hanford contaminants. Stripping voltammetry combined with adsorptive accumulation has been used to determine 


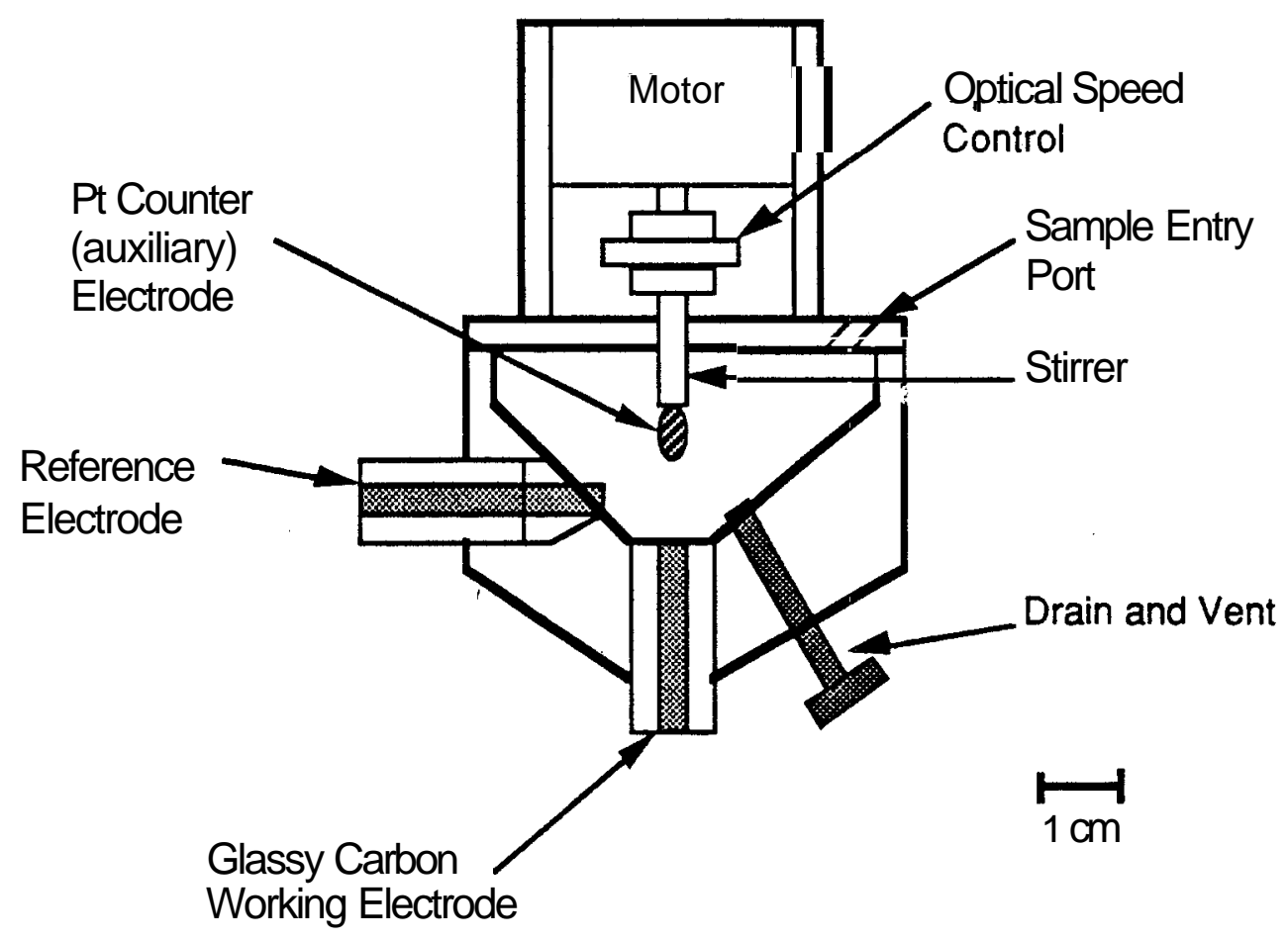

FIGURE 4.14. Flow Cell for the PDV 2000 Voltammetric Analyzer.

trace levels of $\mathrm{Ca}, \mathrm{Mg}, \mathrm{Sr}, \mathrm{Ba}, \mathrm{Ni}, \mathrm{Go}, \mathrm{Al}, \mathrm{U}, \mathrm{Fe}, \mathrm{V}, \mathrm{Cu}$, and $\mathrm{Y}$ (Wang, Percio, and Mahmoud 1985; Wang and Zadeii 1986).

\subsubsection{Catalvtic Surface-Modified Ion Electrode}

Catalytic surface-modified ion electrodes are based on amperometric titration. Amperometric titration is a voltammetric method that can be employed to estimate the equivalence point of titrations, if either one of the participants or products of the reaction involved is oxidized or reduced at the microelectrode (Skoog and West 1980). Current at a fixed potential is measured as a function of the reagent volume. The advantages to this sensing technique are 1 ) it is inherently more accurate than other voltammetric methods, 2) temperature need not be fixed accurately, although it must be kept constant during the titration, and 3) the substance being determined need not itself be reactive at the electrode; a reactive reagent or product can be detected. Past applications of amperometric titrations are listed in Table 4.3. 
$I A B \mid F$ 4.3. Past Applications of Amperometric Titrations (from Skoog and West 1980)

\begin{tabular}{|c|c|c|c|}
\hline Reaaent & $\begin{array}{c}\text { Reaction } \\
\text { Product } \\
\end{array}$ & Type of & Substance Determined \\
\hline $\mathrm{K}_{2} \mathrm{CrO}_{4}$ & Precipitate & DME & $\mathrm{Pb}^{2+}, \mathrm{Ba}^{2+}$ \\
\hline $\mathrm{Pb}\left(\mathrm{NO}_{3}\right)_{2}$ & Precipitate & DME & $\mathrm{SO}_{4}{ }^{2-}, \mathrm{MoO}_{4}{ }^{2-}, \mathrm{F}-, \mathrm{Cl}-$ \\
\hline 8-H ydroxyquinoline & Precipitate & DME & $\begin{array}{l}\mathrm{Mg}^{2+}, \mathrm{Zn}^{2}+, \mathrm{Cu}^{2+}, \mathrm{Cd}^{2+}, \\
\mathrm{Al}^{3+}, \mathrm{Bi}^{3+}, \mathrm{Fe}^{3+}\end{array}$ \\
\hline Cupferron & Precipitate & DME & $\mathrm{Cu}^{2+}, \mathrm{Fe}^{3+}$ \\
\hline Dimethylglyoxime & Precipitate & DME & $\mathrm{Ni} 2+$ \\
\hline a-Nitroso-b-naphthol & Precipitate & DME & $\mathrm{Co}^{2+}, \mathrm{Cu}_{2+}, \mathrm{Pd}^{2+}$ \\
\hline $\mathrm{K}_{4} \mathrm{Fe}(\mathrm{CN})_{6}$ & Precipitate & DME & $\mathrm{Zn} 2+$ \\
\hline $\mathrm{AgNO}_{3}$ & Precipitate & $\mathrm{RP}$ & $\mathrm{Cl}-, \mathrm{Br}-, \mathrm{I}-, \mathrm{CN}-, \mathrm{RSH}$ \\
\hline EDTA & Complex & DME & $\mathrm{Bi}^{3+}, \mathrm{Cd}^{2+}, \mathrm{Cu}^{2+}, \mathrm{Ca}^{2+}$, etc. \\
\hline $\mathrm{KBrO}_{3}, \mathrm{KBr}$ & $\begin{array}{l}\text { Substitution, } \\
\text { addition, or } \\
\text { oxidation }\end{array}$ & $\mathrm{RP}$ & $\begin{array}{l}\text { Certain phenols, aromatic } \\
\text { amines, olefins; } \mathrm{N}_{2} \mathrm{H}_{4} \text {, } \\
\mathrm{As}(\text { III), } \mathrm{Sb} \text { (III) }\end{array}$ \\
\hline
\end{tabular}

$\mathrm{DME}=$ dropping mercury electrode; $\mathrm{RP}=$ rotating platinum electrode.

Wang is developing multifunctional polymeric coatings to enhance the selectivity of amperometric microelectrodes. By coating the microelectrode with a selective ligand, molar sensitivities for such metals as $\mathrm{Ni}$ can be achieved. In previous work, Wang incorporated the powerful electrocatalyst cobalt phthalocyanine into a permselective polymer, such as Nafion or cellulose acetate, to achieve either charge or sizeexclusion properties of the coating. The electrocatalyst enhanced the sensitivity of the microelectrode, while the permselective coatings increased its selectivity. Choice of an appropriate polymer coating also determines the reversibility of the microelectrode. In cooperation with PNL, Wang will use this technique to build microelectrodes for $\mathrm{Cr}(\mathrm{VI})$ and $\mathrm{U}$. 
Like stripping voltammetry, amperometric titration is highly sensitive, making this technique very attractive for environmental monitoring. The potential reversibility of these sensors is also attractive for in situ applications. Wang has demonstrated that, by adjusting the voltage of the microsensor, the reagent can often be removed from the catalytic coating, creating a new surface for the next determination. Reversibility is a property of the specific microelectrodedesign.

\subsubsection{Immunoassay Sensors}

Immunoassay sensors are being developed primarily by Westinghouse BioAnalytic Systems (WBAS) in conjunction with EPA Las Vegas. This capacitive-based biosensor directly measures the binding of biological molecules to the surface of the electrode (or sensor). The capacitive biosensor employs antibodies as the binding molecules. The antibodies can bind to an analog of the target substance that has been chemically immobilized on the sensor's surface. The antibodies bind by non-covalent interaction with the analog on the surface. This binding establishes an initial low capacitive value. If a target contaminant is present, the antibodies on the sensor surface are competitively displaced. This results in an increase in the measured capacitance. The displacement of the antibodies from the sensor surface is related to the concentration of the contaminant. WBAS has designed the sensor so that it is reversible (Figure 4.15). The limited operational life of the current version of this sensor could preclude its use in remote, in situ applications.

This type of sensor can be a highly specific detector of target contaminants. Antibodies can distinguish two chemical structures differing by a single atom, and the] also exhibit stereochemical selectivity. The instrument can easily distinguish a 0.1 picofarad change, a signal 10 to 100 times smaller than the signal usually generated by the binding process. Interferences from ionic strength, $\mathrm{pH}$, and temperature are eliminated by using a reference sensor. The operation of this device using target contaminants has not been reported in the literature, and the sensitivity for typical ground-water contaminants is unknown. 


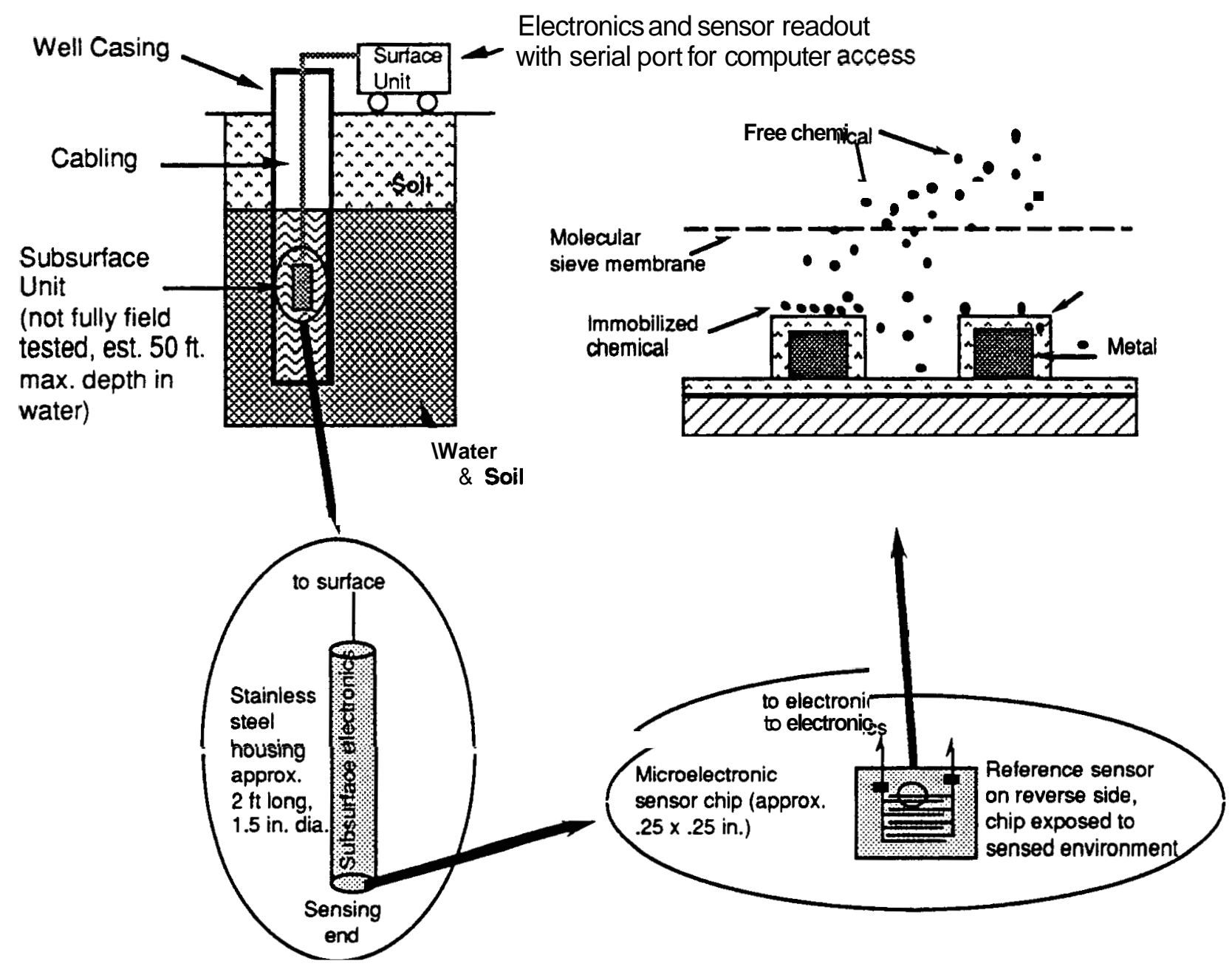

FIGURE 4.15. Schematic Illustration of WBAS Immunoassay Sensor Operation

WBAS is currently developing methods to apply immunoassay sensors to realtime, discrete-measurement systems. A selectively permeable membrane may be added to cover the active area of the sensor. This membrane would allow the contaminant to reach the active area, but would not allow the antibody to escape. In this way, the antibodies are conserved, while the small-molecular-weight contaminants are allowed to move freely. As the level of contaminant changes in the active area, capacitance also changes as a result of the coupling or decoupling of antibodies on the sensor surface. 
The future application of these sensors to ground-water monitoring is encouraging. The WBAS sensors are solid-state, microelectronic devices. Standard semiconductor techniques are used to form an interdigitated capacitor structure. Passive layers are added by chemical vapor deposition, and an analog of the target contaminant is covalently bonded to the surface. The sensor is encapsulated in a probe configuration. The probe is connected to a small, battery-operated instrument that provides the user with a quantitative measurement on a liquid crystal display. The instrument has a keyboard for data entry and internal memory for data storage. Stored data can be transferred through an RS-232 serial interface.

The applicability of immunoassay sensors for detecting Hanford contaminants is limited at this time. Specific antibodies developed are currently limited to those for contaminants that are at least as large as a benzene ring. Many of the chlorinated hydrocarbons found in Hanford ground waters are smaller than a benzene ring and so immunoassay sensors cannot detect them.

\subsubsection{Resistance/Capacitance}

Small sensors have been developed that combine simple, straight forward resistance or capacitance measurements with chemically specific polymer coatings. The Adsistor ${ }^{\mathrm{TM}}$ is one example of a hydrocarbon sensor based on an electrical resistance measurement. A resistive element forming one leg of a Wheatstone bridge is coated with a polymer that selectively adsorbs hydrocarbons. Adsorption of the hydrocarbons results in a change in resistance that is linearly proportional to the concentration of the hydrocarbon in the vapor phase. A hand-held voltmeter can be used to take the resistance measurement in the field. This particular sensor is mainly targeted for monitoring leaking gas tanks in the vadose zone and would have limited use in ground water.

WBAS is currently marketing a hydrocarbon sensor that can detect a variety of petroleum products in water. The hydrocarbon sensor is a solid-state, capacitancebased device that derives its specificity from a polymeric coating that selectively concentrates these compounds near the sensor surface. Capacitance is modulated by the 
dielectric properties of a substance within its electric field. The dielectric constant is an intrinsic property of all substances and is a measure of the ability of a substance to store energy in response to an electric field. Typically the dielectric constants of hydrocarbons and water differ widely.

The polymeric coating is specific for medium-chain aliphatic hydrocarbons, such as the range from pentane through decane. These hydrocarbons would typically be found in gasoline-contaminated ground waters. Although the sensor will respond to gasoline even at $1 \mathrm{ppm}$, it does not respond to benzene, the major component of gasoline (roughly $30 \%$ of gasoline is benzene). For ground-water monitoring applications, the lack of specificity and the sensitivity may make the hydrocarbon sensor of limited use. The device could be effectively used as an alarm sensor in areas where ground water is susceptible to petroleum pollution. However, it would be better to detect a gasoline leak or spill in the vadose zone before it reaches the ground water.

\subsection{MASS-SENSITIVE SENSORS}

Mass-sensitive sensors are in a broad category of sensors that measure a change in mass. Janata and Bezegh (1988) divided mass-sensitive sensors into two types: those based on piezoelectric bulk oscillators, and those based on surface acoustic wave (SAW) devices. The most common bulk oscillators are quartz crystal microbalances (QCM). Almost all of these sensors involve piezoelectric transduction, meaning that an electrical signal is converted to a mechanical stress or, conversely, a mechanical stress is converted to an electrical signal. This conversion between mechanical energy and electrical energy can be used effectively in sensors and oscillators.

Both SAW and piezobalance devices use a chemically selective film on the surface of the piezoelectric material (Haugen and Hieftje 1988). In the ideal case, the selective film permits only the target contaminant to diffuse from the environment into the film. The change of mass in the film is then sensed and related to concentration in the environment. In bulk oscillators, resonant frequency is dependent on the mass of 
the film. Figure 4.16 illustrates the concept of a piezobalance. Note that the piezobalance operates as an oscillator.

Surface acoustic wave devices are more complicated. A SAW device employs surface acoustic waves with frequencies in the range of 107 and $10^{9}$ hertz, traveling on the optically polished surface of the piezoelectric substrate, to process electronic signals. When the surface acoustic wave travels through a piezoelectric material, it is

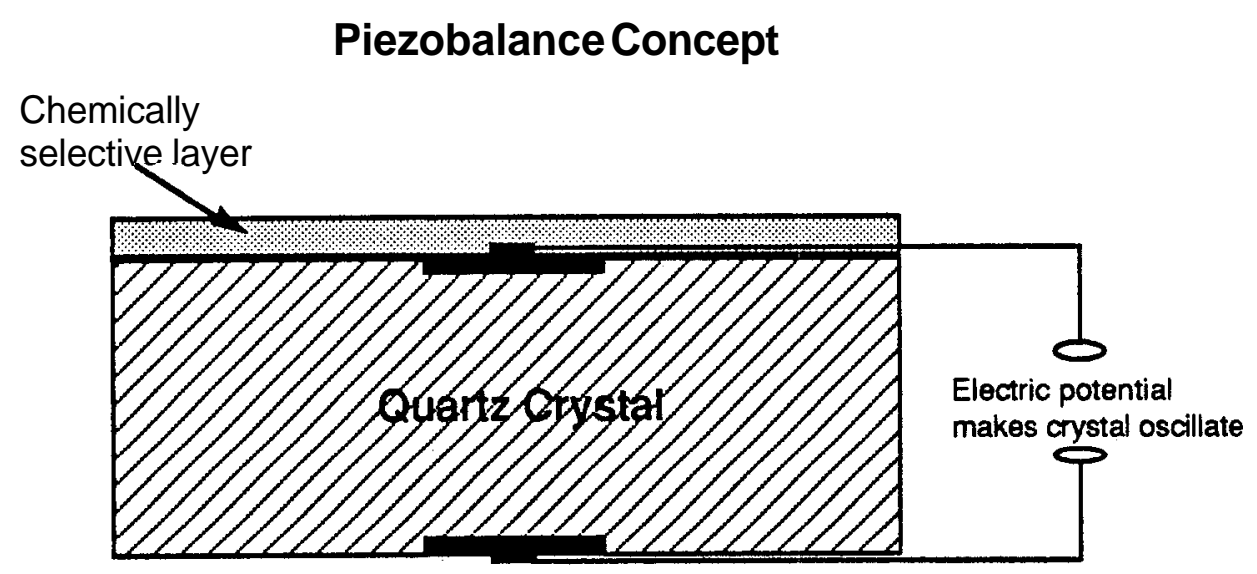

Resonant frequency of crystal depends on mass of chemically selective layer.

\section{Surface Acoustic Wave (SAW) Concept}

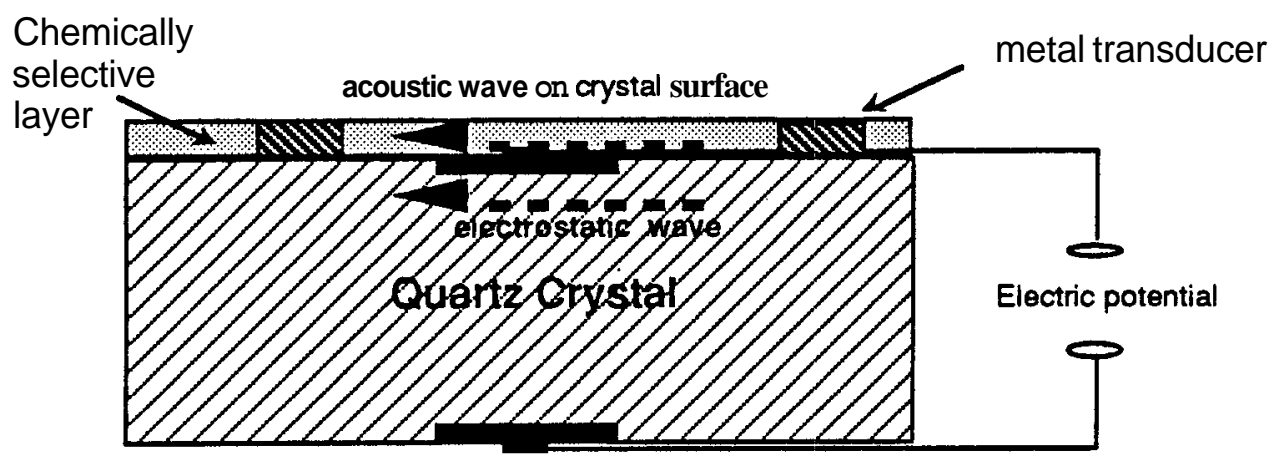

Characteristics of electrostatic wave are modified by mass of surface layer.

FIGURE 4.16. Conceptual Drawings of Piezobalance and Surface Acoustic Wave Devices 
accompanied by an electrostatic wave. The electrostatic retardation of these two waves is related to the density of the selective film. Figure 4.16 illustrates the concept of a SAW device. In the SAW device, changes in electric potential are measured at the crystal's electrodes.

The many attractive features of mass-sensitive sensors can best be illustrated by describing some of the microsensor designs published in the literature. One innovative approach to chemical sensing involves a quartz piezobalance coated with a chemically selective layer. The resonant frequency of the crystal depends on the total mass and dimensions of the crystal and its coating. As a selective contaminant is adsorbed to the coating, the mass loading is detected as a change in the crystal frequency. If a coating is applied to the surface of a quartz crystal, the resonant frequency of the quartz will change according to the following equation (Saurbrey 1959):

$$
\mathrm{AF}=-2.3 \times 106 \times \mathrm{F}^{2} \times(\Delta \mathrm{W} / \mathrm{A})
$$

where $A F=$ frequency change relative to bare quartz (hertz)

$\mathbf{F}=$ resonant frequency of bare quartz (megahertz)

$\mathrm{W}=$ weight of coated film (grams)

$A=$ area of coated film (square centimeters)

This approach has been used by Ito (1987) to build a balanced adsorption quartz hygrometer. He coated a quartz crystal with a hydrophobic polymer (epoxy resin film) and constructed a thermal insulator around the sensor element to maintain the sensor at a temperature slightly higher than room temperature. With this design, both the adsorption and desorption of water vapor come into equilibrium on the polymer surface, and hysteresis was almost completely eliminated.

Wohltjen et al. (1987) have described a dual-SAW-delay-line oscillator configuration designed to detect organic vapors. Two SAW delay lines were fabricated on the same quartz substrate, one coated with a chemically selective film (fluoropolyol) and

\subsection{5}


the other left uncoated. The frequencies of the two delay-line oscillators were mixed to provide a frequency equal to the difference between the two oscillator frequencies (Wohltjen et al. 1987). The difference frequency is much lower than the frequency of the oscillators themselves, permitting SAW vapor response to be measured using inexpensive, digital counter circuitry. Surface acoustic wave devices rely on a surface mass change to cause a shift in their resonant frequencies, so the selectivity of the coating is extremely important. In the experiment described by Wohltjen et al. (1987), the fluoropolyol exhibited the highest sensitivity for dimethyl acetamide and the lowest sensitivity for water, isooctane, and dichloroethane. The coating was not uniquely selective for any of the vapors tested. Wohltjen et al. (1987) estimated a vapor concentration detection limit of $0.1 \mathrm{ppm}$.

Martin et al. (1987) used an uncoated SAW device to measure adsorption/ desorption isotherms and thermal desorption spectra of a number of organic vapors, including acetone, i-propanol, carbon tetrachloride, and benzene. A meander-line heater was incorporated into the device to facilitate thermal desorption. Martin et al. (1987) were able to detect submonolayer changes in coverage of several organic vapors as a function of temperature or pressure.

Thompson et al. (1987) evaluated the potential of bulk acoustic wave devices as liquid-phase sensors. The bulk wave device is less expensive than SAW devices; however, the SAW device is potentially more sensitive. Thompson et al. (1987) immobilized an antigen on the crystal surface in order to detect specific antibodies in blood. The bulk acoustic wave sensor is similar to an immunoassay sensor, and like the other mass-sensitive devices, it should be highly specific for individual analytes. 


\subsection{EVAI UATION OF INSTRUMENT SYSTEMS AND SENSORS}

The overall goal of this project is to match Hanford needs for contaminant monitoring with appropriate instrumental methods. Basic sensing principles and transduction methods, reviewed in Section 4.0, are the basis of this evaluation. The primary considerations for initially screening the instrument systems an! sensors are detectability and sensitivity; in other words, can they measure a specific contaminant at the necessary concentration? Because few of the instrument systems or sensors have been field tested this evaluation is somewhat qualitative. In most cases, we can only state the concentration limits established in the laboratory.

If an instrument system can detect a specific contaminant with the required accuracy, then the system should be evaluated in more detail. Considerations for the detailed evaluation of instrument systems are 1) selectivity and interferences, 2) predicted sensitivity and dynamic range, 3) field-screening or in situ detection, 4) response time and reversibility, and 5) field operability.

\subsection{PRIMARY CONSIDERATIONS: DETECTABILITY AND SENSITIVITY}

By understanding the basic transduction principle of a instrument system, we can often determine what classes of compounds can be detected and at what sensitivity. The matrix in Figure 5.1 was used to evaluate whether the priority contaminants at the Hanford Site can be detected by the individual sensing methods. The matrix matches priority contaminants against all major chemical sensing techniques. The current status of development is shown for each combination of instrument type and contaminant. Uranium is the only radionuclide that can be analyzed by a chemical transduction measurement. Tritium and the other radionuclides listed in Table 3.2 are typically measured by radioactive decay and, therefore, are not included in Figure 5.1. As a class of contaminants, hydrocarbons have not been detected in Hanford monitoring wells; however, none of the monitoring wells are near the gasoline and diesel storage tanks on the Hanford Site. New EPA regulations require that gasoline storage tanks 


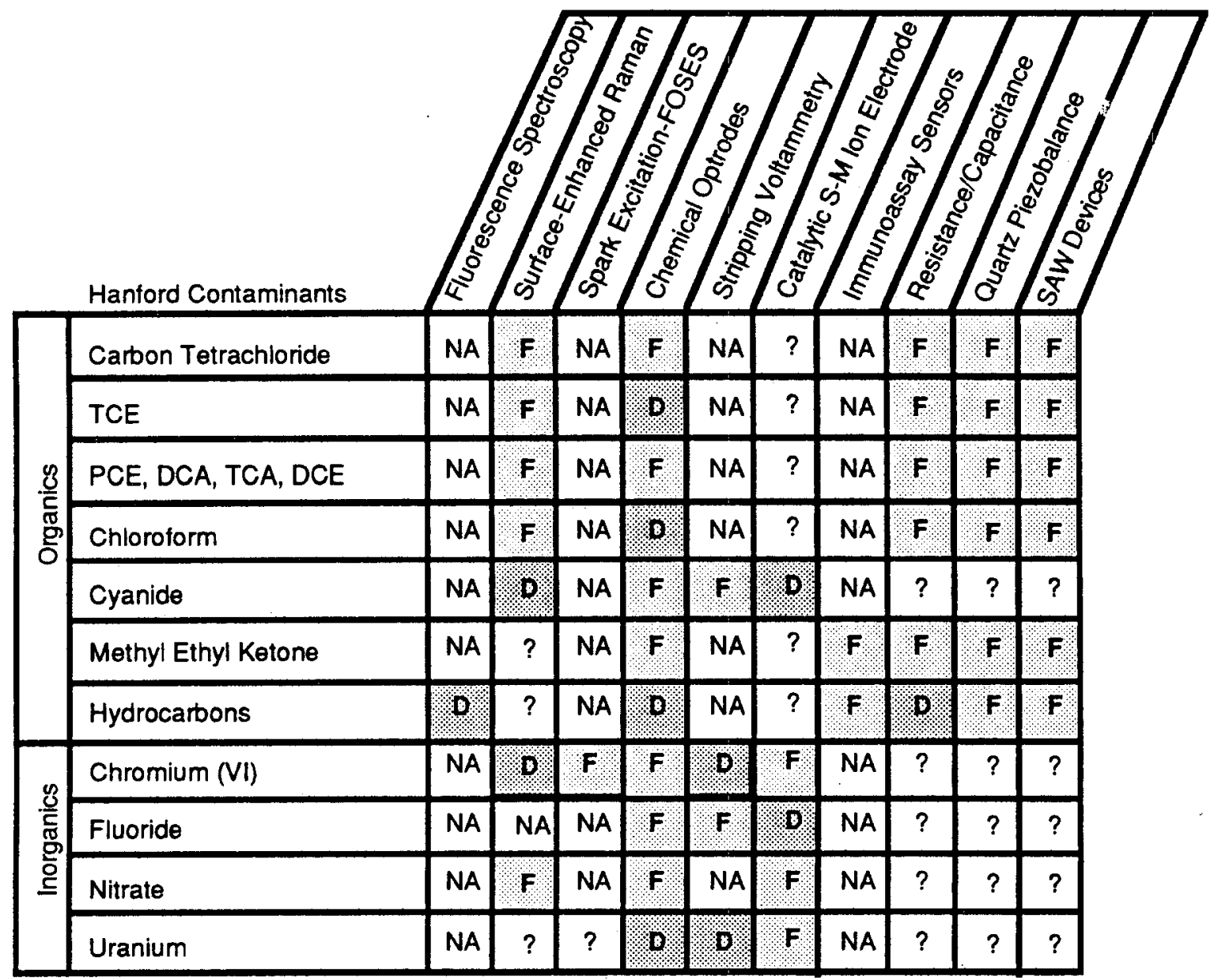

FIGURE 5.1. Evaluation Matrix Illustrating Whether Hanford Contaminants Can Be Detected by the Individual Sensing Methods. NA = not applicable based on transduction principle; ? = potential unknown; $\mathrm{F}=$ believed feasible based on transduction principle; and $\mathrm{D}=$ demonstrated in laboratory or field.

be monitored for potential contaminant release; therefore, hydrocarbons have been included in this list for the purpose of evaluation.

The designation "not applicable" in the matrix is based on first principles; in other words, the basic transduction principle simply cannot be used to detect certain classes 
of compounds. The "believed feasible" designation was used when the detection of functionally similar compounds by a particular technique has been demonstrated. The "potential unknown" designation indicates that there has been a lack of development activity for that combination of instrument technique and contaminant, although there is no obvious reason for a "NA" designation.

Figure 5.1 illustrates that Fluorescence Spectroscopy will have limited use at Hanford, even though this technique is probably the most advanced in the application of ground-water monitoring. Only gasoline or diesel hydrocarbons have sufficient aromaticity to be detected by this method. An important conclusion that can be drawn from this matrix is that, at this point, no single system will be adequate for monitoring all of the priority contaminants at Hanford. The two instrumental approaches that may in the future be able to detect all of the priority contaminants are chemical optrodes and mass-sensitive devices. However, although mass-sensitive devices hold promise, few measurements have been done in aqueous systems, which makes it difficult to evaluate this technique. The success of optrodes, electrochemical, and masssensitive devices depends on whether or not highly selective chemical reactions or polymer coatings can be designed for specific Hanford contaminants.

The matrix in Figure 5.2 shows an evaluation of the detection limit or sensitivity of each technique for each priority contaminant. The sensitivity of the instrument system is a major criterion, because if an instrument system is to take the place of laboratory analysis, it must be sensitive enough to measure at the MCL level or below. Sensitivity is a dynamic property of the instrument system affected by fluctuating environmental conditions. Sensitivity is also a dynamic property of the transduction method and often can be improved by advances in the basic instrumentation. Unfortunately, measuring compounds at trace levels is rarely a goal of researchers. However, recent funding for environmental monitoring has prompted the reevaluation of several sensing methods. For example, the intensities of Raman lines are usually at most $0.01 \%$ of the source, necessitating the use of a laser source and sensitive analyzers. But because Raman spectra can be obtained in aqueous systems, investigators are currently studying ways to enhance this weak signal. Therefore, it is possible that 


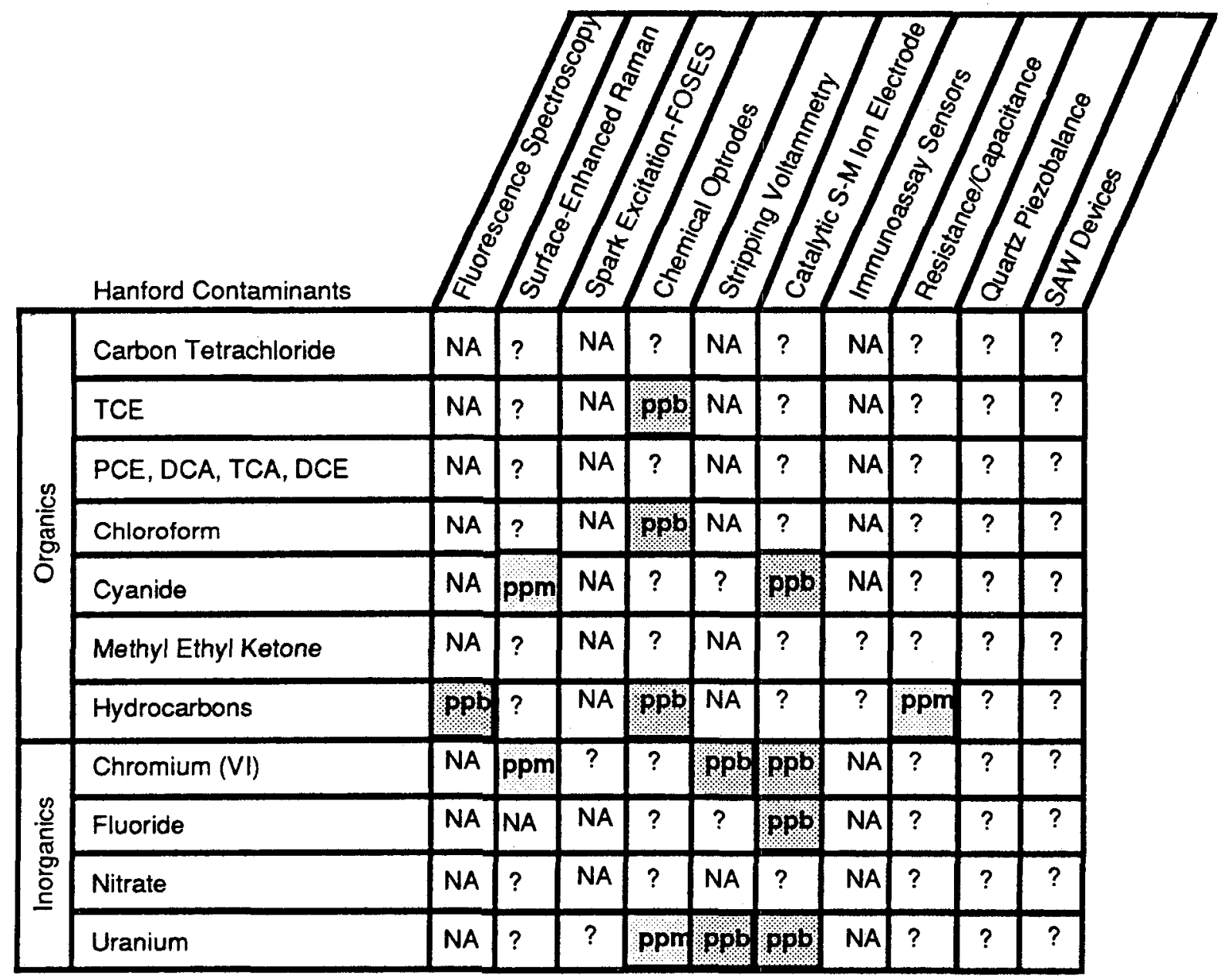

FIGURE 5.2. Evaluation Matrix of the Sensitivity of the Instrument Systems and Sensors. $\mathrm{ppm}=$ parts per million, $\mathrm{ppb}=$ parts per billion.

lower sensitivity limits for Raman will be achieved in the future making it more applicable to environmental monitoring.

An initial evaluation of sensitivity can be based on laboratory performance, although environmental conditions almost always reduce the sensitivity of sophisticated instruments used in the field. In some cases, the difference between laboratory 
and field sensitivity levels may be two orders of magnitude. The estimates of sensitivity in Figure 5.2 are based mainly on laboratory results; therefore, sensitivities are listed only for demonstrated techniques. Predicted or theoretical sensitivities will be discussed in the next section. Optrodes and electrochemicaltechniques can be quite sensitive, provided that a selective chemistry can be designed for a specific contaminant. Mass-sensitive devices can be very sensitive for non-aqueous systems in the laboratory; however, so little work has been done with mass-sensitive devices in aqueous systems that it is impossible to predict a sensitivity level. Surface acoustic wave devices are typically more sensitive than bulk wave devices, detecting organic vapors in air at the ppb level.

\subsection{GENERAL CONSIDERATIONS IN EVALUATING INSTRUMENT SYSTEMS}

General considerations for the detailed evaluation of instrument systems are 1) selectivity and interferences, 2) predicted sensitivity and dynamic range, 3) fieldscreening or in situ detection, 4) response time and reversibility, and 5) field operability. Information on selectivity, sensitivity, and general operating conditions is occasionally stated in the literature. This information is usually derived from laboratory tests in which the interferences normal in the field have been minimized. Therefore, extrapolating from this information to potential field performance can be dangerous. The field application of sophisticated instrument systems can be costly and time consuming, and it may produce discouraging results. Nevertheless, field testing is the only way to adequately evaluate these systems.

The instrument systems discussed in this report may be used either as field screening devices or as remote, in situ analysis systems. For the purposes of this report, field-screening is defined as making measurements in the field on groundwater samples that have been pumped or bailed from a well. The instruments are taken into the field. Field-screening capabilities can be very useful for quickly delineating a contaminant plume or a point-source release. Field-screening techniques can also be used for testing wells outside of the standard monitoring well network. 
For in situ measurements, the sensor is placed directly in the ground water. Ideally, several adjacent wells would be multiplexed to a single instrument system. This multiplexed instrument system would utilize smart data loggers and remote communications to relay information back to a central computer. Such multiplexed instrument systems and remote communications have been used in many commercial operations. For example, the city of Tucson, Arizona, uses a central computer facility to monitor drawdown, pumping rate, and other parameters in more than 50 wells scattered around the city. The limitations of environmental in situ sensing techniques are not in developing remote communication monitoring networks, but rather in developing highly sensitive sensors capable of detecting ppb concentrations in ground water. The distinction between field screening and in situ techniques is important because it affects how field performance should be evaluated. Fieldscreening measurements are labor intensive, so analysis or response time, portability, and power requirements are all important. For in situ applications, analysis time and portability are not important if the contaminant concentrations are being monitored remotely .

Selectivity and interferences are both major criteria for evaluation, and they pose perhaps the most significant obstacle to effective in situ monitoring. The matrix in Figure 5.1 illustrated the detectability of the instrument systems and sensors under laboratory conditions, but did not evaluate the selectivity and impact of interferences from other chemical substances. A system's ability to detect contaminants can be completely undermined if the instrument system or sensor is not selective. For example, if another constituent in ground water has a more intense fluorescence or has a greater affinity for a selective polymer coating, it may completely mask the target contaminant. Such interferences must be evaluated under field conditions.

In the previous subsection, laboratory measurements of sensitivity were reported in Figure 5.2. Little information is available on the sensitivity of these instruments for the contaminants at the Hanford Site, so the predicted sensitivity of the instrument system is evaluated qualitatively in this subsection. If an instrument system is to take the place of laboratory analyses, it must be sensitive enough to measure at the $\mathrm{MCL}$ 
level or lower. The dynamic range of the instrument should ideally span from below the MCL to the solubility limit of the contaminant in water.

The response time and reversibility of an instrument system or sensor will determine how it can best be used in environmental monitoring. Response time matters more for field screening than for in situ measurements, because of labor costs. To rapidly screen several wells, a response time of less than 10 minutes is desirable. As mentioned above, if the contaminant concentrations are being monitored remotely (as in an in situ application), then response time is not an important factor. Reversibility is an important criterion for sensors that are based on a chemical reaction. That is, contaminants must be able to desorb from selective polymer coatings as their concentrations in solution decrease. Reversibility is less important for field screening applications, in which a sensor may be used once and then thrown away.

The broad category of field operability encompasses many aspects of the field readiness of a instrument or sensor: 1) ruggedness and reliability of the instrument system or sensor, 2) ease of use, 3) system support, 4) power requirements, 5) portability, 6) data acquisition capability, and 7) communications capability. The ruggedness and reliability of an instrument system or sensor are especially important for field operation. In situ sensors must be able to withstand the considerable amount of banging that often occurs when sensors are lowered into a well. Aboveground instrumentation should be able to withstand climatic extremes, such as the $40^{\circ} \mathrm{F}$ daily fluctuations in temperature often observed at the Hanford Site. In situ systems will in general be difficult to calibrate, so instrument stability is also a factor to consider when evaluating reliability. Their ease of use and adequate system support will facilitate the use of sophisticated instrument systems. Portability is especially important for field screening. A suitcase-size instrument system that can be carried by one person would be best. Rechargeable power supplies are often more convenient than generators for field screening; however, solar power cells may be more practical for remote, in situ applications.

Familiarity with the components of the instrument system will give some indication of the effect of environmental parameters on sensor performance. For example, 
instrument systems that contain lasers are likely to be sensitive to temperature changes. A complete evaluation of environmental parameters, however, will require field testing. The cost of field implementation can be qualitatively evaluated based on the individual components of the instrument system. In general, systems with sophisticated instruments will cost more to implement and operate under field conditions. The longevity of the sensor will directly impact the cost savings on field labor. A minimum longevity of one year would probably be sufficient, because it is expected that ground water would be collected for complete laboratory analyses at least that often. Replacement of sensors coupled with ground-water collection would minimize the number of trips made to the field sites.

The following criteria, described in detail above, have been used for a qualitative evaluation of the instrument systems and sensors described in Section 4.0:

1) selectivity and interferences, 2) predicted sensitivity and dynamic range, 3 ) field screening or in situ detection applicability, 4) response time and reversibility, and 5) field operability. This evaluation by instrument system is presented below in a bulleted format. In many cases, information is insufficient for a rigorous evaluation.

\section{Fluorescence Spectroscopv}

- Selectivity and Interferences - The selectivity of fluorescence spectroscopy is based on the excitation and emission wavelength of the light. Presumably, different compounds give unique fluorescence spectra. The subjects of interferences and resolution of spectra have not been adequately addressed in the literature.

- Predicted Sensitivity and Dynamic Range- Reported sensitivities are at the ppb level. This system has a wide dynamic range that depends, to a certain extent, on the instrument's electronics.

- Field-Screening or In Situ Applicability - Most of the current emphasis is on using fluorescence spectroscopy as a field-screening technique. As lasers and detection electronics become smaller, cheaper, and more reliable, a multiplexed system for remote in situ applications may become feasible. 
- Response Time and Reversibility - The response time of this system is fast, limited primarily by the sampling electronics. Excitation of molecules to fluoresce is reversible.

- Field Operability - The major drawback of the in situ fluorescence system developed at Tufts University were its temperature sensitivity and the bulkiness of the laser in their ield tests. The bulkiness will be reduced as microlasers become available; however, temperature sensitivity may still be a problem.

\section{Surface-Fnhanced Raman Spectroscopy}

- Selectivity and Interferences-Selectivity is potentially good; however, interferences have not been evaluated.

- Predicted Sensitivity and Dynamic Range - The sensitivity of SERS is currently at the ppm level. Future modifications may enable measurements at the ppb level. The quality of the detection electronics will probably determine the dynamic range.

- Field-Screening or In Situ Applicability - Similar to fluorescence spectroscopy.

- Response Time and Reversibility-Response time should be fast, primarily limited by the sampling electronics. For SERS, reversibility is the ability of the signal to return to baseline, which is directly related to fouling of the electrode tip. Additional testing will be necessary to determine its reversibility, especially under field conditions.

- Field Operability - Like fluorescence spectroscopy, the major drawback of SERS is the laser component of this instrument system, specifically its bulkiness, which may be improved, and its sensitivity to temperature.

\section{Spark Excitation-FOSES}

- Selectivity and Interferences - This technique is not selective for specific contaminants; it measures the atomic component of the compounds in the 
water. In wells containing multiple contaminants, it may be difficult to discriminate between individual contaminants by the atomic component. Interferences are unknown.

- Predicted Sensitivity and Dynamic Range- The sensitivity and dynamic range have not been reported.

- Field-Screening or In Situ Applicability - The conceptual design of FOSES would allow both field-screening and in situ applications; however, at this time it is not sufficiently developed to determine whether this method will be better suited for one application or the other.

- Response Time and Reversibility - Response time should be fast. The actual spark-excitation reaction is irreversible; however, this factor should not affect the functioning of the probe. The time that must elapse between successive measurements may depend only on how fast the spark chamber is flushed. In field use, care must be taken to ensure that flushing the chamber to the ground water does not bias subsequent samples.

- Field Operability- The field operability of this instrument system is unknown. Power requirements include a high-voltage source to create the spark in situ.

\section{Chemical Optrodes}

- Selectivity and Interferences - The selectivity and interferences must be individually evaluated for each kind of optrode, because they are primarily a function of the selective coating or the chemical reaction. Chemical optrodes have the potential to be very selective.

- Predicted Sensitivity and Dynamic Range-Most optrodes are designed to be sensitive at the ppb level. The dynamic range under environmental conditions is largely unknown, with the exception of the chloroform sensor developed by the EPNLLNL. 
- Field-Screening or In Situ Application - Chemical optrodes may be used for either field screening or in situ applications. An optrode that contains a chemical reactant will have a limited lifetime in an in situ application.

- Response Time and Reversibility- Response time varies from instantaneous to several minutes, depending on the speed of the chemical reaction. Generally, the response time is much slower than for the spectroscopic methods discussed above. Reversibility depends upon the design of the individual chemical optrode.

- Field Operability - Although further testing is necessary, the reliability and ruggedness of this system is expected to be quite high because its instrumentation is relatively simple compared to other chemical sensing techniques.

\section{Stripoina Voltammetry}

- Selectivity and Interferences - Stripping voltammetry can be highly selective in the laboratory; however, interferences under environmental conditions are unknown.

- Predicted Sensitivity and Dynamic Range - This method has good sensitivity. Under laboratory conditions, a fairly narrow response range was evaluated. The ease of setting a dynamic range suitable for environmental monitoring is unknown.

- Field-Screening or In Situ Applicability - Currently this method can be used for field-screening. Development of a flow cell will enable in situ application.

- Response Time and Reversibility- The response time is about 1 minute, which puts it between spectroscopic methods (few seconds or less) and chemical optrodes (several minutes).

- Field Operability - The field operability of this system is largely unknown. The system should be less susceptible to environmental conditions than 
those instruments containing lasers. The stripping voltammetry instrumentation is more complicated than that used for chemical optrodes. The effect of stray and/or transient voltages in a borehole is unknown, but may be significant for in situ applications.

\section{Catalytic Surface-Modified lon Electrode}

- Selectivity and Interferences-Selectivity is largely a property of the selective coating. This method is selective under laboratory conditions where interferences are minimized. Its selectivity under environmental conditions is unknown.

- Predicted Sensitivity and Dynamic Range- High sensitivity can be obtained under laboratory conditions. The dynamic range under environmental conditions is unknown.

- Field-Screening or In Situ Applicability - This method could potentially be used for either field-screening or in situ applications.

- Response Time and Reversibility - The response time and reversibility are similar to stripping voltammetry.

- Field Operability - Like that of stripping voltammetry, the field operability of the system is unknown.

Immunoassay Sensors

- Selectivity and Interference-This sensor is still in the early developmental stage. Its selectivity is expected to be good; however, immunoassay sensors can detect only compounds that have a greater molecular weight than benzene.

- Predicted Sensitivity and Dynamic Range - In principle, the sensitivity is very good (ppm to ppb). The dynamic range is unknown.

- Field-Screening or In Situ Applicability - This type of sensor is being developed primarily for field screening applications. In situ applications 
would require bundling the probe plus some of the electronics in a single unit, because low-level capacitance measurements cannot be made very far from the electronics.

- Response Time and Reversibility- Response time is fast (seconds to minutes), but the reversibility is unknown. The reversibility depends on the selective coating and enzyme in the sensor.

- Field Operability- The field operability is unknown.

\section{Besistance/Capacitance}

- Selectivity and Interferences - The sensors on the market are only selective for a class of compounds (i.e., hydrocarbons). Their selectivity depends on the design of the selective coating.

- Predicted Sensitivity and Dynamic Range- The sensitivity of current sensors is inadequate for ground-water monitoring.

- Field-Screening or In Situ Applicability - Resistance/capacitance sensors may be used for either application. Their small size and ruggedness make them good for in situ applications.

- Response Time and Reversibility - The response time is generally fast. The reversibility of the sensor depends on the desorption of the contaminant from the selective coating. Initial tests of at least one of the sensors on the market shows that reversibility may be a significant problem.

- Field Operability - The sensors on the market are rugged and have relatively simple instrumentation. Therefore, it is expected that this kind of system will be reliable and easy to use in the field. 


\section{Quartz Piezobalance}

- Selectivity and Interferences - Selectivity is limited by the design of the selective coating. Interferences may be a minimal problem where water chemistry is stable and known. Sensor arrays may be a solution to selectivity and interference concerns.

- Predicted Sensitivity and Dynamic Range- The system's sensitivity and dynamic range for aqueous systems are unknown. To a certain extent, the sensitivity will be a function of the signal conditioning electronics.

- Field-Screening or In Situ Applicability - Quartz piezobalance sensors could be used in either application.

- Response Time and Reversibility - Response time is rapid; however, reversibility is a function of the desorption of the contaminant from the selective coating.

- Field Operability - The field operability of quartz piezobalance sensors is unknown. Potentially, these sensors can be compact and rugged; their reliability is unknown. This type of sensor is routinely used in process stream applications; however, as mentioned above, the performance of this type of sensor in aqueous systems at low concentrations (ppb) is unknown.

\section{SAW Devices}

- Selectivity and Interferences-Selectivity is limited by the design of the coating. Interferences may be a minimal problem where water chemistry is stable and known.

- Predicted Sensitivity and Dynamic Range - Sensitivities of SAW devices measured in vapor systems ( $\mathrm{ppb}$ ) are better than the sensitivities of quartz piezobalance sensors. Sensitivity and dynamic range in aqueous systems are unknown.

- Field-Screening or In Situ Applicability - These sensors could be used for either application. 
- Response Time and Reversibility - Response time is rapid; reversibility is a function of the coating design.

- Field Operability - The field operability is unknown.

These evaluations illustrate how little information is available on the field performance of environmental sensors. Even in laboratory tests, interferences have rarely been addressed. Selectivity, sensitivity, and dynamic range are probably the most important criteria for evaluating the potential application of instrument systems and sensors for environmental monitoring, yet information on these criteria is often unavailable in the literature. The response time is generally fastest for the spectroscopic methods (fluorescence, SERS, and spark excitation-FOSES). Chemical optrodes, electrochemical, and mass-sensitive devices have slower response times than spectroscopic methods, because these devices depend on a mass-transfer process occurring at the sensing element. However, all methods appear to have response times fast enough for environmental monitoring. Reversibility is a far more important factor.

The instrument systems that use lasers, i.e., fluorescence spectroscopy and SERS, may experience problems with sensitivity, dynamic range, and field operability. However, recent advances in laser technology may solve some of these problems. Amoco Laser has introduced a line of microlasers that could reduce the bulkiness, weight, and cost of the laser systems currently in use. Their microlasers combine laser diodes the size of a grain of salt with nonlinear optical crystals to provide frequency modification. These devices are reported to combine the high efficiency, small size, and ruggedness of laser diodes with the beam quality and broad range of wavelengths of solid-state lasers (Sensor Technology 1988). The laser and power supply are both small enough to be used as a hand-held package. The device only requires $2 \mathrm{~W}$ of electrical power. The laser head weighs $12.9 \mathrm{oz}$ and measures $4.25 \mathrm{in}$. long by 1.75 in. (outer diameter).

All of the instrument systems evaluated can be used for field-screening applications. For in situ applications, chemical optrodes, resistancekapacitance sensors, 
and mass-sensitive devices are currently more appropriate than the other instrument systems. Chemical optrodes especially combine small, rugged sensors with relatively simple aboveground instrumentation. These same comments can be made for field operability. Systems with rugged electrodes and relatively simple electronics/ instrumentation will have fewer problems under field conditions. Stray or transient voltages in the borehole may prove a problem with the voltammetry methods. Although the sources of electrochemical interferences, stray voltages, and currents in boreholes are poorly understood, they can have substantial effects on downhole instrumentation that employs the measurement of small voltages or currents.

This evaluation has shown that chemical sensors are in an early stage of development and that much of the information needed for a complete evaluation is not available. This evaluation has also shown that Hanford priority contaminants may be detectable by a variety of instruments; however, chemical optrodes currently hold the most promise. Fluorescence spectroscopy, spark excitation-FOSES, and immunoassay sensors hold little promise for monitoring the range of Hanford contaminants at this time. 


\subsection{CONCLUUSIONS AND RECOMMFNDATIONS}

The conclusions are drawn from the review and evaluation of instrument systems described in Sections 4.0 and 5.0. The recommendations derive from these conclusions and the authors' understanding of the Hanford Site's needs regarding environmental monitoring. Before the conclusions and recommendations are explained, the most important issues covered by this report will be reviewed briefly.

\subsection{REVIEW OF THE MAJOR ISSUES}

The long-term goal of this work is to establish a capability for in situ detection of Hanford contaminants. The rationale for in situ detection is multifaceted. A primary reason is cost; field sampling and the associated laboratory analyses are expensive. These costs will probably increase, maybe substantially. Another reason for in situ detection of contaminants is it allows sample integrity to be maintained. The process of sampling itself alters the contaminants or their measurement, with some contaminant measurements being more affected than others. In situ detection holds the potential for eliminating sampling as a source of measurement error. Additional reasons for in situ detection of contaminants concern rapid field screening and real-time monitoring. In situ detection avoids the delays inherent in field sampling followed by laboratory analyses, which makes it attractive for both emergency response and remediation activities. Real-time monitoring capabilities will save both time and money during site remediation by eliminating delays required for sampling and analysis.

Westinghouse Hanford, as DOE's operations contractor for Hanford, is very interested in monitoring Hanford contaminants accurately and cost effectively . Furthermore, many of Hanford's waste-disposal activities have been and will continue to be unlike waste disposal in private industry. Although the disposal activities and associated monitoring requirements do overlap, DOE cannot rely on the private sector to develop the necessary instrumentation for applications unique to DOE. Therefore, 
DOE itself must lead in the development of the instruments it needs, and DOE must wisely support instrument development in the private sector, when appropriate.

The objective of this report was to match Hanford monitoring needs with emerging sensor technologies. This report is an initial step in the review of a wide variety of developing chemical sensors with emphasis on the hydrologist's perspective. This is especially important in a rapidly developing technology like chemical sensing for environmental pollutants, in which the more exciting technology will often dominate, irrespective of the application's specific needs. We do not mean to imply that environmental instrumentation should be developed only by hydrologists, because it obviously should not. The development of chemical monitoring systems should clearly be multidisciplinary. But the application's needs and goals must be kept in clear view to effectively guide DOE investment in this evolving technology.

The approach taken in this report consists of two parts: 1) the identification of priority contaminants at Hanford and 2) the identification of instrumentation for in situ contaminant detection. First, three general classes of contaminants were defined: organics, inorganics, and radionuclides. From these classes, fourteen priority Hanford contaminants were identified (ten organic; three inorganic; and one radionuclide). Because only one radionuclide, uranium, can be detected by chemical methods, it is the only one included in this evaluation.

Second, chemical sensors were divided into four classes based on transduction principles: optical, electrochemical, mass sensitive, and thermal. From these classes, ten specific types of instrument systems were identified (four optical, four electrochemical, two mass-sensitive, and no thermal). Thus ten types of instrument systems were evaluated and matched with monitoring needs for fourteen high-priority contaminants. This evaluation was summarized in Figure 5.1, and the sensitivities of instrument systems for specific Hanford contaminants were compared in Figure 5.2. All ten instrument systems were qualitatively evaluated for general selectivity, response time, reliability, and field operability. Those evaluations brought us to the following conclusions and recommendations. 


\subsection{CONCI USIONS}

\subsubsection{Conclusions Reaardina the Develooina Technoloav of Chemical Sensing}

With few exceptions, chemical sensors are in an early state of development. If the development of chemical sensors is divided into two steps, prototype development and final deployment, all instrument systems reviewed are at the first step. The prototype instruments have largely been only laboratory tested, not field tested. Much development must still take place before final, deployable systems can be used in the field. It is likely that many developing systems will not make it to final deployment, and new techniques will also evolve in the near future. DOE should carefully evaluate potential instrument systems to ensure that those systems most suited to its needs are successfully developed.

Activity in chemical sensor development is broadly based. Research and development activities regarding chemical sensors are taking place at universities, at national laboratories, and in industry. Several commercial products for in situ environmental monitoring of contaminants have recently become available, but they have not yet been tested through sustained use. Product development and marketing of chemical sensors is accelerating. DOE must keep abreast of these activities and support them in the most appropriate manner to ensure the development and deployment of instrument systems that meet DOE's needs. By implication, this will also help DOE avoid duplicating successful efforts elsewhere.

\section{A systematic and thorough approach to field testing is needed.} Instrument developers are historically, and understandably, overly optimistic about their instrument systems. New systems for the field need sustained testing over a range of conditions that can never be fully duplicated or anticipated in the laboratory. DOE must develop a method of thoroughly testing new systems in the field. This is no simple matter. In situ detection, by its very nature, is an attempt to do something that cannot be duplicated. Field sampling and laboratory analyses are not equivalent to in situ monitoring, but they will be needed for comparison. In addition, baseline parameters defining in situ water chemistry (e.g., temperature, $\mathrm{pH}$, Eh, total dissolved solids) 
must be monitored to achieve sufficient understanding of the sampled environment. Of particular importance to chemical sensing are interferences. The accuracy and reliability of chemical sensors often depends to a large degree on what other constituents are also in the sampled environment.

Selective coating technology is common to most chemical sensors. To be selective for specific contaminants, most chemical sensors rely on special coatings incorporated into the sensing element. In theory, the coatings restrict masstransfer processes to target contaminants only. In practice, most coatings are not strictly selective. The understanding and proper use of selective coating technology is very important for most chemical sensors and should be emphasized in future research supported by DOE.

Chemical sensors will be essentially "developmental" for the near future. Since chemical sensing for environmental monitoring is just evolving, available systems are likely to have operational problems. Some systems will undoubtedly provide useful data even in early development stages and will satisfy Hanford's needs more effectively than others. Understandingthe limitations of available instrument systems when used in Hanford's hydrologic environment is important. The appropriate systems can then be selected, supported, and deployed for use in monitoring activities.

\subsubsection{Conclusions Specific To Hanford Interests}

These conclusions are drawn directly from the evaluation described in Section 5.0. Two assumptions have been made: 1) the priority Hanford contaminants previously identified are of equal importance, and 2) the evaluation matrix of Figure 5.1 is accurate enough to assess general trends pertinent to Hanford monitoring needs. In fact, the evaluation summarized in the matrix of Figure 5.1 is preliminary. Several trends are clear and, assuming there are no major errors in the matrix, those general trends should hold.

Tables 6.1 and 6.2 illustrate the trends identified from our evaluation. The goal of our evaluation was to match instrument systems with appropriate Hanford 
contaminants. Although all of the instrument systems under development are obviously directed at some purpose, not all of those purposes are consistent with Hanford's needs. The current development statuses of instrument systems are divided into three categories and tabulated based on Figure 5.1 (i.e., demonstrated, demonstrated + feasible, and not applicable). In Table 6.1, these three categories are listed in a matrix for the Hanford contaminant:; in Table 6.2, they are listed for the types of instrument systems.

Hanford contaminants are potentially detectable by a variety of instruments. The column labeled " $\mathrm{D}+\mathrm{F}$ " in Table 6.1 illustrates that each Hanford priority contaminant might be detectable by three to six types of instrument systems. For example, four types of instrument systems have been demonstrated or are feasible for in situ detection of cyanide.

Carbon tetrachloride, MEK, nitrate, PCE, DCA, TCA, and DCE detection has not been demonstrated by the instrument systems reviewed. Though in situ detection appears to be feasible, detection of these priority contaminants has not been demonstrated, as indicated by the zeros in the " $\mathrm{D}$ " column of Table 6.1. There has so far been a lack of interest or support for developing this capability, DOE should move to resolve this and should support necessary research and development for this capability.

Detection of cyanide, chromium, uranium, and hydrocarbon has been demonstrated in the laboratory. Instrumentation for detecting these four contaminants is under development and in some cases is already supported by DOE. In fact, detection of each of these contaminants has been demonstrated with at least two types of instrument systems, as indicated in column "D" in Table 6.1. Current development activities, if they continue, are probably sufficient to satisfy Hanford needs. In situ detection of hydrocarbons is receiving very strong support from the commercial sector, because the potential market is large; therefore, DOE need not support this development to ensure capability. 
JABLE 6.1. Summary of Current Development Status for Instrument Systems

Reviewed. This table summarizes Figure 5.1 ; the possibility of detecting Hanford contaminants using the ten instrument systems reviewed in this report. Each number in the table indicates how many types of instrument systems apply to that column's development status (D, D+F, and NA).

Hanford Contaminants

\section{Development Status}

\begin{tabular}{llll}
\cline { 2 - 4 } Hanford Contaminants & D & D+F & N \\
\hline Organics: & & & \\
Carbon Tetrachloride & 0 & 5 & $\mathbf{4}$ \\
TCE & 1 & 5 & $\mathbf{4}$ \\
PCE, DCA, TCA, DCE & 0 & 5 & $\mathbf{4}$ \\
Chloroform & 1 & 5 & $\mathbf{4}$ \\
Cyanide & 2 & $\mathbf{4}$ & $\mathbf{3}$ \\
Methyl Ethyl Ketone & 0 & $\mathbf{4}$ & $\mathbf{3}$ \\
Hydrocarbons & $\mathbf{3}$ & $\mathbf{6}$ & 2
\end{tabular}

$\begin{array}{llll}\text { Inorganics \& } & \text { Radionuclides: } & & \\ \text { Chromium (VI) } & \mathbf{2} & \mathbf{5} & \mathbf{2} \\ \text { Fluoride } & 1 & \mathbf{3} & \mathbf{4} \\ \text { Nitrate } & 0 & \mathbf{3} & \mathbf{4} \\ \text { Uranium } & \mathbf{2} & \mathbf{3} & 2\end{array}$

\footnotetext{
Key to Symbols:

$D=$ Demonstrated in laboratory or field.

$\mathrm{F}=$ Believed feasible based on transduction principles.

$\mathrm{NA}=$ Not applicable (transduction principles will not work for specific contaminant).
}

Fluorescence spectroscopy and immunoassay sensors currently hold little promise for monitoring the range of Hanford contaminants. In Table 6.2, the "D+F" column (or conversely, the "NA" column) indicates which types of instrument systems hold the least potential for Hanford applications. Fluorescence spectroscopy and immunoassay sensors could each potentially detect only one priority Hanford contaminant. Therefore, DOE should not pursue the development and use of these types of instrument systems for ground-water monitoring at the Hanford Site. 
$I A B \mid F 6$.2. Evaluation of Current Development Status for Instrument Systems Reviewed. This table summarizes Figure 5.1; the possibility of detecting the fourteen Hanford contaminants using the instrument systems reviewed in this report. Each number in the table indicates how many contaminants apply to that column's development status (D, D+F, and NA).

Instrument Svstsm

\section{Development Status}

\section{Optical:}

Fluorescence Spectroscopy

Surface-Enhanced Raman Spectroscopy

Spark Excitation-FOSES

Chemical Optrodes

D D+F NA

Electrochemical:

Stripping Voltammetry

Catalytic Surface-Modified Ion Electrode

Immunoassay Sensors

Resistance/Capacitance

$\begin{array}{ccc}1 & 1 & 10 \\ 2 & 7 & 1 \\ 0 & 1 & 9 \\ 4 & 11 & 0\end{array}$

Mass Sensitive:

Quartz Piezobalance

SAW Devices

$\begin{array}{lll}2 & 4 & 7 \\ \mathbf{2} & 5 & 0 \\ 0 & 1 & 9 \\ 1 & 6 & 0\end{array}$

Key to Symbols:

$\mathrm{D}=$ Demonstrated in laboratory or field.

$\mathrm{F}=$ Believed feasible based on transduction principles.

NA = Not applicable (transduction principles will not work for specific contaminant).

\section{Spark Excitation-FOSES may be valuable for establishing a} "fingerprint" of the ground water in a particular well. Although, as shown in Table 6.1, FOSES could detect only one contaminant under saturated conditions, it might be an extremely valuable technique if it can be used to establish a "fingerprint" for the ground water in a particular well. This capability derives from the measurement of concentrations of atomic components of a sample, rather than specific compounds. Once a fingerprint is established, a statistically significant change in the fingerprint would signal the need for detailed laboratory analyses. 


\section{Chemical optrodes appear to hold the most promise for current}

Hanford needs. In the field, monitoring activities would be simplified if a single type of instrument system could be used for in situ detection. The use and maintenance of a single type of system would be easier. However unlikely the use of a single type of system may be for the near future, it is worth noting which types of instrument systems hold the potential for detection of multiple contaminants. In Table 6.2, the " $D+F "$ column illustrates which types of instrument systems have the widest potential for Hanford applications. Chemical optrodes stand out as the most widely applicable. In addition, their construction and operation may be simpler than those of other methods. This makes optrodes a promising type of instrument system for Hanford monitoring. Surface-enhanced Raman spectroscopy, resistancekapacitance, and mass-sensitive devices also hold promise for wide application.

\subsection{RECOMMENDATIONS}

Chemical sensing as a technology is in its early developmental stages. It is clearly in DOE's best interests to aggressively pursue this technology and to ensure its applicability to DOE needs. The technology requires multidisciplinary effort and cooperation between the government and private sectors concerned, if it is to achieve its potential. An overriding recommendation is that the ultimate users of this technology help to guide its development. In the case of the Hanford Site, hydrologists and monitoring personnel should define how the technology of in situ contaminant detection can be most beneficial to them. The trends identified in the conclusions should be refined and augmented as work proceeds. Additional recommendations follow:

- The research and development of selective coatings is clearly an area that PNL and DOE should support actively. Selective coatings are used in chemical optrodes, electrochemical sensors, and mass-sensitive devices. The development of selective coatings would benefit from PNL's expertise in material science. 
- PNL and Westinghouse Hanford should develop a systematic and thorough approach to field-testing new instrument systems. This capability should accelerate both the development and application of instrument systems to solve environmental problems.

- Support is needed for the research and development of instrument systems to detect carbon tetrachloride, PCE, DCA, TCA, DCE, MEK, and nitrate in ground water. These contaminants have resulted from the energy production activities at the Hanford Site and are, therefore, expected to be problems at other DOE sites. The most promising techniques for detecting these contaminants are chemical optrodes, SERS, and possibly mass-sensitive devices.

- Research on electrochemical sensors currently supported by DOE has been very successful in the laboratory. Research support and field testing of Wang's chromium (VI) sensor should continue.

- The Hanford Site has much to gain by cooperation with the commercial sector. The interest of DOE sites in in situ sensor technology will accelerate commercial development of these sensors. DOE must keep abreast of these activities and support them in the most appropriate manner, to ensure the development and deployment of instrument systems that meet DOE needs. DOE should also avoid duplicating efforts in the commercial sector.

- DOE should facilitate the field-testing of refractive-index chemical optrodes currently being marketed by FiberChem, Inc.

- At this time, fluorescence spectroscopy and immunoassay sensors hold little promise for monitoring the range of Hanford contaminants and, therefore, DOE should not fund research in these areas. Because of the interest in monitoring hydrocarbons in the vadose zone, the development of these instrument systems is being driven by commercial interests.

\section{9}


- Although spark excitation-FOSES cannot be used to monitor the range of Hanford contaminants, it should be evaluated as a tool for fingerprinting ground water.

6.10 


\subsection{REFERENCES}

Alak, A. M., and T. Vo-Dinh. 1987. "Surface-Enhanced Raman Spectrometry of Organophosphorus Chemical Agents." Analvtical Chemistrv 59(17):2149-2153.

Angel, S. M. 1987. "Optrodes: Chemically Selective Fiber-optic Sensors." Spectroscopy 2(4):38-48.

Arnold, M. A., and T. J. Ostler. 1986. "Fiber Optic Ammonia Gas Sensing Probe," Analvtical Chemistrv 58: 1137-1140.

Carrabba, M. M. 1988. "Surface Enhanced Raman Spectroscopy (SERS), An Existing or Emerging Chemical Sensing Technology?" In Proceedinas of the Department of Enerov In Situ Characterization and Monitorina Technoloaies Workshop. DOE/HWP62, NTIS.

Carrabba, M. M., R. B. Edmonds, and R. D. Rauh. 1987. "Feasibility Studies for the Detection of Organic Surface and Subsurface Water Contaminants by SurfaceEnhanced Raman Spectroscopy on Silver Electrodes." Analvtical Chemistry, 59(21):2559-2563.

Chudyk, W., J. Kenny, G. Jarvis, and K. Pohlig. 1987. "Monitoring of Groundwater Contaminants Using Laser Fluorescence and Fiber Optics." In Tech, pp. 53-57.

Chudyk, W. A., M. M. Carrabba, G. B. Jarvis, and J. E. Kenny. 1985a. "Prototype Laser Fluorescence Fiber Optics Groundwater Contaminant Detector." Proceedinas necialty Conference on Fnvironmental Engineering, EE Div., pp. 98-103.

Chudyk, W. A., M. M. Carrabba, and J. E. Kenny. 1985b. "Remote Detection of Groundwater Contaminants Using Far-Ultraviolet Laser-Induced Fluorescence." American Chemical Societv 57:1237-1242.

David, D. J., Willson, M. C., and R. S. Ruffin. 1976. "Direct Measurement of Ammonia in Ambient Air." Analytical Letters 9(4): 389-404.

Eccles, L. A., S. J. Simon, and S. M. Klainer. 1987. Jn Situ Monitorina at Superfund Sites with Fiber Optics. EPA/600/X-87/156, Environmental Monitoring Systems Laboratory, U. S. EPA, Las Vegas, Nevada.

Evans, J. C., P. J. Mitchell, and D. I. Dennison. 1988. Hanford Site Ground-Water Monitorina for April Throuah June 1987. PNL-6315-1, Pacific Northwest Laboratory, Richland, Washington. 
Feilchenfeld, H., and O. Siiman. 1986. "Surface Raman Excitation and Enhancement Profiles for Chromate, Molybdate, and Tungstate on Colloidal Silver." Journal of Phvsical Chemistrv 90(10):2163-2168.

Griffin, J. W., K. B. Olsen, B. S. Matson, D. A. Nelson, and P. A. Eschbach. 1988. "Fiber Optic Spectrochemical Emission Sensors." SPIE International Svmposium and Exhibition on Fiber Optic. Opte Electronics, and Laser Aoplication in Science \& Enaineering. Boston, MA.

Giuliani, J. F., Wohltjen, H., and N. L. Jarvis. 1983. "Reversible Optical Waveguide Sensor for Ammonia Vapors." Optics Letters 8(1): 54-56.

Haugen, G., and G. Hieftje. 1988. "An Interdisciplinary Approach to Microinstrumentation." Analytical Chemistry 60(1):23-31.

Herron, N. R., D. Cardenas, W. H. Hankins, J. W. Curtis, and S. J. Simmon. 1987. Modification. Calibration. and Field Test of a Chloroform Specific Fiber Optic Chemical Sensor. EPA/600/X-87/416, U.S. Environmental Protection Agency, Las Vegas, Nevada.

Hirschfeld, T., T. Deaton, F. Milanovich, and S. Klainer. 1983. "Feasibility of Using Fiber Optics for Monitoring Groundwater Contaminants." Optical Engineering 22(5):527-531.

Ito, H. 1987. "Balanced Absorption Quartz Hygrometer." IEEE Transactions UFFC$34(2): 136-141$.

Janata, J., and A. Bezegh. 1988. "Chemical Sensors." Analytical Chemistry $60(12): 62 R-74 R$.

Jordan, D. M., Walt, D. E., and F. P. Milanovich. 1987. "PhysiologicalpH Fiber Optc Sensor Based on Energy Transfer." Analytical Chemistry 59:437-439.

Kellogg, D. S., and J. E. Pemberton. 1987. "Surface-Enhanced Raman Scattering of $\mathrm{HCN}$ at Pb-Modified Ag Surfaces." Journal of Phvsical Chemistry 91:1126-1130.

Kenny, J. E., G. B. Jarvis, W. A. Chudyk, and K. O. Pohlig. 1989. "Remote LaserInduced Fluorescence Monitoring of Groundwater Contaminants: Prototype Field Instrument." (in press) Analvtical Instrumentation, Medford, Massachusetts.

Klainer, S. M., D. K. Dandge, and K. Goswami. 1988. A Fiber Optic Chemical Sensor (FOCS) for Monitorina Gasoline. Contract No. 68-03-3249, Environmental Monitoring Systems Laboratory, U. S. EPA, Las Vegas, Nevada. 
Law, A. G., J. A. Serkowski, and A. L. Schatz. 1987. Results of the Sedi rations Area Ground-Water Monitorina Network for 1986. RHO-RE-SR-87-24P, Rockwell Hanford Operations, Richland, Washington.

Malstrom, R. A., and T. Hirschfeld. 1983. "On-Line Uranium Determination Using Remote Fiber Fluorimetry." In ORNL-DOE Conference on Analvtical Chemistrv in Energy Technology, Knoxville, Tennessee.

Martin, T. 1987. Electro-Optics. Heath Company, Benton Harbor, Michigan.

Martin, S. J., A. J. Ricco, D. S. Ginley, and T. E. Zipperian. 1987. "Isothermal Measurements and Thermal Desorption of Organic Vapors Using SAW Devices." JEEETransactions UFFC-34(2):142-147.

Martinez, A., M. C. Moreno, and C. Camara. 1986. "Sulfide Determination by N, NDimethyl-p-phenylenediamine Immobilization in Cationic Exchange Resin Using an Optical Fiber System." Analvtical Chemistry 58(8):1877-1881.

Milanovich, F. P., and T. Hirschfeld. 1983. "Process, Product, and Waste Stream Monitoring with Fiber Optics." In ISA International Conference, pp. 407-418.

Moody, R. L., T. Vo-Dinh, and W. H. Fletcher. 1987. "Investigation of Experimental Parameters for Surface-Enhanced Raman Scattering (SERS) Using Silver-Coated Microsphere Substrates." Applied Spectroscopy 41(6):966-970.

Pacific Northwest Laboratory (PNL). 1987. Environmental Monitorina at Hanford for 1986. PNL-6120, Pacific Northwest Laboratory, Richland, Washington.

Peterson, J., Goldstein, S., Fitzgerald, R. and D. Buckhold. 1980. "Fiber Optic pH Probe for Physiological Use," Analvtical Chemistrv 52:864-869.

Rhines, T. D., and M. A. Arnold. 1988. "Simplex Optimization of a Fiber-optic Ammonia Sensor Based on Multiple Indicators." Analvtical Chemistrv 60(1):76-81.

Saari, L. A., and W. R. Seitz. 1982. "pH Sensor Based on Immobilized Fluoresceinamine" Analvtical Chemistrv 54:821-823.

Saurbrey, G. 1959. "Verwendung von Schwingquarzen zur Wagung duner Schlichten und zur Mikrowagung." Zeitschrift fuer Phvsik 155:206-222.

Seitz, W. R. 1984. "Chemical Sensors Based on Fiber Optics." Analytical Chemistrv 56(1):16-34. 
Sensor Technology. 1988. "Microlasers," Sensor Technology Newsletter 4(6):6. Technical Insights, Inc., Englewood, New Jersey.

Skoog, D. A., and D. M. West. 1980. Principles of Instrumental Analvsis 2nd Edition. Saunders College, Philadelphia, Pennsylvania.

Tenge, B., A. Q. Grunke, and D. E. Honigs. 1987. "Fiber Optic 'Chemfuse' Sensors." In Tech pp. 29-33.

Thompson, M., G. K. Dhaliwal, C. L. Arthur, and G. S. Calabrese. 1987. "The Potential of the Bulk Acoustic Wave Device as a Liquid-Phase Immunosensor." IEEE Transactions UFFC-34(2): 127-135.

Urbano, E., H. Offenbacher, and O. S. Wolfbeis. 1984. "Optical Sensor for Continuous Determination of Halides." Analvtical Chemistrv 56(3): 427-429.

U. S. Environmental Protection Agency. 1988. "Subpart G - National Revised Primary Drinking Water Regulations: Maximum Contaminant Levels." 40 CFR Part 141.61, Washington, D. C.

Van Duyne, R. P., K. L. Haller, and R. I. Altkom. 1986. "Spatially Resolved Surface Enhanced Raman Spectroscopy: Feasibility, Intensity Dependence on Sampling Area and Attomole Mass Sensitivity." Chemical Phvsics Letters 126(2): 190-196.

Vo-Dinh, T., M. Y. K. Hiromoto, G. M. Begun, and R. L. Moody. 1984. "SurfaceEnhanced Raman Spectrometry for Trace Organic Analysis." Analvtical Chemistrv 56(9): 1667-1670.

Wang, J., Percio, A. M. F., and J. S. Mahmoud. 1985. "Trace Measurements of Calcium, Magnesium, Strontium and Barium, Based on Stripping Voltammetry with Adsorptive Accumulation." Journal of Electroanalytical Chemistry 195: 165-173.

Wang, J., and J. M. Zadeii. 1986. "Trace Determination of Yttrium and Some Heavy Rare-Earths by Adsorptive Stripping Voltammetry." Ialanta, 33(4): 321-324.

Wohltjen, H., A. W. Snow, W. R. Barger, and D. S. Ballantine. 1987. "Trace Chemical Vapor Detection Using SAW Delay Line Oscillators." UFFC$34(2): 172-178$.

Wolfbeis, O. S., and H. E. Posch. 1986. "Fiber Optic Fluoroscoring Sensor for Ammonia." Analvtica Chimica Acta 185: 321-327. 


\section{DISTRIBUTION}

No. of

Copies

OFFSITE

DOE/Office of Scientific and

Technical Information

J. Mathur

U. S. Department of Energy

DP-123 (GTN)

Washington, DC 20545

F. Wobber

U. S. Department of Energy

Office of Health and

Environmental Research

ER-75

Washington, DC 20545

N. E. Rothermich

Oak Ridge National Laboratory

HAZWRAP Support Contractor Office

Oak Ridge, Tennessee 37831

F. Fong

U. S. Department of Energy

San Francisco Operations

Wells Fargo Bank Building 1333 Broadway

Oakland, CA 94612
No. of

Copies

J. Wang

Department of Chemistry

New Mexico State University

Las Cruces, NM

S. M. Angel

Lawrence Livermore National Laboratory

Environmental Sciences

Division

P. O. Box 5507, L-524

Livermore, CA 94550

G. Coffey

E. I. duPont de Nemours and co.

Savannah River Plant

P. O. Box A

Aiken, SC 29808

M. Carrabba

EIC Laboratories

111 Downey Street

Norwood, MA 01062

W. Chudyk

Civil Engineering Department

Anderson Hall

Tufts University

Medford, MA 02155

J. Thomas

FiberChem, Inc.

3904 Juan Tabo NE

Albuquerque, NM 87111 
No. of

Copies

L. Eccles

EPNEMSL

P.O. Box 93478

Las Vegas, Nevada 89193-3478

D. Eastwood

Advanced Technology Project

Office

Lockeed Engineering and

Sciences Company

Environmental Programs Office

1050 E. Flamingo Road,

Suite 120

Las Vegas, Nevada 89119

\section{ONSITE}

2 DOE Richland Operations Office

G. W. Rosenwald A6-80

K. M. Thompson A6-80

7 Westinahouse Hanford Companv
M. R. Adams
$\mathrm{H} 4-55$
J. W. Cammann H4-54
A. G. Law
$\mathrm{H} 4-56$
S. J. Phillips
$\mathrm{H} 4-54$
J. F. Relyea
$\mathrm{H} 4-54$
C. R. Stroup
T4-10
R. M. Wirsing
$\mathrm{H} 4-55$

No. of

Copies

49 Pacific Northwest Laboratorv

J. W. Brothers K1-86

J.W. Carey K6-77

R. L. Cheatham K1-82

J. C. Evans K6-81

J. W. Falco K6-78

G. W. Gee K6-77

R. E. Gephart K6-97

D. S. Goldman P8-03

J. W. Griffin K5-25

L. K. Grove K6-86

J. M. Hales K6-04

M. S. Hanson K1-51

P. C. Hays K6-86

D. D. Hostetler (5) K1-86

B. J. Kaiser P8-03

K. Kim K6-84

C. T. Kincaid K6-77

W. W. Laity K1-74

E. M. Murphy (10) K6-77

K. B. Olson K6-81

N. J. Olson P8-37

R. G. Riley P7-50

R. Schalla K6-77

R. L. Skaggs K6-77

R. M. Smith K6-77

T. L. Stewart K2-12

J. A. Stottlemyre K6-94

J. E. Szecsody K6-77

P. L. White K3-59

R. E. Wildung P7-50

Technical Report Files (5)

Publishing Coordination 